\title{
PHYTIC ACID PHOSPHORUS AND INORGANIC PHOSPHORUS COMPOSITION IN SEEDS OF SOYBEAN LINES WITH INDEPENDENT \\ INOSITOL PENTAKISPHOSPHATE 2-KINASE MUTATIONS
}

\author{
A Thesis \\ Presented to \\ The Faculty of the Graduate School \\ At the University of Missouri \\ In Partial Fulfillment \\ Of the Requirements for the Degree \\ Master of Plant, Insect \& Microbial Science \\ By \\ JENNIFER VINCENT \\ Dr. Kristin Bilyeu and Dr. Anne McKendry, Thesis Supervisors \\ DECEMBER 2013
}


The undersigned, appointed by the dean of the Graduate School, have examined the Thesis entitled

PHYTIC ACID PHOSPHORUS AND INORGANIC PHOSPHORUS COMPOSITION IN SEEDS OF SOYBEAN LINES WITH INDEPENDENT INOSITOL PENTAKISPHOSPHATE 2-KINASE MUTATIONS

\author{
Presented by Jennifer Vincent \\ A candidate for the degree of \\ Master of Plant, Insect \& Microbial Science \\ And hereby certify that, in their opinion, it is worthy of acceptance.
}

Dr. Kristin Bilyeu

Dr. Anne McKendry

Dr. Emmanual Liscum 
Dedicated to

My parents: Jack and Nancy

My younger siblings: Nicole and Ryan

My older half-brothers: John and Josh and their families

My friends, both from Illinois and Columbia, who stood by me

My maternal grandparents

My paternal grandparents, may they rest in peace 


\section{ACKNOWLEDGEMENTS}

First and Foremost, I would like to thank my thesis supervisor, Dr. Kristin Bilyeu, for welcoming me into her lab after only meeting a few times. Kristin, you took a huge gamble asking me to join your lab, and for this, I am grateful. You have taught me an innumerable amount of information, both inside and outside the workplace. I have learned how to think more like a scientist and become more scientific in my writings. Through the infuriating numerous attempts at PCR, you taught me that sometimes a 'lucky charm' will do the trick. Outside of the lab, we have rooted alongside one another for the Cardinals baseball team and even attended a few games together. Through numerous lunches during intense field or lab work that needs to be done NOW, we have gotten to know each other on a personal level. It has been a real pleasure getting to know you and your family throughout my time at Mizzou.

I want to express my gratitude for the time and dedication of my committee members: Dr. Anne McKendry, Dr. Hari Krishnan, and Dr. Mannie Liscum. I greatly appreciate all of the dedication and wisdom you have shown me throughout these years in obtaining my thesis.

I cannot express the gratitude I have for the Bilyeu lab members who have supported me throughout my time at Mizzou. Paul Little and Christi Cole: between planting and harvesting duties you guys have for Kristin, you both found 
time to help me with my experiments, especially when it came to watering the plants in the growth chamber. Besides finding time to help me with my experiments, you both found time to make me a part of the Bilyeu lab family. Whether it be making fun of me for breaking (then fixing!) a vortex or discussing "important" information over coffee and diet coke, you both made me feel welcome in the lab and helped me to relax when things were getting stressful. Katy Hagely: your unending wisdom on how to read scientific papers and how to manage grad school life with a personal life was very helpful and welcoming. I will always be grateful for the information you shared and willingness to answer questions when I was stuck. Tiffany Langewisch: I value the advice and insight you shared with me throughout our overlapping time in the Bilyeu lab. To the newest members of the lab, Surya Sapkota and Hyun Jo, words could not express my gratitude of your enthusiasm to help me finish up these last few months when it was crunch time.

Throughout my time at Mizzou, there have been a few visitors to the Bilyeu lab that have helped me in one way or another. Tiago Tezotto: I appreciate your expertise when it came to spraying soybeans with a back-pack sprayer. I do not think I could have ever done as well as you. Maria Smehilova: it has been a real pleasure getting to know you. I am so lucky to have found such a great friend and roommate. Drs. Joe Polacco and Jason Gillman: the time and wisdom you both have shared about your personal experiences have aided me in surviving grad school. 
Lastly, I would like to thank my loving and supporting family members, whom have always been my cheerleaders throughout my college career. You may not have understood what I was doing, but you stood behind me $100 \%$ even when I struggled. Just by listening to my complaining and telling me the shenanigans of the pets, you made every day, even if it was not a bad one, 10 times better. Mom: every day, even several times a day, you called to check on my progress with creating the "miracle soybean." You almost always call at the most inopportune times, but I know you called with love in your heart. Dad: it may not seem like much, but you taught me to reach for the stars because I am capable of doing anything I desire. Whether it be homework I didn't understand or sitting outside in the cold weather just to hand you a tool as you fix my car, you taught me to be responsible and give $110 \%$ even if I'm was not sure what I was doing. Nik and Ry: you guys are the best younger siblings any person could have. We may have taken turns teasing each other when we were younger, and maybe a bit now, but we always had each others' backs when needed. John, Josh, and their families: we do not get to see each other, but when we do, we have a blast. It always makes me laugh when you guys ask if I have created a killer soybean plant.

It would take me pages upon pages to list all those who have helped me through my studies, but to those not mentioned above, do not be offended because you still hold a special place inside my heart. 


\section{TABLE OF CONTENTS}

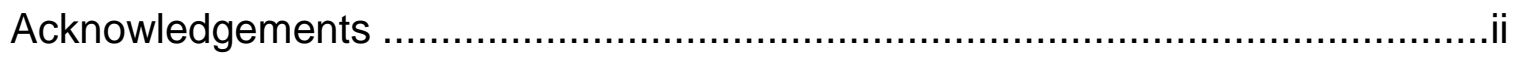



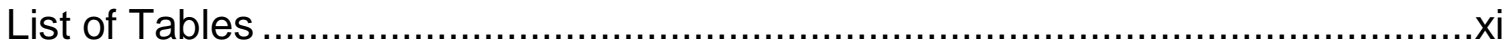

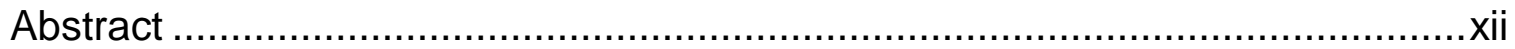

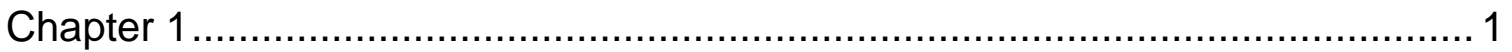

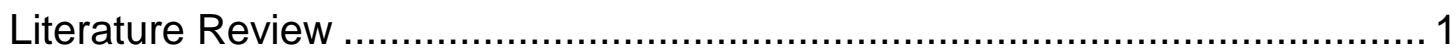



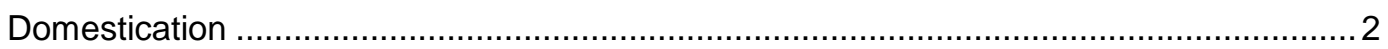



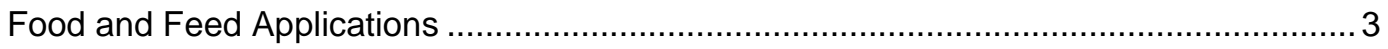

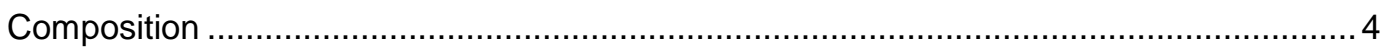



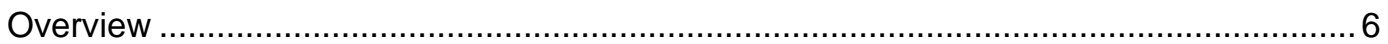



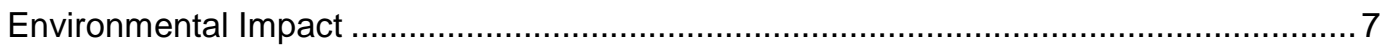

Low Phytic Acid Mutants ............................................................ 8

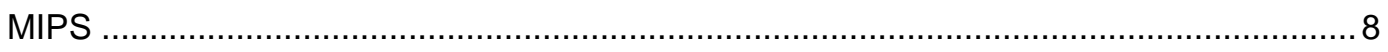

LPA1 and LPA2

IPK1 ㅅ…

Inositol Pentakisphosphate $2-K i n a s e$........................................ 11

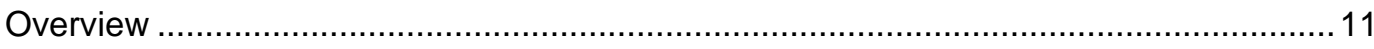

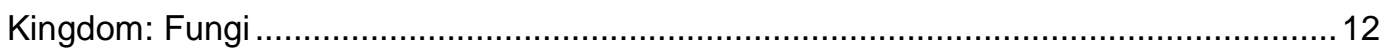

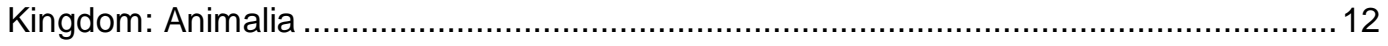








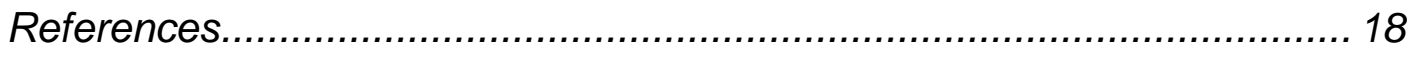

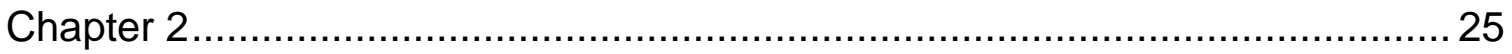

Characterization of a Fast Neutron Population with a Multifoliate Leaf

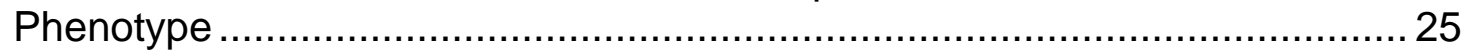

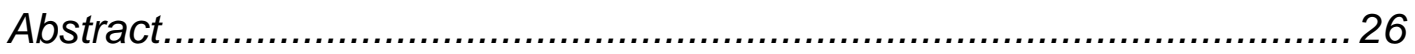

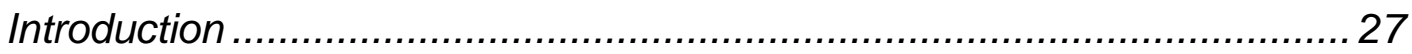

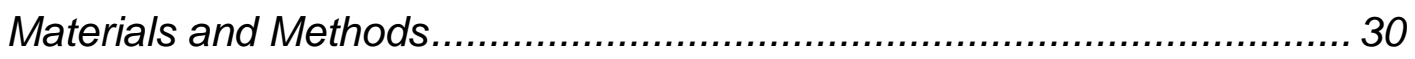

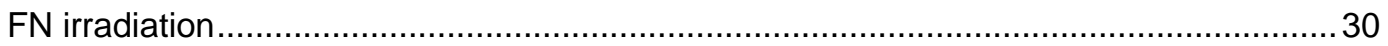

Comparative genomic hybridization (CGH) of FN38 compared to W82 …..................... 30

Plant material and segregating population development ................................................ 31

Genotypic analysis of the sequence around the FN38 deletion ................................... 31

Sequencing of HOX in other genotypes with multifoliate phenotype ….......................... 32

Genotypic analysis of the FN38 deletion in Jake 4/5 population ................................... 33

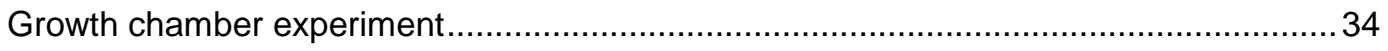

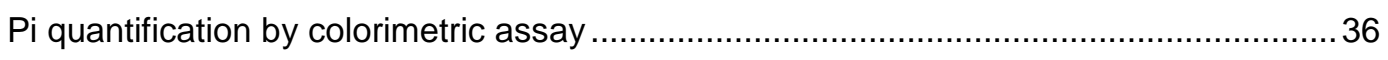

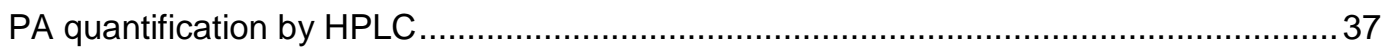

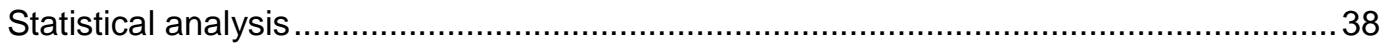

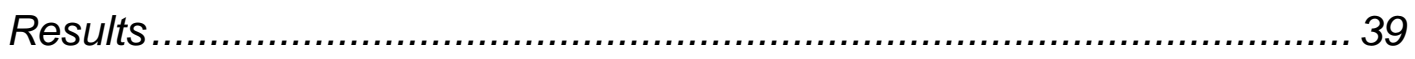

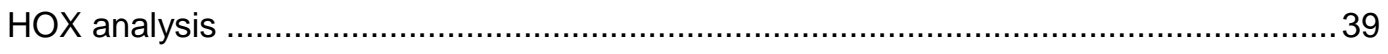

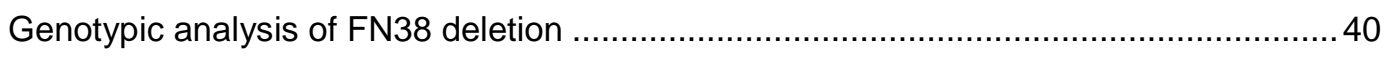

Jake 4/5 $F_{3}$ populations: Phenotypic analyses .......................................................... 41

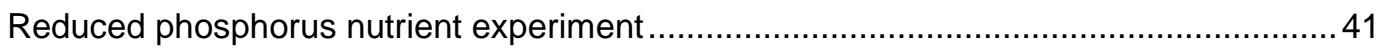





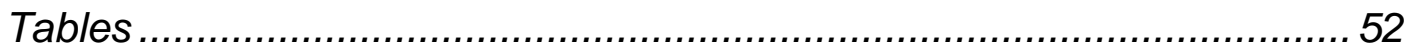




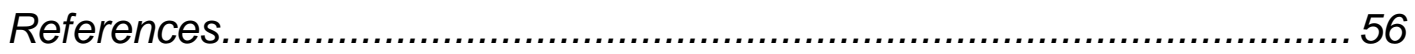

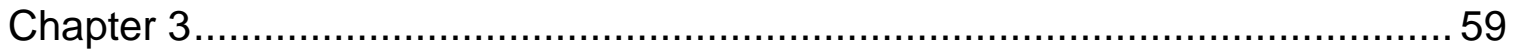

Characterization of a Population Developed by Breeding Two Single Inositol Pentakisphosphate 2-Kinase Mutants ...................................................... 59

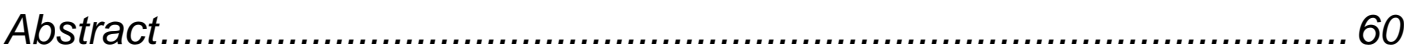

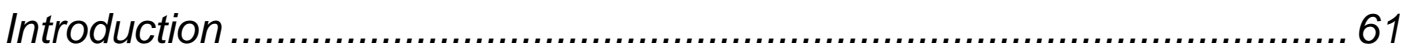

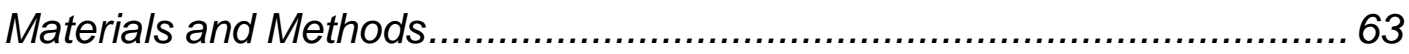

Plant material and segregating population development............................................63

IPK1 (Glyma14g07880) molecular assay development for use in genotyping $F_{1}$ and $F_{2}$

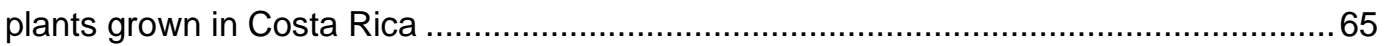

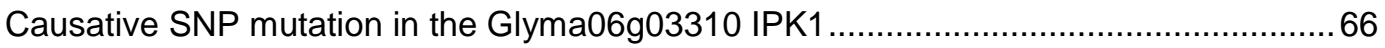

IPK1 (Glyma06g03310)-linked molecular assay development for use in determining

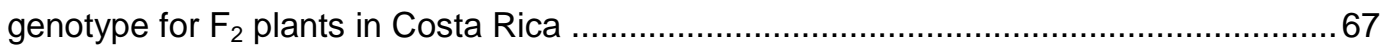

Genotypic analysis of the FN38 deletion in mutants for IPK1 (Glyma06g03310) ............68

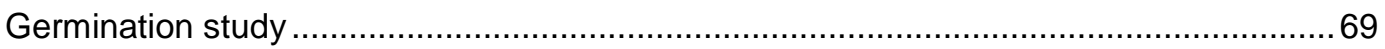

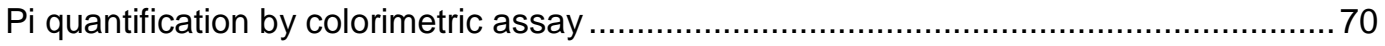

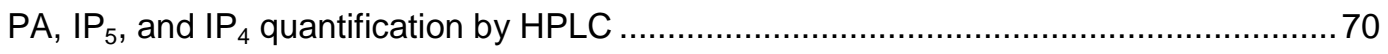





Molecular assay development for 2-kinase population ................................................. 72

Analyses of Costa Rica 2-kinase population ............................................................. 73

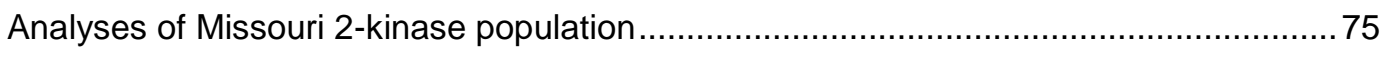

Comparison of the two locations: Costa Rica and Missouri .............................................. 76

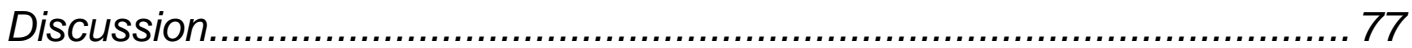

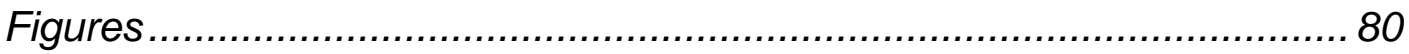

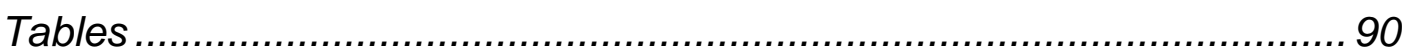




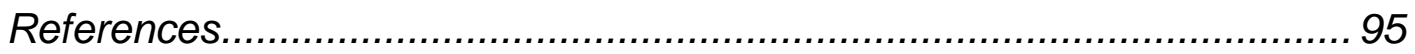

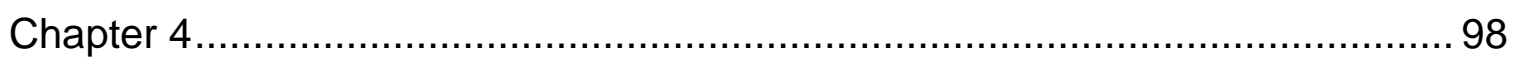

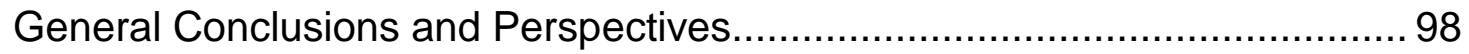

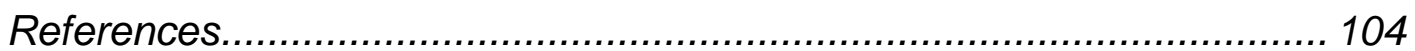

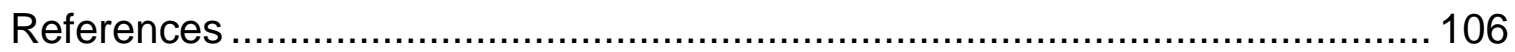




\section{LIST OF FIGURES}

Figure

Page

1.1. An analogy of the numbering system for myo-inositol in terms of

Bernie Agranoff's turtle. 16

1.2. Proposed pathway for phytic acid synthesis in plants 17

2.1. Mulfitfoliate leaflet phenotype for FN38 47

2.2. Location of primer sets to the left and right of the deletion 48

2.3. Phenotypic comparisons for the Jake $4 / 5 \mathrm{~F}_{3}$ generation, parental lines, and discovered Ipa mutants 49

2.4. HPLC peaks for PA and lower inositols 50

2.5. Phenotypic analyses comparison between the full field treatment and reduced phosphorus treatment in the growth chamber 51

3.1. Single nucleotide polymorphism located in the low phytic acid mutant ZC-2 81

3.2. Single nucleotide polymorphism linked to the deletion of IPK1 in FN38 82

3.3. Phenotypic analyses for the 2-kinase population grown in Costa Rica 83

3.4. Lower inositol characterization of lines with the Glyma14g07880 mutation grown in Costa Rica 84 
3.5. Phenotypic analyses for the 2-kinase population grown in Missouri 85

3.6. Lower inositol characterization of lines with the Glyma14g07880 mutation grown in Missouri 86

3.7. Germination percentages for $\mathrm{F}_{2: 4}$ seeds of the 2-kinase population grown in Missouri 87

3.8. Phenotypic analyses for comparison of Costa Rica and Missouri 88

3.9. Glyma14g07880 mutation lower inositol comparison of the two locations: Costa Rica and Missouri 89 


\section{LIST OF TABLES}

Table

2.1. Left and right primer sets flanking the FN38 deletion on chromosome 6 53

2.2. Primers used to amplify HOX genes in PI416892 54

2.3. Leaflet numbers for lines grown in the reduced phosphorus nutrient experiment 55

3.1. Primer sets used for determination of SNP in ZC-2 linked to FN38 deletion 91

3.2. Type 3 tests for fixed effects ANOVA table. 92

3.3. Leaflet number phenotype for the 2-kinase population grown in Columbia, Missouri 93

3.4. Means and standard deviations for the reps of each line grown in Columbia, $\mathrm{MO}$ 94 


\section{ABSTRACT}

Soybean [Glycine max (L.) Merr] seeds contain a large amount of phosphorus $(\mathrm{P})$, which is stored as phytic acid (PA). PA is indigestible by nonruminant livestock and considered an anti-nutritional factor because PA chelates divalent cations and prevents the uptake of essential nutrients. Interest in reducing PA has increased greatly over the years and several low PA soybean lines have been discovered; however, many of these lines have inadequate germination and emergence. A gamma irradiated soybean line, ZC-2, with $50 \%$ reduction in PA was found to have excellent germination and emergence. The low PA phenotype was a result of a mutation in a gene orthologous to inositol pentakisphosphate 2-kinase (IPK1; Glyma14g07880), which is responsible for phosphorylating inositol pentakisphosphate into PA. Our own fast neutron irradiated line, FN38, has a large deletion of an independent gene homologous to IPK1 (Glyma06g03310), as well as two homeobox genes (HOX; Glyma06g03200 and Glyma06g03210). Preliminary studies have shown that HOX genes are responsible in leaf architecture. Our objectives were to characterize the deletion in FN38, determine if deleted HOX genes were the cause of the multifoliate phenotype, and reduce PA levels by more than $50 \%$ with conventional breeding methods. Jake was bred with FN38 to develop a segregating population, and we designed primers and used them to determine the presence or absence in the 
deletion. ZC-2 and FN38 were bred to decrease PA by more than $50 \%$, and we developed and utilized molecular marker assays to select for the two IPK1 mutations. We performed high-performance liquid chromatography (HPLC) to measure PA levels and a colorimetric assay to measure Pi levels in the selected soybean lines. Initial characterization of PA and inorganic phosphorus (Pi) levels for the deletion indicated that a mutated Glyma06g03310 IPK1 gene does not increase $\mathrm{Pi}$ or decrease PA by itself. The deleted HOX genes may be responsible for the multifoliate phenotype because all progeny lines containing the deletion had multifoliate leaflets. Lines containing both mutations, Glyma14g07880 and Glyma06g03310, in IPK1 increased Pi and decreased PA significantly more than either parental genotype. 


\section{CHAPTER 1}

\section{Literature Review}




\section{Soybeans}

\section{Domestication}

For many years, soybean [Glycine max (L.) Merr] origination was not very well known because it was rare for people to keep records (Hymowitz, 1990; Hymowitz and Newell, 1980). However, some scientists have made progress to report the soybean domestication and dissemination. In the Northeastern region of China, during the Chou dynasty, the soybean became known as a domesticate (Hymowitz and Newell, 1980; Hymowitz and Newell, 1981). However, domestication is a continuous process, so the soybean most likely appeared during, or before, the Shang Dynasty, (ca. 1700-1100 B.C.) (Hymowitz, 1990; Hymowitz and Newell, 1981). Eventually, the soybean was traded in exchange for other goods to local countries, such as South China, Japan, Thailand, and Vietnam, which created secondary gene pools (Hymowitz and Kaizuma, 1979; Hymowitz and Newell, 1980).

In 1765, Samuel Bowen brought soybean seeds from China to North America, specifically Savannah, Georgia (Hymowitz and Harlan, 1983). However, he was not always known as the one to have brought soybeans to North America. For many years, researchers believed that Benjamin Franklin was the first to send soybeans to America, and it was also thought that Dr. James Mease was the first because the term 'soybean' first appeared in his writings (Hymowitz, 1990; Hymowitz, 2008; Hymowitz and Harlan, 1983; Hymowitz and Newell, 1980; Hymowitz and Newell, 1981). It was suggested that 
Dr. Mease used this term because soybeans were similar to other bean species, and were used to make soy sauce, in China (Hymowitz, 1970; Hymowitz, 2008).

\section{Economic Importance}

It was not until the 1920's that the soybean was grown as a grain crop instead of just a forage crop in North America (Hymowitz, 1990). With technological advances, soybean production has dramatically increased, as well as the drive to boost soybean nutritional quality (Hymowitz, 2008). From 1924 to 1994, soybean production in the United States (U.S.) jumped from 5 million bushels (bu) to 2.6 billion bu and yields increased from 11 bu/acre to 42 bu/acre (Janick et al., 1996).

Since 1986, the area of soybeans planted in the U.S. has increased roughly 15 million acres, and this advance has resulted in over $30 \%$ million bu production boost (Soystats, 2012). These dramatic increases in soybean acreage have led the U.S. to be the world's top producer of soybeans, followed closely by Brazil (Soystats, 2012). This production increase is crucial for countries because $68 \%$ of protein meal and $28 \%$ of vegetable oil consumed is produced using soybeans (Soystats, 2012). Soybean is the leading source of protein meal, but it follows palm oil in vegetable oil production (Soystats, 2012; USDA-ERS, 2012).

\section{Food and Feed Applications}

There are also numerous livestock, with poultry, swine, and beef being among the top three, and people in many countries that consume soybeans as a 
major source of their diet due to its high protein content (Krishnan, 2005; Soystats, 2012). Humans eat soybeans indirectly in foods such as salad dressings, bakery ingredients, and pasta and meat products (Soystats, 2012). Soy is needed in the human body for several different health reasons, especially since it contains all eight essential amino acids and is an excellent source of fiber and nutrients (Montgomery, 2003). Soybeans also contain oil, which has many uses as well.

Even though it has less oil than protein, the oil amount in soybean is one of the highest in oilseed crops (Soystats, 2012). Oil is mainly used as cooking or salad oil, but it can also be used for industrial purposes, such paint strippers or disinfectants (Soystats, 2012). Lecithin, a natural emulsifier and lubricant, is derived from soybean oil and has many uses, especially in pharmaceuticals (Soystats, 2012). Soybean oil uses are determined by its fatty acid composition, which contains roughly $4 \%$ stearic, $8 \%$ linolenic, $13 \%$ palmitic, $20 \%$ oleic, and 55\% linoleic acids (Pham et al., 2010).

\section{Composition}

Soybean contains about $40 \%$ protein and $20 \%$ oil; however, it is also composed of $35 \%$ carbohydrates and $5 \%$ ash on a dry weight basis (Liu, 1999). Of the carbohydrate composition, there are insoluble and soluble molecules. Soluble carbohydrates include a class of anti-nutritional factors that make it difficult for animals or humans to properly digest and use nutrients and minerals. The major components of soluble carbohydrates are the raffinose family 
oligosaccharides (RFOs), which are mainly stachyose, raffinose (Clarke and Wiseman, 2000). Sucrose is also present. However, stachyose and raffinose are the molecules that increase intestinal distress in monogastric animals (Clarke and Wiseman, 2000). This intestinal distress is caused by microflora, in the lower intestine, that degrade these molecules producing gases (Clarke and Wiseman, 2000). Even though RFOs are not eliminated by heat, (East et al., 1972; Suarez et al., 1999), some anti-nutritional factors are removed via cooking. Additional anti-nutritional factors that are able to be eliminated with heat are protease inhibitors and lectins. The type of protease inhibitor in soybean is known as serine-type protease inhibitors, which have a great affinity for trypsin (Clarke and Wiseman, 2000; Kakade et al., 1969). Thus, many researchers and scientists refer to them as trypsin inhibitors $(\mathrm{TI})$. TI prevent crucial nutrient uptake because they bind to the enzyme trypsin, which is important for turning protein into amino acids (Kakade et al., 1973). Lectins are found in most plants as glycoproteins, but as a dietary substance, they have a high affinity for intestine epithelial cells and resist gut proteases, which may cause structural changes and serious damage (reviewed in Clarke and Wiseman, 2000; Douglas et al., 1999). These changes and damages may result in nutrient and mineral loss and decreased growth rate (reviewed in Douglas et al., 1999). 


\section{Phytic Acid}

\section{Overview}

Plants absorb and use inorganic phosphorus (Pi) from the soil (Raboy and Dickinson, 1984). Plant $P$ is responsible for many cellular functions, which is essential in typical growth and development. Deoxyribonucleic acid (DNA) and ribonucleic acid (RNA) structures are held together with phosphorus bonds, which are important for the synthesis of proteins (Raboy et al., 2001). However, most grain crops accumulate much more $\mathrm{P}$ than is needed, so this is stored as phytic acid (PA) (Raboy and Dickinson, 1984; Raboy et al., 2001).

Roughly $75 \%$ of the total $\mathrm{P}$ in plants is in the form of $\mathrm{PA}$, otherwise known as myo-inositol hexakisphosphate, $\operatorname{Ins}(1,2,3,4,5,6) \mathrm{P}_{6}$ or $\operatorname{Ins} \mathrm{P}_{6}$, which constitutes about $2 \%$ of a mature soybean seed (Raboy et al., 1984). Phytic acid numbering is the same as myo-inositol. A PA precursor, and its' numbering system can be demonstrated by the Bernie Agranoff "turtle" analogy (Irvine and Schell, 2001). In most literature, the D-conformation is used; thus, numbering begins on the right "flipper" of the turtle and goes counter-clockwise (Figure 1.1). Figure 1.1a shows the Haworth projection of PA, while Figure 1.1b shows the chair conformation.

PA is important for seedlings because an enzyme known as phytase hydrolyzes PA-P into Pi (Urbano et al., 2000). Pi presents a source of nutrition for seedlings beginning to germinate and unable to photosynthesize the sun's 
rays (Hegeman and Grabau, 2001). Even though PA is important to seedling germination, it presents a problem when consumed by monogastric species.

\section{Nutritional Implication}

$\mathrm{PA}$ is a major anti-nutritional factor in crop grains causing deficiencies in $\mathrm{P}$ and important metal minerals. PA-P is indigestible by nonruminant livestock, such as poultry and swine, because they do not contain gut phytase enzymes to break down PA (Clarke and Wiseman, 2000; Raboy et al., 1984; Wilcox et al., 2000). PA is a chelating agent that binds to most metals, preventing mineral and protein absorption in nonruminant livestock; thus, soybean meal fed to monogastric animals are supplemented with $\mathrm{Pi}$ and minerals in order to supply adequate nutrients, as well as phytases to break down PA (Clarke and Wiseman, 2000; Wilcox et al., 2000). Studies have shown that $\mathrm{Pi}$, the other variable factored into total $\mathrm{P}$, and PA have an inverse relationship, and it is possible to reduce $\mathrm{PA}$, subsequently increasing $\mathrm{Pi}$, without deleterious effects (Bilyeu et al., 2008; Raboy et al., 2000; Wilcox et al., 2000). This is not only beneficial to the feed industry, which will not need to spend time, money, and resources on supplementation, but the environment as well.

\section{Environmental Impact}

Phytic acid phosphorus (PA-P) is passed through the intestines of nonruminant livestock, ending up in the manure (Clarke and Wiseman, 2000; Daverede et al., 2004; Ferket et al., 2002). Deleterious effects of $P$ runoff are expensive and timely to fix because when symptoms are visible, the damage is 
too great to be corrected simplistically (Sharpley et al., 1994). Manure, with high amounts of $\mathrm{P}$, and $\mathrm{P}$ fertilizer applied to fields, have a negative impact on the environment (Sharpley et al., 1994). This P may run off into the water system causing oxygen reduction, inconsistency in the $\mathrm{pH}$, and more aquatic plant growth, which causes algae and decreased water visibility (Daverede et al., 2004; Ferket et al., 2002; Sharpley et al., 1994). With the discovery of low PA (Ipa) mutations in many grain crops, the reduction of $\mathrm{P}$ runoff, as well as more nutritious soybean meal, has increased (Wilcox et al., 2000).

\section{Low Phytic Acid Mutants}

\section{MIPS}

Sebastian et al. (2000) were the first to discover Ipa mutations in soybean. Through screening of plant introduction lines and mutagenesis of those lines, LR33 was found with a small reduction in RFOs; however, after more generations of self-fertilization, this line was discovered to have another mutation that, when homozygous, resulted in low to no germination (Sebastian et al., 2000). Preliminary results identified that myo-inositol 1-phosphate synthase was mutated, so it was designated the acronym mips (Sebastian et al., 2000). Characterization of LR33 determined that the MIPS gene MIPS1 also resulted in a reduction of $\mathrm{PA}$, besides just RFOs, and an increase in inorganic $\mathrm{P}$ (Hitz et al., 2002). 


\section{LPA1 and LPA2}

Mutagenesis of CX1515-4 was discovered to create two independent Ipa mutatants, M153 and M766, with M153 hypothesized to have been caused by a single locus (Wilcox et al., 2000). M153, with the greater reduction in PA, was bred to develop CX1834 for further analysis of the Ipa mutation(s) (Oltmans et al., 2004; Walker et al., 2006; Wilcox et al., 2000). This led to the discovery that two independent recessive mutations are needed for the CX1834 Ipa phenotype (Oltmans et al., 2004; Scaboo et al., 2009; Walker et al., 2006). With the earlier discovery of the mips1 mutation, characterization of all soybean MIPS genes in CX1834 began in hopes of identifying the cause of the Ipa phenotype; however, no mutations or associations were discovered in MIPS, including MIPS1 (Chappell et al., 2006; Maroof et al., 2009). To identify the CX1834 genomic reasons for Ipa phenotype, analysis began on its genome using of quantitative trait loci (QTL) mapping. Two different regions were identified on linkage group (LG) N and LG L that were associated with the previously identified Ipa loci (Gao et al., 2008; Maroof et al., 2009; Scaboo et al., 2009; Walker et al., 2006).

Maize was discovered to have two Ipa mutants that reduced PA levels and increased inorganic $\mathrm{P}$; thus, the total $\mathrm{P}$ levels did not change in wild-type maize versus Ipa maize (Raboy and Gerbasi, 1996). The maize allele Ipa1-1 was shown to be associated with a multi-drug resistance-associated protein ATPbinding cassette (Shi et al., 2007). With this information, Gillman et al. (2009) identified two homologous soybean genes, Ipa1 and Ipa2, that together 
associated with the Ipa phenotype and the QTL regions in derivatives of the M153 Ipa line. Characterization of these genes in M153 and M766 revealed two alleles for Ipa1, designated Ipa1a and Ipa1b, and two alleles for Ipa2 designated Ipa2a and Ipa2b (Gillman et al., 2013; Gillman et al., 2009). Maize only requires one recessive mutant to create the Ipa phenotype, while soybean requires both recessive mutations (Gillman et al., 2009).

\section{IPK1}

A novel Ipa mutation in a soybean line, ZC-2, resulted in an increase in inositol phosphates and inorganic $\mathrm{P}$, and these increases were concomitant with a 22\%-57\% PA reduction (Frank et al., 2009a; Yuan et al., 2007). Fortunately, this mutation did not result in any other decrease in nutritional value, and ZC-2 has initially shown promising potential with no germination issues, compared to the wild-type parent, arose when grown in a subtropical environment (Frank et al., 2009b; Yuan et al., 2007; Yuan et al., 2009). This was promising because most soybean lines with an Ipa mutation were also shown to have decreased emergence, especially seed from (sub)tropical environments (Anderson and Fehr, 2008; Maupin and Rainey, 2011; Maupin et al., 2011; Meis et al., 2003).

ZC-2's mutation was hypothesized to be caused by inositol polyphosphate 2-kinase, so mapping studies and molecular characterization of its genome was used to identify the mutation (Yuan et al., 2012). An identified gene, Glyma14g07880, in the mapping region was acknowledged to be a soybean ortholog of inositol pentakisphosphate 2-kinase (IPK1) (Yuan et al., 2012). 
Molecular studies discovered a single nucleotide polymorphism (SNP) in the IPK1 gene (Yuan et al., 2012). This SNP in ZC-2 led to a splice site defect, in which the fifth exon was excluded in mRNA production (Yuan et al., 2012). In plants, including soybean, IPK1 is responsible for synthesis of PA from inositol pentakisphosphate (Ives et al., 2000; Phillippy et al., 1994).

\section{Inositol Pentakisphosphate 2-Kinase}

\section{Overview}

Many studies have provided key information to the biosynthesis pathway of phytic acid (Figure 1.2). Early on, rice experts believed that only one enzyme functions to create PA from myo-inositol monophosphate, but studies conducted in mung bean proposed other enzymes and intermediates, including inositol pentaphosphate, otherwise known as $\mathrm{I}(1,3,4,5,6) \mathrm{P}_{5}$ or $\mathrm{IP}_{5}$ (reviewed in Raboy and Dickinson, 1987). Discovery of intermediates in the PA pathway in mold led to the identification of $\mathrm{I}(1,3,4,5,6) \mathrm{P}_{5}$ as the precursor to $\mathrm{PA}$, while $\mathrm{I}(1,2,3,4,6) \mathrm{P}_{5}$ and $\mathrm{I}(1,2,4,5,6) \mathrm{P}_{5}$ were the product when PA was dephosphorylated (Brearley and Hanke, 1996a; Brearley and Hanke, 1996b; Stephens et al., 1991; Stephens and Irvine, 1990). Most of the scientific community has further confirmed that the last step to PA synthesis is the phosphorylation of the 2-position on $\mathrm{IP}_{5}$ (reviewed in York et al., 1999). This phosphorylation is executed by an enzyme known as inositol pentakisphosphate 2-kinase, abbreviated $\mathrm{I}(1,3,4,5,6) \mathrm{P}_{5}$ 2-kinase or IPK1 
(reviewed in Sweetman et al., 2006). Many studies on the IPK1 gene have been performed across various kingdoms.

\section{Kingdom: Fungi}

Identification and functional gene characterization of $\mathrm{I}(1,3,4,5,6) \mathrm{P}_{5} 2$ kinase activity began in Saccharomyces cerevisiae, budding yeast, Schizosaccharomyces pombe, fission yeast, and Candida albicans, fungus (Ives et al., 2000; Miller et al., 2004; Ongusaha et al., 1998; Sarmah and Wente, 2009; Shears, 1998; York et al., 1999). Early researchers began by identifying the IPK1 activity, but they were unable to characterize particular genetics (Ongusaha et al., 1998; Shears, 1998). Eventually, molecular characterization was performed, and IPK1 was shown to be crucial for mRNA export from the nucleus due to its production of PA (Miller et al., 2004; Sarmah and Wente, 2009; York et al., 1999). S. cerevisiae and S. pombe IPK1 genes were demonstrated to be exchangeable, and the IPK1 protein was demonstrated to be the enzyme responsible for PA production, in vitro and in vivo (Ives et al., 2000). With such homology between the two yeasts, C. albicans IPK1 gene was identified, and when all three IPK1 genes were compared, two conserved amino acid sequences were identified (Ives et al., 2000).

\section{Kingdom: Animalia}

Through comparison of these species to the animal kingdom, functional IPK1 genes were identified in several species: Homo sapiens (humans), Mus musculus (house mice), Rattus norvegicus (brown rats), and Drosophila 
melanogaster (common fruit fly) (Brehm et al., 2007; Fujii and York, 2005; Seeds et al., 2004; Verbsky et al., 2005; Verbsky et al., 2002). Human IPK1 gene was able to be used in an ipk1 yeast mutant to restore functionality; interestingly, this kind of conservation across such diverse species is very rare, especially since human and yeast IPK1 were discovered to have low similarity overall (Verbsky et al., 2002). Besides PA production, IPK1 functions in various gene expressions in humans, and may be used to analyze the function of PA in development and diseases (Brehm et al., 2007; Verbsky et al., 2002). Mice with homozygous ipk1 mutant genes resulted in death during embryogenesis and indications show that higher inositols were needed in order to continue living as an embryo (Verbsky et al., 2005). Identification of IPK1 in plants was next to be characterized.

\section{Kingdom: Plantae}

Ins $(1,3,4,5,6) \mathrm{P}_{5}$ 2-kinase has been characterized in Arabidopsis thaliana (Arabidopsis) (Stevenson-Paulik et al., 2005; Sweetman et al., 2006), Zea mays (maize) (Sun et al., 2007), and Glycine max (soybean) (Phillippy et al., 1994; Yuan et al., 2012). Plant mutants with ipk1 do not result in yield loss, but they do effect the size of the plants during growth and development (Stevenson-Paulik et al., 2005). Phillippy et al. (1994) provided evidence for the activity of IPK1 being predominant in immature soybean seeds that are accumulating too much $\mathrm{P}$, and the reverse reaction, PA to lower inositols, were favored in mature, germinating soybean seeds. In the soybean genome, three different IPK1 genes have been found: Glyma14g07880, Glyma06g03310, and Glyma04g03240 (Yuan et al., 
2012). Studies have shown that Glyma14g07880 had more expression in soybean seeds than vegetative tissue, and it had much higher expression in developing seeds, 20 days after flowering (DAF) and later, than the other two genes (Yuan et al., 2012). 
Figures 
a

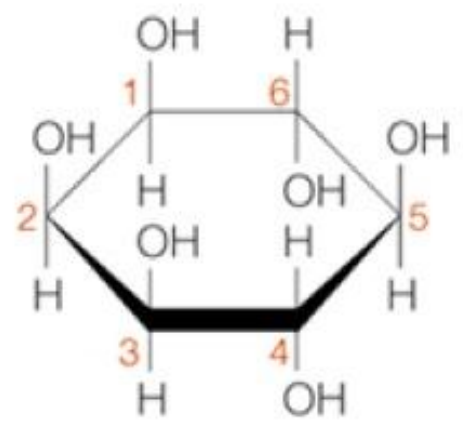

b

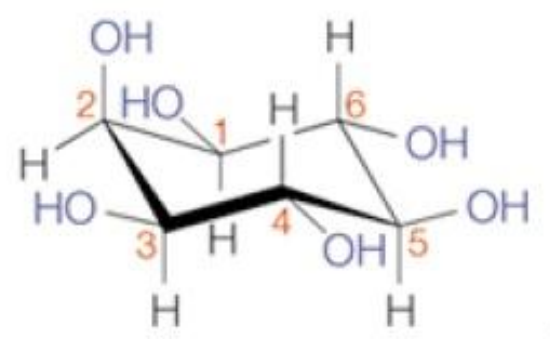

c

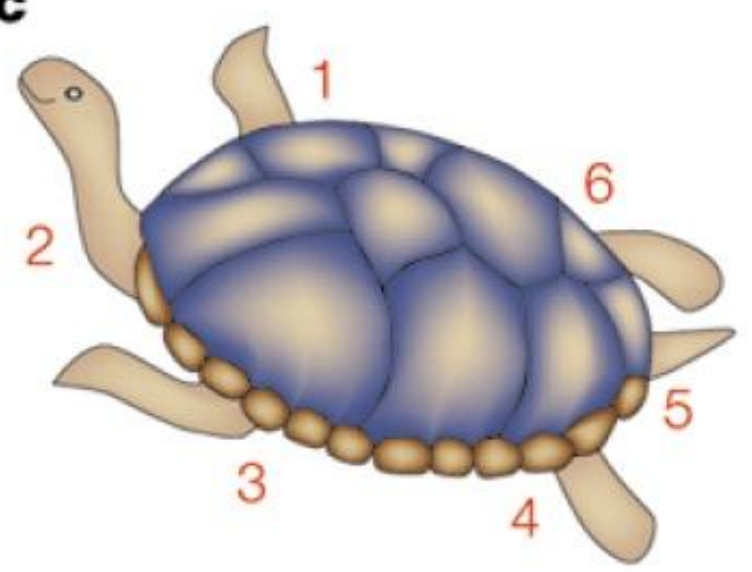

Nature Reviews | Molecular Cell Biology

Figure 1.1. An analogy of the numbering system for myo-inositol in terms of Bernie Agranoff's turtle. A Haworth projection, B stair chair depiction, and C Agranoff's turtle of myo-inositol are shown in this diagram (taken from (Irvine and Schell, 2001). 


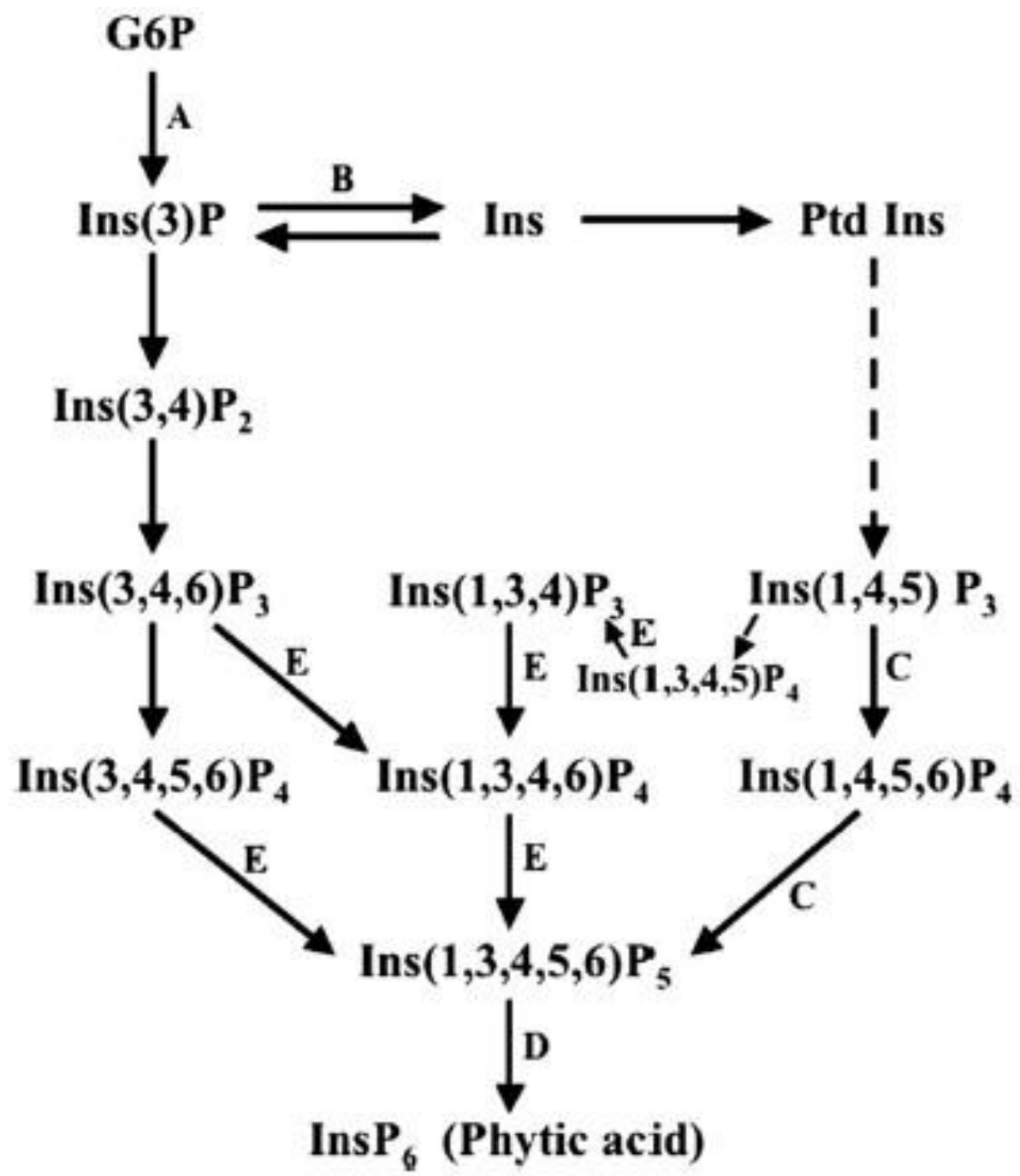

Figure 1.2. Proposed pathway for phytic acid synthesis in plants. On the left is the lipidindependent pathway, while the right shows the lipid-dependent pathway. A, MIPS (myo-inositol 3-phosphate synthase); B, IMP (inositol monophosphatase); C, IPK2 (inositol 1,4,5-tris-phosphate kinase/inositol polyphosphate kinase); D, IPK1 (inositol 1,3,4,5,6-pentakisphosphate 2-kinase); E, ITP5/6K (inositol 1,3,4-triskisphosphate 5/6-kinase); Ins, myo-inositol; Ptdlns, phosphatidyl inositol (taken from (Suzuki et al., 2007). 


\section{References}

Anderson B.P., Fehr W.R. (2008) Seed Source Affects Field Emergence of LowPhytate Soybean Lines. Crop Sci 48:929-932.

Bilyeu K.D., Zeng P., Coello P., Zhang Z.J., Krishnan H.B., Bailey A., Beuselinck P.R., Polacco J.C. (2008) Quantitative Conversion of Phytate to Inorganic Phosphorus in Soybean Seeds Expressing a Bacterial Phytase. Plant Physiol 146:468-77.

Brearley C.A., Hanke D.E. (1996a) Inositol Phosphates in the Duckweed Spirodela polyrhiza L. Biochem J 314:215-225.

Brearley C.A., Hanke D.E. (1996b) Metabolic Evidence for the Order of Addition of Individual Phosphate Esters to the myo-Inositol Moiety of Inositol Hexakisphospate in the Duckweed Spirodela polyrhiza L. Biochem J 314:227-233.

Brehm M.A., Schenk T.M., Zhou X., Fanick W., Lin H., Windhorst S., Nalaskowski M.M., Kobras M., Shears S.B., Mayr G.W. (2007) Intracellular Localization of Human Ins $(1,3,4,5,6) \mathrm{P}_{5}$ 2-Kinase. Biochem $\mathrm{J}$ 408:335-45.

Chappell A.S., Scaboo A.M., Wu X., Nguyen H., Pantalone V.R., Bilyeu K.D. (2006) Characterization of the MIPS Gene Family in Glycine max. Plant Breed 125:493-500.

Clarke E.J., Wiseman J. (2000) Developments in Plant Breeding for Improved Nutritional Quality of Soya Beans ii. Anti-Nutritional Factors. J Ag Sci 134:125-136.

Daverede I.C., Kravchenko A.N., Hoeft R.G., Nafziger E.D., Bullock D.G., Warren J.J., Gonzini L.C. (2004) Phosphorus Runoff from Incorporated and Surface-Applied Liquid Swine Manure and Phosphorus Fertilizer. J Environ Qual 33:1535-1544.

Douglas M.W., Parsons C.M., Hymowitz T. (1999) Nutritional Evaluation of Lectin-Free Soybeans for Poultry. Poultry Sci 78:91-95. 
East J.W., Nakayama T.O.M., Parkman S.B. (1972) Changes in Stachyose, Raffinose, Sucrose, and Monosaccharides During Germination of Soybeans. Crop Sci 12:7-9.

Ferket P.R., van Heugten E., van Kempen T.A.T.G., Angel R. (2002) Nutritional Strategies to Reduce Environmental Emissions from Nonruminants. J Anim Sci 80:E168-E182.

Frank T., Habernegg R., Yuan F.-J., Shu Q.-Y., Engel K.-H. (2009a) Assessment of the Contents of Phytic Acid and Divalent Cations in Low Phytic Acid (Ipa) Mutants of Rice and Soybean. J Food Comp Anal 22:278-284.

Frank T., Norenberg S., Engel K.H. (2009b) Metabolite Profiling of Two Novel Low Phytic Acid (Ipa) Soybean Mutants. J Agric Food Chem 57:6408-16.

Fujii M., York J.D. (2005) A Role for Rat Inositol Polyphosphate Kinases rIPK2 and rIPK1 in Inositol Pentakisphosphate and Inositol Hexakisphosphate Production in Rat-1 Cells. J Biol Chem 280:1156-64.

Gao Y., Biyashev R.M., Maroof M.A.S., Glover N.M., Tucker D.M., Buss G.R. (2008) Validation of Low-Phytate QTLs and Evaluation of Seedling Emergence of Low-Phytate Soybeans. Crop Sci 48:1355-1364.

Gillman J.D., Baxter I., Bilyeu K. (2013) Phosphorus Partitioning of Soybean Lines Containing Different Mutant Alleles of Two Soybean Seed-Specific Adenosine Triphosphate-Binding Cassette Phytic Acid Transporter Paralogs. Plant Genome 6:1.

Gillman J.D., Pantalone V.R., Bilyeu K. (2009) The Low Phytic Acid Phenotype in Soybean Line CX1834 Is Due to Mutations in Two Homologs of the Maize Low Phytic Acid Gene. Plant Genome 2:179-190.

Hegeman C.E., Grabau E.A. (2001) A Novel Phytase with Sequence Similarity to Purple Acid Phosphatases Is Expressed in Cotyledons of Germinating Soybean Seedlings. Plant Physiol 126:1598-1608.

Hitz W.D., Carlson T.J., Kerr P.S., Sebastian S.A. (2002) Biochemical and Molecular Characterization of a Mutation That Confers a Decreased Raffinosaccharide and Phytic Acid Phenotype on Soybean Seeds. Plant Physiol 128:650-60.

Hymowitz T. (1970) On the Domestication of the Soybean. Ec Bot 24:408-421. 
Hymowitz T. (1990) Soybeans: The Success Story, in: J. Janick and J. E. Simon (Eds.), Advances in New Crops, Timber Press, Portland, Oregan. pp. 159163.

Hymowitz T. (2008) The History of the Soybean, in: L. A. Johnson, et al. (Eds.), Soybeans: Chemistry, Production, Processing, and Utilization, AOCS Press, Urbana, IL. pp. 1-31.

Hymowitz T., Harlan J.R. (1983) Introduction of Soybean to North America by Samuel Bowen in 1765. Ec Bot 37:371-379.

Hymowitz T., Kaizuma N. (1979) Dissemination of Soybeans (Glycine max): Seed Protein Electrophoresis Profiles among Japanese Cultivars. Ec Bot 33:311-319.

Hymowitz T., Newell C.A. (1980) Taxonomy, Speciation, Domestication, Dissemination, Germplasm Resources and Variation in the Genus Glycine, in: R. Summerfield and A. Bunting (Eds.), Advances in Legume Science, Royal Botanical Garden, Kew, England. pp. 251-264.

Hymowitz T., Newell C.A. (1981) Taxonomy of the Genus Glycine, Domestication and Uses of Soybeans. Ec Bot 35:272-288.

Irvine R., Schell M. (2001) Back in the Water: The Return of the Inositol Phosphates. Nat Rev Mol Cell Biol 2:327-338.

Ives E.B., Nichols J., Wente S.R., York J.D. (2000) Biochemical and Functional Characterization of Inositol 1,3,4,5, 6-Pentakisphosphate 2-Kinases. J Biol Chem 275:36575-83.

Janick J., Blase M.G., Johnson D.L., Jolliff G.D., Myers R.L. (1996) Diversifying U.S. Crop Production, in: J. Janick (Ed.), Progress in New Crops, ASHS Press, Alexandria, VA. pp. 98-109.

Kakade M.L., Arnold R.L., Leiner I.E., Waibel P.E. (1969) Unavailability of Cystine from Trypsin Inhibitors as a Factor Contributing to the Poor Nutritive Value of Navy Beans. J Nutr 99:34-42.

Kakade M.L., Hoffa D.E., Leiner I.E. (1973) Contribution of Trypsin Inhibitors to the Deleterious Effects of Unheated Soybeans Fed to Rats. J Nutr 103:1772-1778.

Krishnan H.B. (2005) Engineering Soybean for Enhanced Sulfur Amino Acid Content. Crop Sci 45:454-461. 
Liu K. (1999) Chemistry and Nutritional Value of Soybean Components, Soybeans: Chemistry, Technology, and Utilization, Aspen Publishers, Gaithersburg, MD. pp. 25-113.

Maroof M.A.S., Glover N.M., Biyashev R.M., Buss G.R., Grabau E.A. (2009) Genetic Basis of the Low-Phytate Trait in the Soybean Line CX1834. Crop Sci 49:69-76.

Maupin L.M., Rainey K.M. (2011) Improving Emergence of Modified Phosphorus Composition Soybeans: Genotypes, Germplasm, Environments, and Selection. Crop Sci 51:1946-1955.

Maupin L.M., Rosso M.L., Rainey K.M. (2011) Environmental Effects on Soybean with Modified Phosphorus and Sugar Composition. Crop Sci 51:642-650.

Meis S.J., Fehr W.R., Schnebly S.R. (2003) Seed Source Effect on Field Emergence of Soybean Lines with Reduced Phytate and Raffinose Saccharides. Crop Sci 43:1336-1339.

Miller A.L., Suntharalingam M., Johnson S.L., Audhya A., Emr S.D., Wente S.R. (2004) Cytoplasmic Inositol Hexakisphosphate Production is Sufficient for Mediating the Gle1-mRNA Export Pathway. J Biol Chem 279:51022-32.

Montgomery K.S. (2003) Soy Protein. J Perinat Educ 12:42-45.

Oltmans S.E., Fehr W.R., Welke G.A., Cianzio S.R. (2004) Inheritance of LowPhytate Phosphorus in Soybean. Crop Sci 44:433-435.

Ongusaha P., Hughes P., Davey J., Michell R. (1998) Inositol Hexakisphosphate in Schizosaccharomyces pombe: Synthesis from Ins $(1,4,5) \mathrm{P}_{3}$ and Osmotic Regulation. Biochem J 335:671-679.

Pham A.-T., Lee J.-D., Shannon J.G., Bilyeu K. (2010) Mutant Alleles of FAD2$1 A$ and FAD2-1B Combine to Produce Soybeans with the High Oleic Acid Seed Oil Trait. BMC Plant Biol 10:195.

Phillippy B.Q., Ullah A.H., Ehrlich K.C. (1994) Purification and Some Properties of Inositol 1,3,4,5,6-Pentakisphosphate 2-Kinase from Immature Soybean Seeds. J Biol Chem 269:28393-9.

Raboy V., Dickinson D.B. (1984) Effect of Phosphorus and Zinc Nutrition on Soybean Seed Phytic Acid and Zinc. Plant Physiol 75:1094-1098. 
Raboy V., Dickinson D.B. (1987) The Timing and Rate of Phytic Acid Accumulation in Developing Soybean Seeds. Plant Physiol 85:841-844.

Raboy V., Dickinson D.B., Below F.E. (1984) Variation in Seed Total Phosphorus, Phytic Acid, Zinc, Calcium, Magnesium, and Protein among Lines of Glycine max and G. soja. Crop Sci 24:431-434.

Raboy V., Gerbasi P. (1996) Genetics of myo-Inositol Phosphate Synthesis and Accumulation, in: B. B. Biswas and S. Biswas (Eds.), myo-Inositol Phosphates, Phosphoinositides, and Signal Transduction, Plenum Press, New York. pp. 257-285.

Raboy V., Gerbasi P.F., Young K.A., Stoneberg S.D., Pickett S.G., Bauman A.T., Murthy P.P.N., Sheridan W.F., Ertl D.S. (2000) Origin and Seed Phenotype of Maize Low Phytic Acid 1-1 and Low Phytic Acid 2-1. Plant Physiol 124:355-368.

Raboy V., Young K.A., Dorsch J.A., Cook A. (2001) Genetics and Breeding of Seed Phosphorus and Phytic Acid. J Plant Physiol 158:489-497.

Sarmah B., Wente S.R. (2009) Dual Functions for the Schizosaccharomyces pombe Inositol Kinase IPK1 in Nuclear mRNA Export and Polarized Cell Growth. Eukaryot Cell 8:134-46.

Scaboo A.M., Pantalone V.R., Walker D.R., Boerma H.R., West D.R., Walker F.R., Sams C.E. (2009) Confirmation of Molecular Markers and Agronomic Traits Associated with Seed Phytate Content in Two Soybean RIL Populations. Crop Sci 49:426-432.

Sebastian S., Kerr P.S., Pearlstein R., Hitz W. (2000) Soybean Germplasm with Novel Genes for Improved Digestibility, in: J. Drackley (Ed.), Soy in Animal Nutrition, Federation of Animal Science Societies, Savoy, IL. pp. 56-74.

Seeds A.M., Sandquist J.C., Spana E.P., York J.D. (2004) A Molecular Basis for Inositol Polyphosphate Synthesis in Drosophila melanogaster. J Biol Chem 279:47222-32.

Sharpley A.N., Chapra S.C., Wedepohl R., Sims J.T., Daniel T.C., Reddy K.R. (1994) Managing Agricultural Phosphorus for Protection of Surface Waters: Issues and Options. J Environ Qual 23:437-451.

Shears S.B. (1998) Review: The Versatility of Inositol Phosphates as Cellular Signals. Biochim Biophys Acta 1436:49-67. 
Shi J., Wang H., Schellin K., Li B., Faller M., Stoop J.M., Meeley R.B., Ertl D.S., Ranch J.P., Glassman K. (2007) Embryo-Specific Silencing of a Transporter Reduces Phytic Acid Content of Maize and Soybean Seeds. Nat Biotechnol 25:930-7.

Soystats. (2012) Available at http://www.soystats.com/.

Stephens L., Hawkins P., Stanley A., Moore T., Poyner D., Morris P., Hanley M., Kay R., Irvine R. (1991) myo-Inositol Pentakisphospates: Structure, Biological Occurrence, and Phosphorylation to myo-Inositol Hexakisphosphate. Biochem J 275:485-499.

Stephens L., Irvine R. (1990) Stepwise Phosphorylation of myo-Inositol Leading to myo-Inositol Hexakisphosphate in Dictyostelium. Nature 346:580-583.

Stevenson-Paulik J., Bastidas R.J., Chiou S.T., Frye R.A., York J.D. (2005) Generation of Phytate-Free Seeds in Arabidopsis through Disruption of Inositol Polyphosphate Kinases. Proc Natl Acad Sci U S A 102:12612-7.

Suarez F.L., Springfield J., Furne J.K., Lohrmann T.T., Kerr P.S., Levitt M.D. (1999) Gas Production in Human Ingesting a Soybean Flour Derived from Beans Naturally Low in Oligosaccharides. Am J Clin Nutr 69:135-139.

Sun Y., Thompson M., Lin G., Butler H., Gao Z., Thornburgh S., Yau K., Smith D.A., Shukla V.K. (2007) Inositol 1,3,4,5,6-Pentakisphosphate 2-Kinase from Maize: Molecular and Biochemical Characterization. Plant Physiol 144:1278-91.

Suzuki M., Tanaka K., Kuwano M., Yoshida K.T. (2007) Expression Pattern of Inositol Phosphate-Related Enzymes in Rice (Oryza sativa L.): Implications for the Phytic Acid Biosynthetic Pathway. Gene 405:55-64.

Sweetman D., Johnson S., Caddick S.E., Hanke D.E., Brearley C.A. (2006) Characterization of an Arabidopsis Inositol 1,3,4,5,6-Pentakisphosphate 2Kinase (AtIPK1). Biochem J 394:95-103.

Urbano G., López-Jurado M., Aranda P., Vidal-Valverde C., Tenorio E., Porres J. (2000) The Role of Phytic Acid in Legumes: Antinutrient or Beneficial Function? J Physiol Biochem 53:283-294.

USDA-ERS. (2012) Soybeans \& Oil Crops: Overview. Available at http://www.ers.usda.gov/topics/crops/soybeans-oilcrops.aspx\#.UZKnkrWG2So. 
Verbsky J., Lavine K., Majerus P.W. (2005) Disruption of the Mouse Inositol 1,3,4,5,6-Pentakisphosphate 2-Kinase Gene, Associated Lethality, and Tissue Distribution of 2-Kinase Expression. Proc Natl Acad Sci U S A 102:8448-53.

Verbsky J.W., Wilson M.P., Kisseleva M.V., Majerus P.W., Wente S.R. (2002) The Synthesis of Inositol Hexakisphosphate. Characterization of Human Inositol 1,3,4,5,6-Pentakisphosphate 2-Kinase. J Biol Chem 277:3185762.

Walker D.R., Scaboo A.M., Pantalone V.R., Wilcox J.R., Boerma H.R. (2006) Genetic Mapping of Loci Associated with Seed Phytic Acid Content in CX1834-1-2 Soybean. Crop Sci 46:390-397.

Wilcox J.R., Premachandra G.S., Young K.A., Raboy V. (2000) Isolation of High Seed Inorganic P, Low-Phytate Soybean Mutants. Crop Sci 40:1601-1605.

York J.D., Odom A.R., Murphy R., Ives E.B., Wente S.R. (1999) A Phospholipase C-Dependent Inositol Polyphosphate Kinase Pathway Required for Efficient Messenger RNA Export. Science 285:96-100.

Yuan F.J., Zhao H.J., Ren X.L., Zhu S.L., Fu X.J., Shu Q.Y. (2007) Generation and Characterization of Two Novel Low Phytate Mutations in Soybean (Glycine max L. Merr.). Theor Appl Genet 115:945-57.

Yuan F.J., Zhu D.H., Deng B., Fu X.J., Dong D.K., Zhu S.L., Li B.Q., Shu Q.Y. (2009) Effects of Two Low Phytic Acid Mutations on Seed Quality and Nutritional Traits in Soybean (Glycine max L. Merr). J Agric Food Chem 57:3632-8.

Yuan F.J., Zhu D.H., Tan Y.Y., Dong D.K., Fu X.J., Zhu S.L., Li B.Q., Shu Q.Y. (2012) Identification and Characterization of the Soybean IPK1 Ortholog of a Low Phytic Acid Mutant Reveals an Exon-Excluding Splice-Site Mutation. Theor Appl Genet 125:1413-23. 


\section{CHAPTER 2}

Characterization of a Fast Neutron Population with a Multifoliate

Leaf Phenotype 


\section{Abstract}

Soybean [Glycine $\max$ (L.) Merr] seeds contain a large amount of phosphorus $(\mathrm{P})$, which is stored as phytic acid (PA). PA is indigestible by nonruminant livestock and considered an anti-nutritional factor because PA chelates divalent cations and prevents the uptake of essential nutrients. Interest in reducing PA has increased greatly over the years and several low PA soybean lines have been discovered; however, many of these lines have inadequate germination and emergence. A gamma irradiated soybean line, ZC-2, with 50\% reduction in PA was found to have excellent germination and emergence. The low PA phenotype was a result of a mutation in a gene orthologous to inositol pentakisphosphate 2-kinase (IPK1; Glyma14g07880), which is responsible for phosphorylating inositol pentakisphosphate into PA. Fast neutron irradiated Williams82 seed led to the discovery of a line, FN38, with a multifoliate leaflet phenotype. Through comparative genomic hybridization, FN38 was discovered to have a deletion in a homologous IPK1 gene (Glyma06g03310) and two homeobox genes (HOX; Glyma06g03200 and Glyma06g03210). Preliminary studies have indicated that HOX genes are important for leaf architecture. Our objectives were to characterize the HOX gene deletions in FN38, as well as PA levels. Jake was bred with FN38 to develop a segregating population, and we designed primers and used them to determine the presence or absence in the deletion. We performed high-performance liquid chromatography (HPLC) to measure PA levels and a colorimetric assay to measure Pi levels. We were 
unable to identify the exact location of the start and end of the deletion due to gene similarity, and we were also unable to span the deletion with any of our primer sets most likely due to rearrangements. Initial characterization of PA and inorganic phosphorus $(\mathrm{Pi})$ levels for the deletion indicated that a mutated Glyma06g03310 IPK1 gene does not increase Pi or decrease PA by itself.

\section{Introduction}

Many crops, including soybean, contain myo-inositol hexakisphosphate, otherwise known as phytic acid (PA); however, monogastric consumers, such as poultry and swine, are unable to digest PA due to the lack of gastric phytases that break down PA (Raboy et al., 1984). PA is also a chelating agent that binds to metal ions present in the digestive system, which prevents absorption of essential nutrients (Clarke and Wiseman, 2000). This causes feed companies to supplement with phytase and minerals for nonruminant livestock to get the adequate nutrients for their bodies' needs (Wilcox et al., 2000). Phosphorus in PA passes through monogastric species ending up in their waste, and excess phosphorus in the environment has a huge negative impact on water systems (Sharpley et al., 1994). Fortunately, many studies have been successfully performed to create low phytic acid mutations (Ipa) without decreased nutritional quality (Raboy et al., 2001).

Identification of two independent mutagenized soybean seeds, from different laboratories, led to the discovery of genes that can be mutated to result 
in Ipa (Sebastian et al., 2000; Wilcox et al., 2000). Through characterization of these mutants, three genes were mutated to cause Ipa phenotype: myo-inositol 1-phosphatase synthase (mips) and two ATP-binding cassette transporters (Ipa1 and Ipa2), which were both required, in soybean, for the Ipa phenotype (Gillman et al., 2013; Gillman et al., 2009; Hitz et al., 2002). Another mutagenized soybean line was discovered to contain the Ipa phenotype (the mutant was designated ZC-2), but it resulted in an increase in lower inositols, unlike other soybean Ipa mutants (Yuan et al., 2007).

A few studies have shown that ZC-2 does not result in any negative seed quality or decreased nutritional importance (Frank et al., 2009a; Frank et al., 2009b; Yuan et al., 2009). Preliminary testing also indicated that the Ipa mutant does not decrease germination, in subtropical environments, compared to its wild-type parent, and these results were of interest because most lpa mutations have been shown to have poor germination, especially in (sub)tropical environments (Anderson and Fehr, 2008; Maupin and Rainey, 2011; Maupin et al., 2011; Meis et al., 2003; Yuan et al., 2007). Results concluded that the gene responsible for the novel lpa mutant was an inositol $(1,3,4,5,6)$ pentakisphosphate 2-kinase, otherwise known as IPK1 (Yuan et al., 2012).

IPK1 has been discovered in many diverse species, and it is well known to be the enzyme that places the last phosphate on inositol $(1,3,4,5,6)$ pentakisphosphate to create PA (Yuan et al., 2012). In the ZC-2 soybean mutant, a gene orthologous to IPK1 (Glyma14g07880) resulted in the Ipa 
phenotype; however, there are two homologous IPK1 genes: Glyma04g03240, and Glyma06g03310 (Yuan et al., 2012). Their results designated Glyma14g07880 as the main gene expressed for PA production in soybean seeds; however, the other two genes did exhibit some activity (Yuan et al., 2012).

Previously, fast neutron (FN) irradiated Williams82 (W82) soybean seeds were analyzed for several field generations for visible phenotypes, and one line produced $M_{2: 3}$ plants segregating for tetra- or penta-foliate leaflets, instead of the trifoliate leaflets normally observed in wild-type soybeans (Figure 2.1) (Bilyeu, unpublished results). Lycopersicon esculentum (tomato) was overexpressed with LeT6, the tomato homeobox $(\mathrm{HOX})$ gene, and the progeny created contained extra leaflets (Janssen et al., 1998). Comparative genomic hybridization ( $\mathrm{CGH})$ was then performed on the line, designated FN38, and a large deletion on chromosome 6 , including most of the IPK1 homologue Glyma06g03310 and two HOX protein transcription factors (Glyma06g03200 and Glyma06g03210) were discovered (Stacey and Stacey, personal communication, 2011). In our study, our first objective was to identify the HOX genes responsible for the FN38 multifoliate phenotype. The next objective was to analyze inorganic phosphorus (Pi) and PA content of FN38 compared to ZC-2. 


\section{Materials and Methods}

\section{FN irradiation}

In the fall of $2007,70,000$ W82 seeds were treated with 30 Gy fast neutrons at McClellan Nuclear Radiation Center (University of California Davis, Davis, CA). Seeds were sent to grow in Costa Rica for increase, and in May 2008, approximately 9,000 single plant packets were returned to Columbia, Missouri as $\mathrm{M}_{2}$ seeds. Only 4096 packets were planted in a field with 4096 rows in 8x8 plots of $M_{2: 3}$ lines, each representing one $M_{2}$ packet. Visual phenotyping of $M_{3}$ plants in the field led to the discovery of one line segregating for a multifoliate phenotype. Two mulitifoliate plants from the same line were threshed at maturity, and several $\mathrm{M}_{3: 4}$ seeds of one of those plants was provided to $\mathrm{Dr}$. Minviluz Stacey (Division of Plant Sciences, University of Missouri Columbia)

\section{Comparative genomic hybridization (CGH) of FN38 compared to W82}

CGH was performed on DNA from a single plant designated FN38 by Dr. Minviluz Stacey as described by Bolon et al. (2011). NimbleGen soybean CGH microarray, which consists of 696,139 unique oligonucleotide probes (50- to 70mers) were designed from the reference sequence, W82, and spaced at approximately 1.1 kilobases $(\mathrm{kb})$ intervals (platform details can be found in Gene Expression Omnibus accession number GPL11198 at www.ncbi.nlm.nih.gov/geo/). Mutant (Сy3 dye) and reference (Сy5 dye) labeling reactions were performed with $1 \mu \mathrm{g}$ each of genomic DNA from FN38 (mutant)

and W82 (wild-type) leaf tissue samples. Mutant and wild-type DNA were 
labeled, quantified, and then hybridized for 72 hours at $42^{\circ} \mathrm{C}$ on the $\mathrm{CGH}$ microarrays. There were several deletions across all 20 chromosome; however, one region on chromosome 6 was found to include the two HOX genes (Stacey and Stacey, personal communication, 2011).

\section{Plant material and segregating population development}

A segregating population was developed by crossing FN38 (homozygous for ipk1; Glyma06g03310) and Jake (homozygous for IPK1; Glyma06g03310). FN38 was used as the male for these crosses (see above). Jake was used as the female, and it is a mid-group $V$, registered plant line that was received from Dr. Grover Shannon (Division of Plant Sciences, University of Missouri ColumbiaDelta Center) (Shannon et al., 2007).

Both lines were grown at South Farm in Columbia, Missouri during the summer of 2011. FN38 was crossed onto Jake in order to obtain $F_{1}$ seeds. $F_{1}$ plants were grown in a growth chamber with 14 hour days at $28^{\circ} \mathrm{C}$ and 10 hour nights at $22^{\circ} \mathrm{C} . \quad F_{2}$ seeds were produced in the winter of 2011-2012, and they were planted at South Farm in the summer of 2012. Individual $F_{2}$ plants were identified by "Jake $4 / 5$ " then a specialized number and observed for the FN38 multifoliate leaflet phenotype. During harvest, progeny seed from each plant were collected individually for phenotypic and genotypic analyses.

\section{Genotypic analysis of the sequence around the FN38 deletion}

FN38 and W82 single seeds were powdered in liquid nitrogen for DNA isolation using the DNeasy Plant Mini Kit (Qiagen Sciences Inc., Germantown, 
$M D$ ). Primers were designed to the region left of the deletion known start point and the right of the deletion known end point using W82 as a reference at Phytozome (www.phytozome.net), and the primers were manufactured through IDT (Coralville, IA). Primers were designed to amplify various size products in different regions due to homologous genes on chromosome 4 of soybean, and all of the primers were at a final concentration of $0.5 \mu \mathrm{M}$ (Error! Reference source not found.). Reactions were carried out with a total volume of $20 \mu \mathrm{L}$ containing: 5-50 ng DNA template, primers, buffer (40 mM Tricine- $\mathrm{KOH}(\mathrm{pH} 8.0), 16 \mathrm{mM}$ $\mathrm{KCl}$, $3.5 \mathrm{mM} \mathrm{MgCl}_{2}$, $3.75 \mu \mathrm{mL}^{-1} \mathrm{BSA}, 200 \mu \mathrm{M}$ dNTPs), and 0.2X Titanium Taq polymerase (BD Biosciences, Palo Alto, CA). PCR was carried out on a thermocycler at these conditions: $95^{\circ} \mathrm{C}$ for 5 minutes trailed by 40 cycles of $95^{\circ} \mathrm{C}$ for 20 seconds, $60^{\circ} \mathrm{C}$ for 20 seconds, and $72^{\circ} \mathrm{C}$ for 30 seconds. An agarose gel, $1.2 \%$ concentration, was used to determine the presence of PCR product, and if PCR product was present, an image was taken with Fotodyne Imager.

\section{Sequencing of HOX in other genotypes with multifoliate phenotype}

Independent lines, a total of six, with the tetra- or penta-foliate leaflets were obtained through the USDA Soybean Germplasm Collection. The germplasm lines containing the multifolate phenotype: T236, PI416892, PI200454, PI471940, PI578318B, and PI587894. These lines were chosen because they did not have the deletion that FN38 contained; thus, amplifications of HOX genes were able to be performed. Single seeds from these 6 different lines with the tetra- or penta-foliate leaflets were ground in liquid nitrogen for 
DNA isolation using the DNeasy Plant Mini Kit (Qiagen Sciences Inc., Germantown, MD).

Primers were designed using the W82 reference sequence at SoyBase (www.soybase.org) and manufactured through IDT (Coralville, IA). Primers were designed to amplify various size products in different regions due to homologous genes on chromosome 4 of soybean, and all of the primers were at a final concentration of $0.5 \mu \mathrm{M}$ (Error! Reference source not found.). Reactions were carried out with a $20 \mu \mathrm{L}$ total volume with the same PCR set-up and protocol as before ("Genotypic analysis of the sequence around the FN38 deletion") with the exception of the extension time, which was based on the number of sequenced bps (1 minute per $1 \mathrm{~kb}$ of product). Product was sequenced at the University of Missouri DNA Core Facility (web.rnet.missouri.edu/biotch/dnacore/index.html), and sequences were viewed and analyzed using the DNA Core's Chromatogram. Sequences were aligned to the reference, W82, using the free internet program ClustalW (http://www.genome.jp/tools/clustalw/).

\section{Genotypic analysis of the FN38 deletion in Jake 4/5 population}

A 15-seed sample was dried and ground from $F_{3}$ seeds of the plants in the Jake 4/5 soybean population for DNA isolation using the DNeasy Plant Mini Kit (Qiagen Sciences Inc., Germantown, MD). Seeds were dried via lyophilization and ground with modified coffee grinders. The R2 primer set (Error! Reference source not found.) was used to identify progeny with the FN38 deletion, and since the primers were targeted to a $\sim 400$ bps sequence within the deletion, 
homozygous wild-type and heterozygotes made product, while the homozygous mutants did not. Control primers were used to verify PCR success for the homozygous mutants because there would be no band present due to containing the deletion. Both primer sets, R2 and control, were at a final concentration of $0.5 \mu \mathrm{M}$. The control primers amplified $\sim 200 \mathrm{bps}$ in the wild-type FAD3A gene, which was not mutated in FN38 (3Aix: 5'-AGCTATTATCTAGCATTAACCTCA-3' and 3Ad1: 5'-TTGCATCACCATGGTCATCAT-3') (Bilyeu et al., 2005). Reactions were carried out in $20 \mu \mathrm{L}$ containing the same PCR set-up, conditions, and visualization as before ("Genotypic analysis of the sequence around the FN38 deletion") with the addition of the control primers.

\section{Growth chamber experiment}

This experiment was performed in order to create the Ipa phenotype based on the results given by Raboy and Dickinson (1984). Their results state that feeding soybean lines with a nutrient solution with only reduced amounts of phosphorus creates the Ipa phenotype. This experiment was performed in one Percival Growth Chamber (GC), with two reps of each line. Since the GC only holds up to 16 pots, both reps received the same treatment. There were a total of 8 genotypes selected for this experiment: 5 of the $F_{3}$ Jake 4/5 population were chosen (394, 404, 414, 415, and 419), FN38, Jake, and ZC-2 (Pengyin Chen, University of Arkansas, Fayetteville, AR). Selections of the $F_{3}$ Jake 4/5 population were based on those seen with multifoliate leaflets (Jake 4/5: 394, 404,414 , and 415 ) in the field experiment and those postulated to have the FN38 
deletion, whether or not the line had multifoliate leaflets (Jake 4/5: 404, 415, and 419). Plants received, per day, 14 -hours of light at $28^{\circ}$ with 10 -hours of dark at $22^{\circ}$. Three seeds per line were placed into a pot containing ProMix, and pots were thinned down to one plant per pot 11 days after planting. Pots were watered with double deionized water until germination.

The only differences between our experiment and that presented in Raboy and Dickinson (1984) were that MiracleGro was used as the full nutrient solution, a final concentration of $1.646 \mathrm{mM} \mathrm{MgSO}{ }_{4}{ }^{\star} 7 \mathrm{H}_{2} \mathrm{O}$ was added into the reduced $\mathrm{P}$ solution, and $300 \mathrm{~mL}$, instead of $1 \mathrm{~L}$, was fed per pot on each solution day. Final concentrations of all chemicals were based on feeding $300 \mathrm{~mL}$ per pot instead of $1 \mathrm{~L}$. MiracleGro feeding began 14 days after planting (DAP), and every 14 days, the pots were fed with MiracleGro. MiracleGro was mixed according to instructions on the label: $10 \mathrm{~mL}$ per gallon of water.

At 42 DAP, the plants were fed reduced phosphorus nutrient solution, and they were then fed two times per week, on Tuesday and Friday, until harvested. The reduced phosphorus solution contained, at final concentration, $0.215 \mathrm{mM}$ $\mathrm{KH}_{2} \mathrm{PO}_{4}, 8.924 \mathrm{mM} \mathrm{Ca}\left(\mathrm{NO}_{3}\right)_{2}{ }^{*} 4 \mathrm{H}_{2} \mathrm{O}, 1.19 \mathrm{mM}\left(\mathrm{NH}_{4}\right)_{2} \mathrm{SO}_{4}, 4.263 \mathrm{mM} \mathrm{KCl}, 1.646$ $\mathrm{mM} \mathrm{MgSO}_{4}{ }^{*} 7 \mathrm{H}_{2} \mathrm{O}, 0.142 \mathrm{mM}$ Sprint $330,0.154 \mathrm{mM} \mathrm{H}_{3} \mathrm{BO}_{3}, 0.037 \mathrm{mM}$ $\mathrm{MnCl}^{\star} 4 \mathrm{H}_{2} \mathrm{O}, 0.003 \mathrm{mM} \mathrm{ZnSO}_{4}{ }^{\star} 7 \mathrm{H}_{2} \mathrm{O}, 0.001 \mathrm{mM} \mathrm{CuSO}_{4}{ }^{*} 5 \mathrm{H}_{2} \mathrm{O}$, and $0.0004 \mathrm{mM}$ $\mathrm{H}_{2} \mathrm{MoO}_{4}$. Every pot got $300 \mathrm{~mL}$ of reduced phosphorus solution twice per week, and the pots were fed with deionized water between MiracleGro and reduced phosphorus solution treatments, as needed. 
FTA cards were used to make leaf presses for DNA isolation from both reps and were cleaned using the standard protocol (Whatman FTA Protocol BD05). PCR analysis was performed to see which of the Jake $4 / 5$ genotypes contained the deletion segment and if the reps of each line were the same. New primers were designed using the genetic sequence of W82, available from SoyBase (www.soybase.org), and were synthesized by IDT (Coralville, IA). Primers were designed to amplify $\sim 400$ base pairs (bps) in only the Glyma06g03310 IPK1 region, and since the primers were in the deletion, homozygous wild-type and heterozygotes made product, while the homozygous mutants did not. Primers, including the control primers, were at a final concentration of $0.5 \mu \mathrm{M}$ (IP5delF: 5'-GGAGGAAGGTATAAGAGTG-3' and IP5deIR: 5'-CCAGCAGAAGCTGAACC-3'). Reactions were carried out with a total volume of $20 \mu \mathrm{L}$ containing the same PCR set-up, conditions, and visualization as before ("Genotypic analysis of the sequence around the FN38 deletion") with the addition of the control primers. During harvest, only a few lines gave enough seed for analysis due to death before maturity; thus, we only used four of the genotypes, which were an average of both reps, for Pi analysis: FN38, Jake, Jake 4/5 414 and Jake 4/5 419.

\section{Pi quantification by colorimetric assay}

Through small variations of the assay described by Wilcox et al. (2000), $\mathrm{Pi}$ was quantified. Genotypes used for Pi analysis: Jake 4/5 $\mathrm{F}_{3}$ progeny, FN28, Jake, ZC-2, Ipa1a/2a, and Ipa1a/2b. Seeds for Ipa1a/2a and Ipa1a/2b were 
developed in Dr. Bilyeu's laboratory (Gillman et al., 2013). Of the 15-seed subset that were dried and ground for each line, $10-15 \mathrm{mg}$ were mixed with $0.5 \mathrm{~mL}$ of extraction buffer [12.5\% (V/W) TCA, $25 \mathrm{mM} \mathrm{MgCl}_{2}$ ] and were shaken overnight at $4^{\circ} \mathrm{C}$. The suspensions were allowed to settle for roughly an hour; then, $10 \mu \mathrm{L}$ of supernatant, $90 \mu \mathrm{L}$ of deionized water, and $100 \mu \mathrm{L}$ of colorimetric reagent [1 volume $3 \mathrm{M} \mathrm{H}_{2} \mathrm{SO}_{4}, 1$ volume $0.02 \mathrm{M}$ ammonium molybdate, 1 volume $10 \%(\mathrm{v} / \mathrm{v})$ ascorbic acid, and 2 volumes deionized water] were placed into a 96-well spectrophotometer plate. The solutions were allowed to incubate for 1.5 hours before being read by a spectrophotometer at $825 \mathrm{~nm}$. A standard curve was

made using $\mathrm{K}_{2} \mathrm{HPO}_{4}$, and it was applied to the sample results from field and GC experiments, which were then converted to $\mu \mathrm{g} P \mathrm{mg} \mathrm{seed}^{-1}$.

\section{PA quantification by HPLC}

The HPLC method was used to quantify PA from the field and growth chamber experiments (Chen and Li, 2003). Genotypes used for field PA analysis: Jake 4/5 $\mathrm{F}_{3}$ progeny, FN28, Jake, ZC-2, Ipa1a/2a, and Ipa1a/2b. Genotypes used for GC experiment: five Jake $4 / 5 \mathrm{~F}_{3: 4}$ progeny, FN38, Jake, and ZC-2. Of the 15-seed subset that was dried and ground, $25 \mathrm{mg}$ were combined with $0.5 \mathrm{~mL}$ extraction buffer [500 $\mathrm{mM} \mathrm{HCl}$, shaken for 1 hour at room temperature, spun at $20,000 \mathrm{~g}$ for 15 minutes, supernatant filtered through 0.22 micron filter, and $75 \mu \mathrm{L}$ of filtrate analyzed by a linear gradient elution program on a Dionex CarboPac PA-100 guard column and a CarboPac PA-100 analytical column on an Agilent 1100 series HPLC system. The elution gradient was 
effected by two eluents: deionized water and $0.5 \mathrm{M} \mathrm{HCl}$; time $0 \mathrm{~min}, 8 \% 0.5 \mathrm{M}$ $\mathrm{HCl}$; time 30, 100\% 0.5 M HCl; time 35, 100\% 0.5 M HCl; time 35.1, 100\% $0.5 \mathrm{M}$ $\mathrm{HCl}$; time $40,8 \% 0.5 \mathrm{M} \mathrm{HCl}$. A post-column derivitization was achieved with a solution of $1 \mathrm{~g} \mathrm{~L}^{-1} \mathrm{Fe}\left(\mathrm{NO}_{3}\right)_{3}$ in $0.33 \mathrm{M} \mathrm{HClO}_{4}$ using a $750-\mathrm{mL}$ knitted coil and was followed by detection of $A_{295}$. Flow rates of eluent and post-column solution were 1.0 and $0.4 \mathrm{~mL}^{\text {minutes }}{ }^{-1}$, respectively. PA standard (PA dipotassium salt; Sigma), at $1 \mathrm{mM}$ concentration, eluted at 29.5 minutes, and a standard curve was calculated from serial dilutions of $4 \mathrm{mM}$ PA standard. Results from the field experiment were converted to $\mu \mathrm{g}$ PA-P $\mathrm{mg} \mathrm{seed}^{-1}$.

\section{Statistical analysis}

All statistical analyses were carried out using the SAS 9.3 software (SAS Institute Inc., Cary, NC). It was a completely randomized design, and all lines were grouped into 6 categories based on their genotype: each parental line (FN38 and Jake), ZC-2, the two Ipa mutants, and Jake 4/5 progeny, and each individual line within a category were distinguished. Basic statistic parameters for were obtained using the MIXED procedure. Categories and lines were the classes used, with lines randomized and least square means determined for categories. 


\section{Results}

\section{HOX analysis}

Using $\mathrm{CGH}$, we concluded that the probes, on chromosome 6 , between the bps 2252581 and 2339716 were deleted in FN38 (Stacey and Stacy, personal communication, 2011), and we also verified that this deletion encompassed the two HOX genes and IPK1. Thus, six different primer sets were designed to determine how far beyond the oligonucleotide probes the deletion flanked. Three primer sets, designated L1, L2, and L3, with L3 being closest to deletion, were located on the left side of bp 2252581. Three other primer sets, named R1, R2, R3, with R3 being nearest to the deletion, were positioned on the right side of bp 2339716. Through agarose gel visualization, L3, R2, and R3 were concluded to be deleted (Figure 2.2). We then used L1 and L2 forward primers with $\mathrm{R} 1$ reverse primer to try to span the deletion and discover the exact sequence present. Unfortunately, none of the many attempts to span the deletion of FN38 were successful (data not shown).

HOX genes are known to be involved in leaflet architecture; however, since two divergent $\mathrm{HOX}$ genes were deleted in FN38, one or the other $\mathrm{HOX}$ gene became the prime candidate underlying the multifoliate phenotype. We then began to look at other multifoliate leaflet soybean lines to attempt to narrow down which HOX gene was causing the phenotype by identifying an independent mutant allele of one of the two HOX genes. Two genotypes grown in Dr. Bilyeu's 2011 crossing block, T236 and PI416892, displayed the multifoliate phenotype, 
so these lines were used to investigate genetic differences in HOX genes compared to the reference sequence, W82, on SoyBase (www.soybase.org). By using several different primers, the entire sequence for Glyma06g3200 and Glyma06g3210 were determined for only PI416892. Unfortunately, there were no amino acid or protein changes between PI416892 and the reference, W82 (data not shown). Since we were unable to determine a mutation in PI416892, we used the soybean germplasm to test other lines with the same phenotype. Similar to the situation for T236, we were unable to get a full sequence for Glyma06g3200 and Glyma06g3210 for these germplasm lines (data not shown) due to amplification difficulties. These struggles were caused by the presence of additional copies on chromosome 4 of both HOX genes; thus, a definitive conclusion for which of the two HOX genes was associated with the multifoliate phenotype in line FN38 was not attained.

\section{Genotypic analysis of FN38 deletion}

Jake 4/5 $F_{2}$ leaf presses DNA showed eight progeny plants with the FN38 deletion (data not shown); however, not all the progeny plants were able to be harvested due to death before maturity due to disease. Of the eight Jake $4 / 5 F_{2}$ leaf presses with the FN38 deletion, only one of the Jake $4 / 5 F_{3}$ plants, when SPT seeds were ground and DNA isolated, showed the FN38 deletion (data not shown). Several more attempts of DNA isolation and PCR reactions were performed, but the amplification process was suboptimal for the Jake $4 / 5$ population. After investigation, the Soybase website indicated that all primers of 
the primer sets to the left and right of the deletion were homologous to more than just the specified chromosome 6 region, even though Phytozome specified that the primers were not homologous to any other genes throughout the genome.

\section{Jake 4/5 $F_{3}$ populations: Phenotypic analyses}

Phenotypic analysis showed that the $\mathrm{Pi}$ for the Jake $4 / 5 \mathrm{~F}_{3}$ population and the parental lines, FN38 and Jake, did not increase compared to ZC-2, Ipa1a/2a, or Ipa1a/2b (Figure 2.3a). ZC-2 Pi was higher than the Jake 4/5 population, but it was not nearly as high as the $1 p a 1 a / 2 a$ or $1 p a 1 a / 2 b$ mutants. PA results did not show a decrease in the Jake $4 / 5 \mathrm{~F}_{3}$ population or the parental lines (FN38 and Jake), either (Figure 2.3b). Interestingly, Jake seed showed a slightly lower PA amount than ZC-2, but the Ipa1a/2a and Ipa1a/2b mutants were definitely much lower than the rest of the genotypes. ZC-2 contained lower inositol peaks, $\mathrm{I}(1,4,5,6) \mathrm{P}_{4}$ and $\mathrm{I}(1,3,4,5,6) \mathrm{P}_{5}$, that $\mathrm{FN} 38$, Jake, and the Jake $4 / 5$ population did not (Figure 2.4).

\section{Reduced phosphorus nutrient experiment}

Since a partially deleted Glyma06g03310, IPK1, gene did not have a lower $\mathrm{PA}$ or $\mathrm{Pi}$ by itself, we attempted to create an Ipa phenotype by using a reduced $\mathrm{P}$ treatment that has been shown to alter $\mathrm{P}$ partitioning for Raboy and Dickinson (1984). The experiment involved feeding a reduced $P$ nutrient solution in hopes to alter $\mathrm{P}$ partitioning within a few of our Jake $4 / 5$ lines, the Jake $4 / 5$ parental lines (FN38 and Jake), and ZC-2. We began with a full nutrient solution. Our reduced P solution was based on Raboy and Dickinson (1984), but we added 
$\mathrm{MgSO}_{4}{ }^{*} 7 \mathrm{H}_{2} \mathrm{O}$ and adjusted the formula so that we could feed $300 \mathrm{~mL}$ per pot instead of $1 \mathrm{~L}$.

FTA card leaf presses of all genotypes, with both reps distinguished, were taken to identify lines with the FN38 deletion. New primers were designed to identify Jake $4 / 5$ lines that were homozygous for the deletion. Amplification showed that only one line, Jake $4 / 5419$, which did not show the deletion with the suboptimal PCR, was homozygous for the deletion (data not shown). Another line, Jake 4/5 415, which showed the deletion with the suboptimal PCR from before, showed the deletion in only one of the reps (data not shown). Visual results of the leaflet number showed that the parental and control lines without the deletion, Jake and ZC-2, respectively, and only one rep of one line showed the wild-type trifoliate leaflet phenotype (Error! Reference source not found.). All of the other lines and reps showed a multifoliate leaflet phenotype, with either tetra- or pentafoliate leaflet numbers on one or more nodes of the plant.

When we harvested the seeds from all the reps, many of the lines did not give enough seed for analysis, so when we analyzed $\mathrm{Pi}$, we only used four different genotypes: FN38, Jake, Jake 4/5 414 and Jake 4/5 419. For all four lines, there was no significant difference between the lines or treatment versus no treatment for $\mathrm{Pi}$ (Figure 2.5a). There was only enough remaining seed for both reps of FN38, so we only compared FN38 treatment versus not treatment for PA-P. The reduced P did not significantly increase PA-P (Figure 2.5b). Thus, 
we were unable to create an Ipa phenotype through our reduced $\mathrm{P}$ treatment in the GC.

\section{Discussion}

After identifying FN38 had multifoliate leaflets, we began to analyze the HOX genes in hopes to distinguish the cause of the particular phenotype. However, we were unable to span the deletion, Glyma06g bps 2252581 to 2339716, which may have been due to chromosomal rearrangements during FN irradiation. Another genotype, PI416892, with multifoliate leaflets was identified within Dr. Bilyeu's crossing block in Columbia. Thus, we tried to determine if this genotype contained any mutations in either of the HOX genes, Glyma06g03200 and Glyma06g3210, which are deleted in FN38. Unfortunately, we discovered that there were no protein changes within either of the HOX genes in PI416892. However, it was discovered that the LEAFY (LFY) orthologs in soybean slightly reduced leaflet number when expression was decreased (Champagne et al., 2007), and possible mutations in HOX gene regulators could impact the expression of HOX resulting in multifoliate leaflets (reviewed in Wang et al., 2007). Environmental factors are also capable of having a significant impact on leaf development (reviewed in Peng et al., 2011). Thus, it is a possibility that the multifoliate leaflet phenotype in PI416892 was due to a mutated HOX gene regulator, or the replicated HOX genes on chromosome 4, or one of those with a 
combination of environmental factors, instead of the HOX genes on chromosome 6.

Genotypic analysis of the FN38 deletion in FN38 and the Jake 4/5 population was not completely successful. The use of the R2 primer set to identify the deletion was not ideal, because further investigation revealed that, on SoyBase, the R2 primer set shared almost complete identity with a gene on chromosome 11. We had used only Phytozome to develop the primer sets to the left and right of the deletion in FN38, and that program had shown only identity to the desired region of chromosome 6 . Thus, when using R2 to identify homozygous deletions for the Jake $4 / 5$ population, we got varying results due to the primer set amplifying the region of chromosome 11 on occasion. Therefore, a new primer set was designed in the Glyma06g03310 IPK1 gene and used to identify Jake $4 / 5$ lines with the FN38 deletion during the reduced P GC experiment. There was one line, Jake $4 / 5415$, in the GC experiment that showed rep 1 did not have the deletion, while rep 2 did. Since one seed was used for rep 1 and another for rep 2, $F_{3}$ Jake 4/5 415 was still segregating for the FN38 deletion. Our results have indicated that the deletion is associated with the multifoliate phenotype.

$\mathrm{PA}$ and $\mathrm{Pi}$ content was analyzed for the Jake $4 / 5$ population from Columbia summer 2012 field season. Results indicated that FN38, Jake, and the Jake 4/5 population average did not significantly differ on Pi or PA content from one another. Thus, a non-functional IPK1, Glyma06g03310, is not able to reduce 
$\mathrm{PA}$ or increase $\mathrm{Pi}$ content, even though its homologous counterpart, Glyma14g07880, can (Yuan et al., 2012).

We wanted to try and create an Ipa phenotype by reducing the amount of $\mathrm{P}$ in a nutrient solution used for watering, but we were unable to see a significant difference between a reduced $P$ solution in the $G C$ and a full nutrient solution used in the field. The reduced $P$ treatment on both reps of lines used was ineffective at increasing Pi. PA content was only analyzed for FN38 seeds, due to limited seed count. Except for FN38, most lines and reps did not produce many, if any, seeds for analysis, so we only analyzed lines that had enough seeds for both reps. The most likely cause of low seed number was GC malfunction, which resulted in us moving the plants into the laboratory while the GC was non-usable. The laboratory environment was very hot and dry, so it caused the most of the plants to wilt and begin to die over a three day period, which caused the reduction of plant yield. 
Figures 


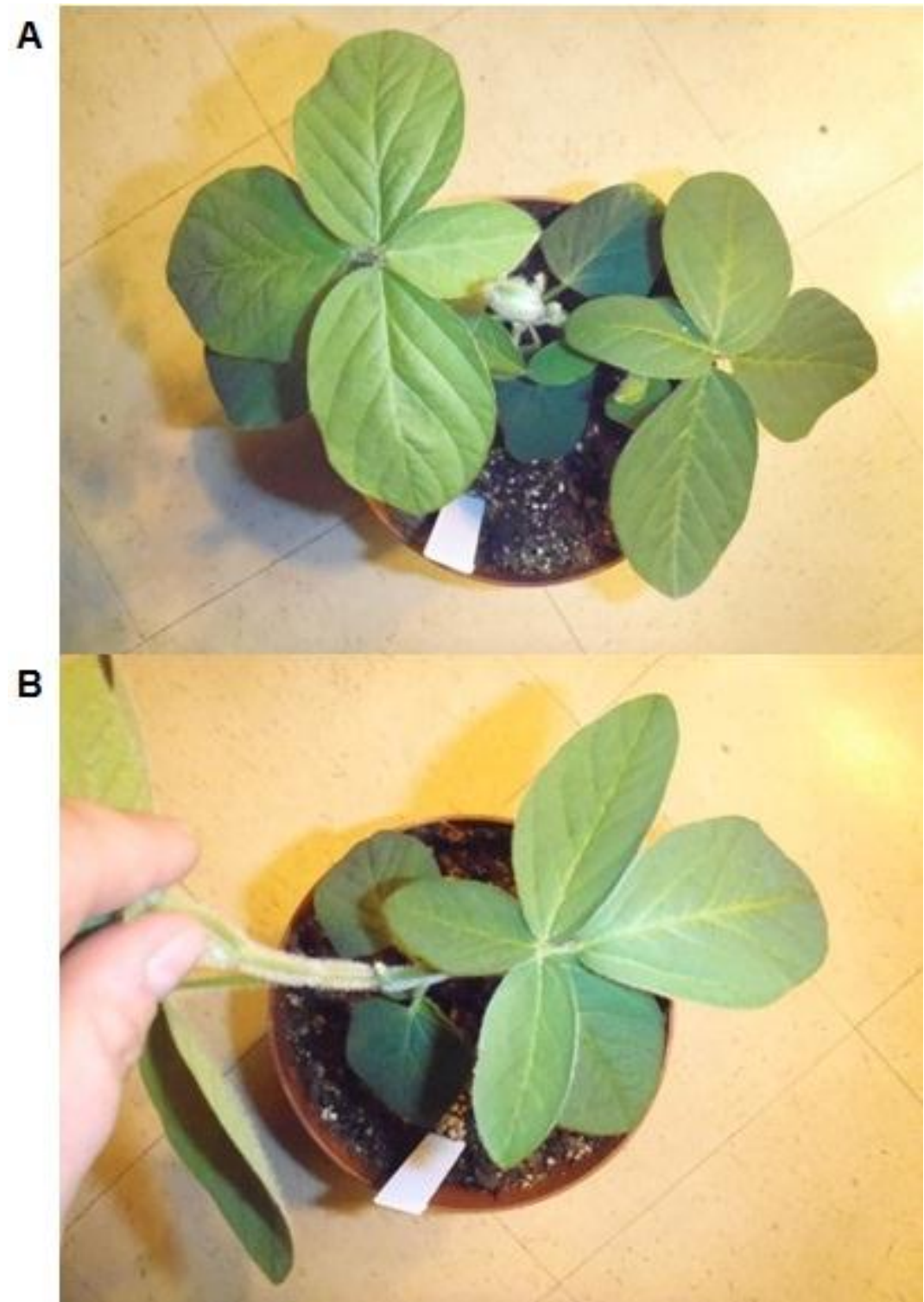

Figure 2.1. Multifoliate leaflet phenotype for FN38. Instead of the wild-type trifoliate leaflets, FN38 showed either $\mathbf{A}$. tetrafoliate or $\mathbf{B}$. pentafoliate leaflets. 


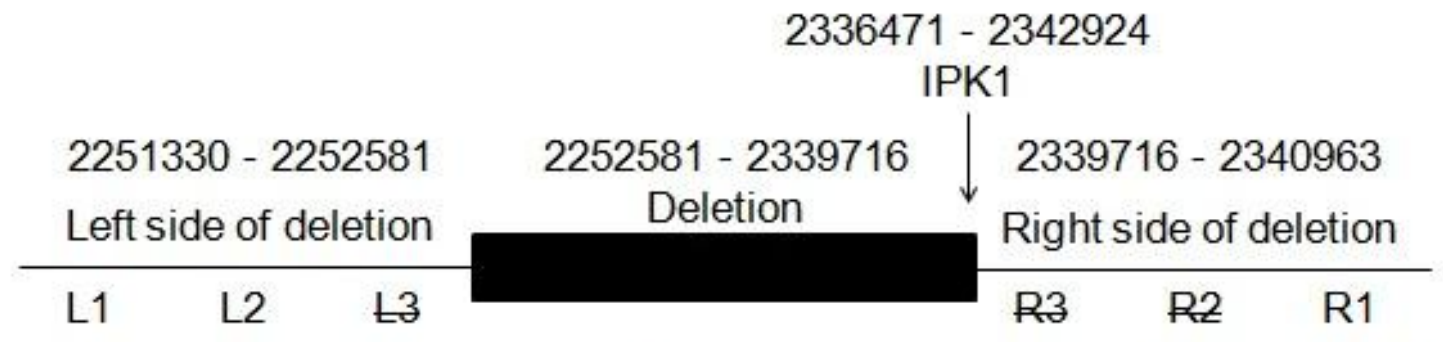

Each primer set includes a forward and reverse, i.e. R1 and L1 are not paired together.

Figure 2.2. Location of primer sets to the left and right of the deletion. Numbers above the figure show the base pair region for the left primer sets, deletion, and right primer sets, respectively. Underneath the figure, the approximate location of the primer sets in comparison to the deletion were shown. The primer sets, L3, R3, and R2, that were crossed out did not amplify product in FN38. NOTE: Each primer set, i.e. L1, contains a forward and reverse primer; thus, L1 is not paired with $\mathrm{R} 1$. 

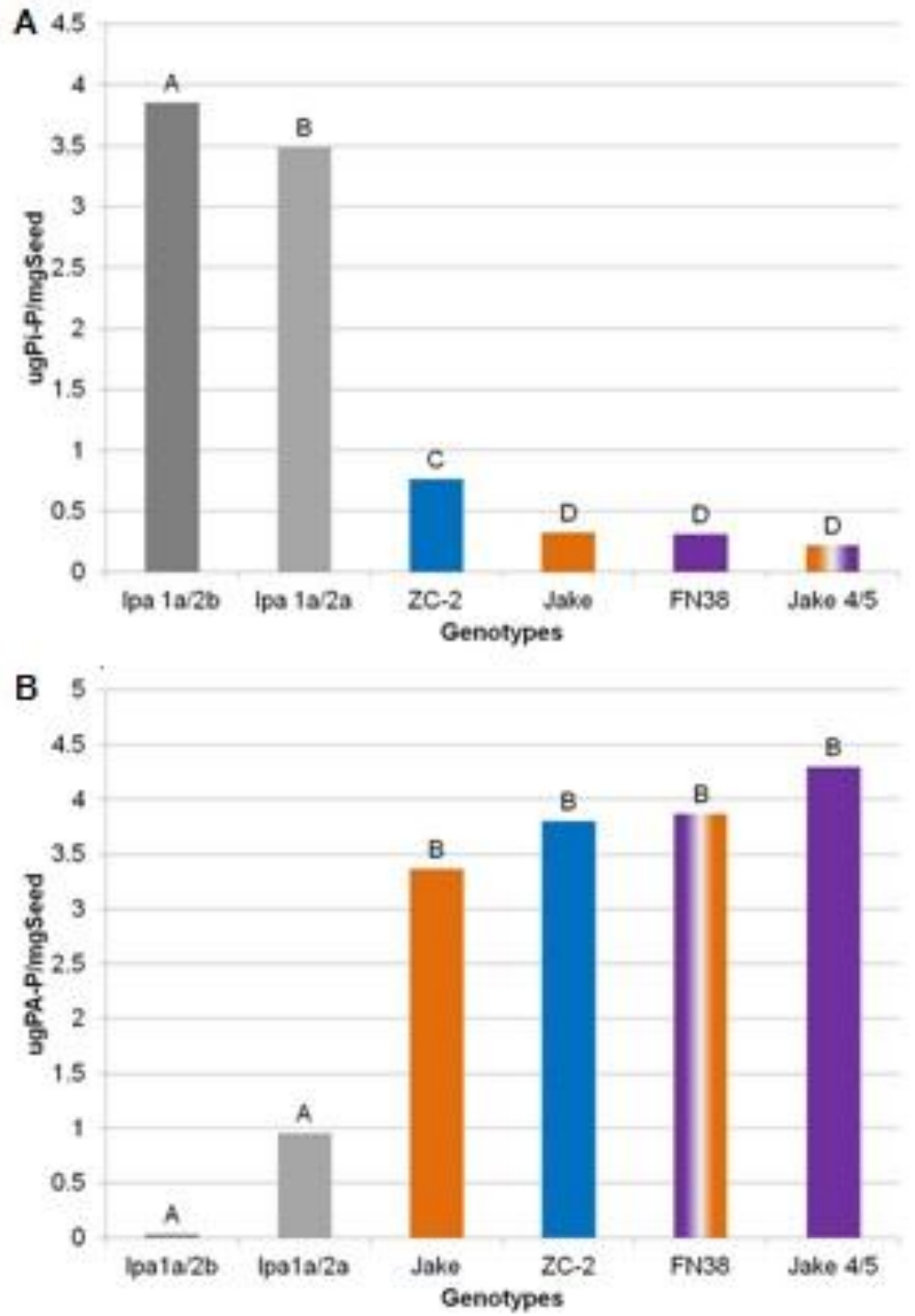

Figure 2.3. Phenotypic comparisons for the Jake $4 / 5 \quad F_{3}$ generation, parental lines, and discovered Ipa mutants. For the Jake $4 / 5$ phenotypes, an average was obtained of all the lines resulting from the cross-pollination of Jake and FN38. A. Pi does not significantly increase for the Jake 4/5 lines compared to the parents; however, there is a significant difference between the Jake $4 / 5$ population, including parental lines, and the documented Ipa mutants. The two ATP$A B C$ mutants, Ipa1a/2a and Ipa1a/2b, and ZC-2 were significantly different than one another. Letters above the bars show statistical analysis by using the Bonferroni test on SAS 9.3, and those genotypes with the same letter are not significantly different. B. PA-P does not show a decrease for the Jake $4 / 5$ population, the parents, and ZC-2 compared to the ATP-ABC mutants, Ipa1a/2a and Ipa1a/2b. PA analysis of the parents, ZC-2, and ATP-ABC mutants was not replicated; thus, no statistical analysis could be done. 
A



B

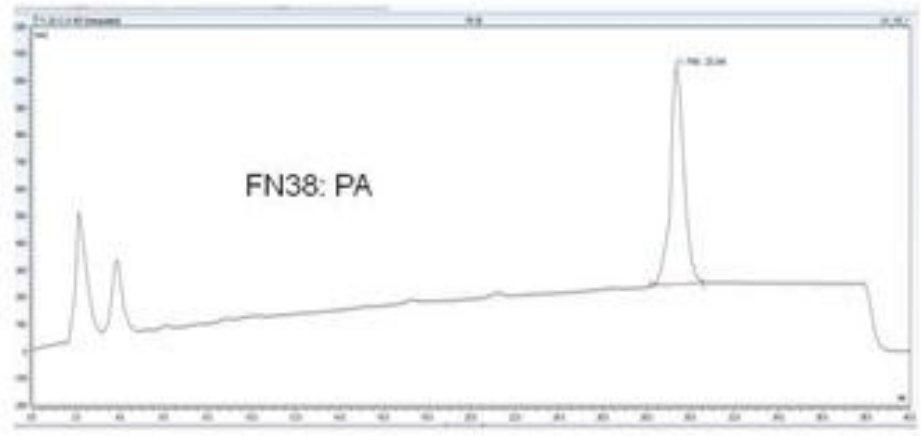

C



Figure 2.4. HPLC peaks for PA and lower inositols. A. ZC-2 shows an increase in lower inositols, while B. FN38 and a representative of the C. Jake $4 / 5$ lines did not show detectable lower inositol peaks. 

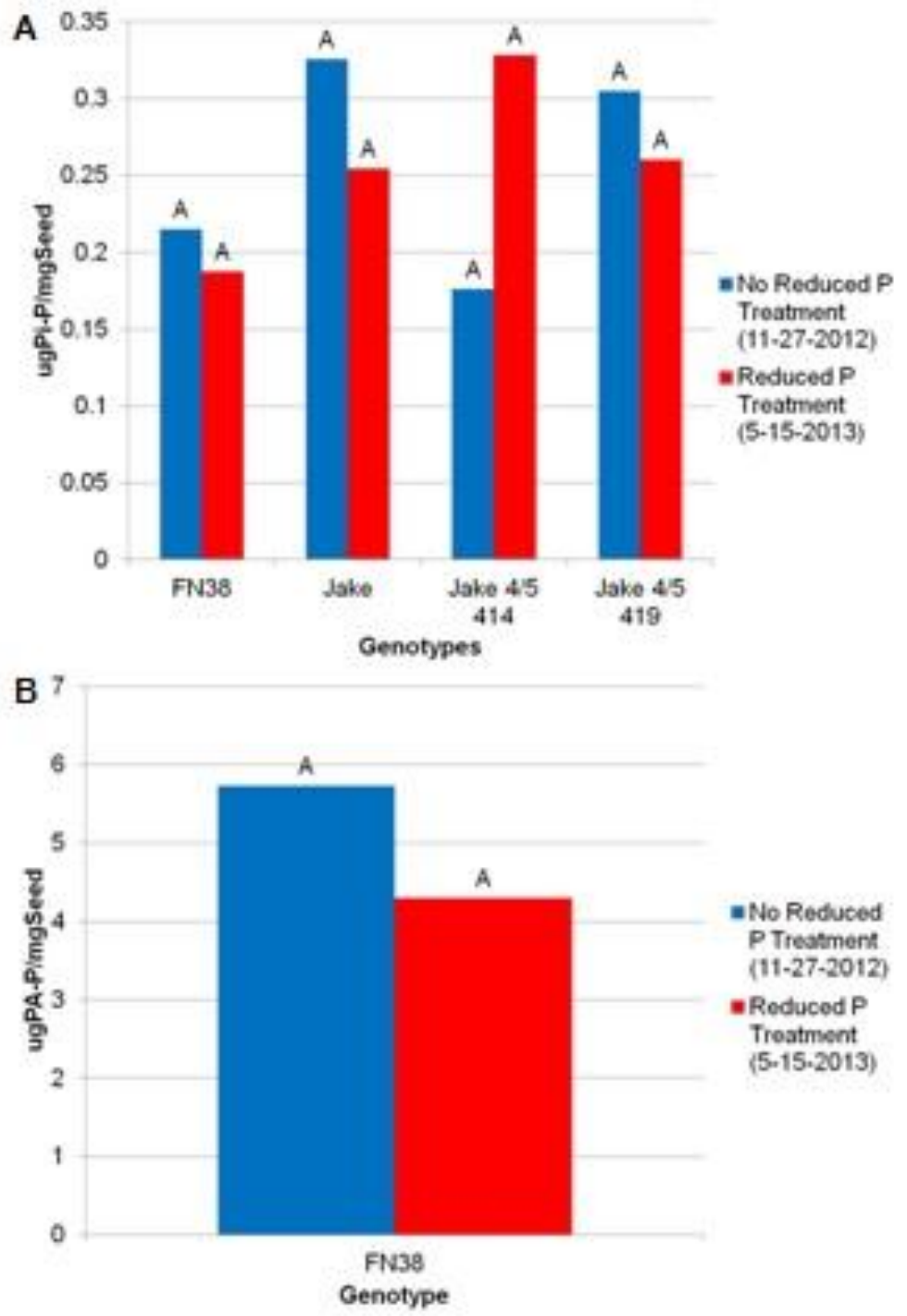

Figure 2.5. Phenotypic analyses comparison between the full field treatment and reduced phosphorus treatment in the growth chamber. There were no significant differences for $\mathbf{A}$. $\mathrm{Pi}$ or $\mathbf{B}$. PA between the full treatment in 2012 field season (shown in blue) and the reduced $P$ treatment during the 2013 growth chamber experiment (shown in red). Letters above the bars shows the results of statistical analyses using the Bonferroni test on SAS 9.3. Bars with the same letter are not statistically different. 
Tables 
Table 2.1. Primers flanking the FN38 deletion on chromosome 6.

\begin{tabular}{|c|c|c|c|}
\hline $\begin{array}{c}\text { Primer } \\
\text { Set }\end{array}$ & Forward (5'-3') & Reverse (5'-3') & $\begin{array}{l}\text { Product } \\
\text { Size }\end{array}$ \\
\hline L1 & CATGATGAGCTTACCCTACTCC & CAAGTCATTCTG & 181 \\
\hline L2 & AACCTAACTCCACTGTATATCGGAA & ATGTTACGTATTCTCGAATAGCAA & 343 \\
\hline L3 & GGTCGGATTTTTTCATCTTGA & TCAGTATGCTTGCTGGTTGC & 256 \\
\hline R1 & CAACTA & ATTATG & 212 \\
\hline $\mathrm{R} 2$ & TAAGAGTGAGAAGC & GTTCAGCTTCTGCTGGTAGG & 402 \\
\hline R3 & GTAACTGTAACAAATCCTGCTAAAAC & TGCTCTGGAATGAGTGGACA & 349 \\
\hline
\end{tabular}

Primers are shown from $5^{\prime}$ to $3^{\prime}$. 
Table 2.2. Primers used to amplify HOX genes in PI416892.

\begin{tabular}{|c|c|}
\hline Primer Name & Primer Sequence (5'-3') \\
\hline HOX 1A & GCAGAATAGCAGGGGATT \\
\hline HOX 1C & CCAACGTTTGAACGGTGTGC \\
\hline HOX 2A & GCTTTGTTGAGGTACACCTCTC \\
\hline HOX 2B & GCAAAAGTGCAACTCCCAGCT \\
\hline HOX 2C & TTTCCCAATAGCTTCTGCTCTTC \\
\hline HOX 2D & GCTGAGTCTTTTGCTGCTG \\
\hline HOX 2E & TGGGCTGTGAATGAGATC \\
\hline HOX 2F & AATCATATTTTGGCAAGAGTCC \\
\hline HOX 2G & GATGTGATGGCCATGTTGA \\
\hline HOX 2H & GATCTCATTCACAGCCCA \\
\hline HOX 2I & GGGTTGGAGTCTTCAGAAG \\
\hline
\end{tabular}

Primer sequences are from 5' to 3'. 
Table 2.3. Leaflet numbers for lines grown in the reduced $\mathrm{P}$ nutrient experiment.

\begin{tabular}{|c|c|c|}
\hline Line & Rep 1 & Rep 2 \\
\hline Jake 4/5 394 & $4 / 5$ & 3 \\
\hline Jake 4/5 404 & $4 / 5$ & $4 / 5$ \\
\hline Jake 4/5 414 & $4 / 5$ & $4 / 5$ \\
\hline Jake 4/5 415 & $4 / 5$ & $4 / 5$ \\
\hline Jake 4/5 419 & $4 / 5$ & $4 / 5$ \\
\hline FN38 & $4 / 5$ & $4 / 5$ \\
\hline Jake & 3 & 3 \\
\hline ZC-2 & 3 & 3 \\
\hline
\end{tabular}

Lines with ' $4 / 5$ ' in one or both reps had at least one node with a tetra- or pentafoliate leaflet number, while those with a ' 3 ' had at wild-type trifoliate leaflet number. 


\section{References}

Anderson B.P., Fehr W.R. (2008) Seed Source Affects Field Emergence of LowPhytate Soybean Lines. Crop Sci 48:929-932.

Bilyeu K., Palavalli L., Sleper D., Beuselinck P. (2005) Mutations in Soybean Microsomal Omega-3 Fatty Acid Desaturase Genes Reduce Linolenic Acid Concentration in Soybean Seeds. Crop Sci 45:1830.

Bolon Y.T., Haun W.J., Xu W.W., Grant D., Stacey M.G., Nelson R.T., Gerhardt D.J., Jeddeloh J.A., Stacey G., Muehlbauer G.J., Orf J.H., Naeve S.L., Stupar R.M., Vance C.P. (2011) Phenotypic and Genomic Analyses of a Fast Neutron Mutant Population Resource in Soybean. Plant Physiol 156:240-53.

Champagne C.E., Goliber T.E., Wojciechowski M.F., Mei R.W., Townsley B.T., Wang K., Paz M.M., Geeta R., Sinha N.R. (2007) Compound Leaf Development and Evolution in the Legumes. Plant Cell 19:3369-78.

Chen Q.-C., Li B.W. (2003) Separation of Phytic Acid and Other Related Inositol Phosphates by High-Performance Ion Chromatography and Its Applications. J Chromatogr 1018:41-52.

Clarke E.J., Wiseman J. (2000) Developments in Plant Breeding for Improved Nutritional Quality of Soya Beans ii. Anti-Nutritional Factors. J Ag Sci 134:125-136.

Frank T., Habernegg R., Yuan F.-J., Shu Q.-Y., Engel K.-H. (2009a) Assessment of the Contents of Phytic Acid and Divalent Cations in Low Phytic Acid (Ipa) Mutants of Rice and Soybean. J Food Comp Anal 22:278-284.

Frank T., Norenberg S., Engel K.H. (2009b) Metabolite Profiling of Two Novel Low Phytic Acid (Ipa) Soybean Mutants. J Agric Food Chem 57:6408-16.

Gillman J.D., Baxter I., Bilyeu K. (2013) Phosphorus Partitioning of Soybean Lines Containing Different Mutant Alleles of Two Soybean Seed-Specific Adenosine Triphosphate-Binding Cassette Phytic Acid Transporter Paralogs. Plant Genome 6:1. 
Gillman J.D., Pantalone V.R., Bilyeu K. (2009) The Low Phytic Acid Phenotype in Soybean Line CX1834 Is Due to Mutations in Two Homologs of the Maize Low Phytic Acid Gene. Plant Genome 2:179-190.

Hitz W.D., Carlson T.J., Kerr P.S., Sebastian S.A. (2002) Biochemical and Molecular Characterization of a Mutation That Confers a Decreased Raffinosaccharide and Phytic Acid Phenotype on Soybean Seeds. Plant Physiol 128:650-60.

Janssen B., Lund L., Sinha N. (1998) Overexpression of Homeobox Gene, LeT6, Reveals Indeterminate Features in the Tomato Compound Leaf. Plant Physiol 117:771-786.

Maupin L.M., Rainey K.M. (2011) Improving Emergence of Modified Phosphorus Composition Soybeans: Genotypes, Germplasm, Environments, and Selection. Crop Sci 51:1946-1955.

Maupin L.M., Rosso M.L., Rainey K.M. (2011) Environmental Effects on Soybean with Modified Phosphorus and Sugar Composition. Crop Sci 51:642-650.

Meis S.J., Fehr W.R., Schnebly S.R. (2003) Seed Source Effect on Field Emergence of Soybean Lines with Reduced Phytate and Raffinose Saccharides. Crop Sci 43:1336-1339.

Peng J., Yu J., Wang H., Guo Y., Li G., Bai G., Chen R. (2011) Regulation of Compound Leaf Development in Medicago truncatula by Fused Compound Leaf1, a Class M KNOX Gene. Plant Cell 23:3929-43.

Raboy V., Dickinson D.B. (1984) Effect of Phosphorus and Zinc Nutrition on Soybean Seed Phytic Acid and Zinc. Plant Physiol 75:1094-1098.

Raboy V., Dickinson D.B., Below F.E. (1984) Variation in Seed Total Phosphorus, Phytic Acid, Zinc, Calcium, Magnesium, and Protein among Lines of Glycine max and G. soja. Crop Sci 24:431-434.

Raboy V., Young K.A., Dorsch J.A., Cook A. (2001) Genetics and Breeding of Seed Phosphorus and Phytic Acid. J Plant Physiol 158:489-497.

Sebastian S., Kerr P.S., Pearlstein R., Hitz W. (2000) Soybean Germplasm with Novel Genes for Improved Digestibility, in: J. Drackley (Ed.), Soy in Animal Nutrition, Federation of Animal Science Societies, Savoy, IL. pp. 56-74. 
Shannon J.G., Wrather J.A., Sleper D.A., Robbins R.T., Nguyen H.T., Anand S.C. (2007) Registration of 'Jake' Soybean. Journal of Plant Registrations $1: 29$.

Sharpley A.N., Chapra S.C., Wedepohl R., Sims J.T., Daniel T.C., Reddy K.R. (1994) Managing Agricultural Phosphorus for Protection of Surface Waters: Issues and Options. J Environ Qual 23:437-451.

Wang J., Wu Y., Yu Z. (2007) A New Soybean [Glycine Max (L.) Merr.] Mutant with Multifoliolate Compound Leaf Acquired by Ion Beam Irradiation. Nuclear Instruments and Methods in Physics Research Section B: Beam Interactions with Materials and Atoms 255:326-330.

Wilcox J.R., Premachandra G.S., Young K.A., Raboy V. (2000) Isolation of High Seed Inorganic P, Low-Phytate Soybean Mutants. Crop Sci 40:1601-1605.

Yuan F.J., Zhao H.J., Ren X.L., Zhu S.L., Fu X.J., Shu Q.Y. (2007) Generation and Characterization of Two Novel Low Phytate Mutations in Soybean (Glycine max L. Merr.). Theor Appl Genet 115:945-57.

Yuan F.J., Zhu D.H., Deng B., Fu X.J., Dong D.K., Zhu S.L., Li B.Q., Shu Q.Y. (2009) Effects of Two Low Phytic Acid Mutations on Seed Quality and Nutritional Traits in Soybean (Glycine max L. Merr). J Agric Food Chem 57:3632-8.

Yuan F.J., Zhu D.H., Tan Y.Y., Dong D.K., Fu X.J., Zhu S.L., Li B.Q., Shu Q.Y. (2012) Identification and Characterization of the Soybean IPK1 Ortholog of a Low Phytic Acid Mutant Reveals an Exon-Excluding Splice-Site Mutation. Theor Appl Genet 125:1413-23. 


\section{CHAPTER 3}

Characterization of a Population Developed by Breeding Two Single Inositol Pentakisphosphate 2-Kinase Mutants 


\section{Abstract}

Soybean [Glycine $\max$ (L.) Merr] seeds contain a large amount of phosphorus $(\mathrm{P})$, which is stored as phytic acid (PA). PA is indigestible by nonruminant livestock and considered an anti-nutritional factor because PA chelates divalent cations and prevents the uptake of essential nutrients. Interest in reducing PA has increased greatly over the years and several low PA soybean lines have been discovered; however, many of these lines have inadequate germination and emergence. A gamma irradiated soybean line, ZC-2, with 50\% reduction in PA was found to have excellent germination and emergence. The low PA phenotype was a result of a mutation in a gene orthologous to inositol pentakisphosphate 2-kinase (IPK1; Glyma14g07880), which is responsible for phosphorylating inositol pentakisphosphate into PA. Our objective was to reduce PA levels by more than $50 \%$ with conventional breeding methods. Our own fast neutron irradiated line, FN38, has a large deletion of an independent gene homologous to IPK1 (Glyma06g03310). Initial characterization of PA and inorganic phosphorus (Pi) levels for the deletion indicated that a mutated Glyma06g03310 IPK1 gene does not increase Pi or decrease PA by itself. In order to determine if we could further reduce PA, FN38 was bred with ZC-2 to develop a population of soybean lines for phenotype and genotype association analysis. We developed and utilized molecular marker assays to select for the two IPK1 mutations. We performed high-performance liquid chromatography (HPLC) to measure PA levels and a colorimetric assay to measure Pi levels in 
the selected soybean lines. Lines containing both mutations, Glyma14g07880 and Glyma06g03310, in IPK1 increased Pi and decreased PA significantly more than either parental genotype.

\section{Introduction}

Inositol hexakisphosphate, otherwise known as phytic acid (PA), is a major component of mature soybean seeds, roughly $2 \%$, and it is roughly $75 \%$ of the total phosphorus found in soybean seeds (Raboy et al., 1984). The rest of the phosphorus in soybean seeds is in the form inorganic phosphorus and cellular components, such as proteins (Raboy et al., 2001). PA is an important component of seedling germination because phytase hydrolyzes some of the PA$\mathrm{P}$ (PA phosphorus) in order to get inorganic phosphorus (Pi), which is utilized by soybean seedlings for energy and nutrients (Urbano et al., 2000). The rest of the PA-P in mature soybean seeds, which are fed to livestock and humans, is unavailable for use by nonruminant livestock.

Monogastric species, such as swine and poultry, do not contain phytase enzymes in their gut for the breakdown of PA-P to Pi (Clarke and Wiseman, 2000; Wilcox et al., 2000). Not only is $P$ unable to be utilized by the livestock, but PA binds to metal ions in the stomach and prevents their uptake and use (Clarke and Wiseman, 2000; Wilcox et al., 2000). Since PA-P is not used by nonruminant livestock, it goes directly through the gastric system into the manure, and excess $\mathrm{P}$ runoff, from manure and over-fertilization, cause 
detrimental effects to the water table environment (Daverede et al., 2004; Ferket et al., 2002; Sharpley et al., 1994). Discovery of low phytic acid (Ipa) mutants has led to more nutritious and environment-friendly soybeans for consumption.

Two independent irradiated soybean lines were discovered to contain low phytic acid (Sebastian et al., 2000; Wilcox et al., 2000). Further investigation into the genetics of these lines identified the mutations: myo-inositol 1phosphatase synthase (mips) and two ATP-binding cassette transporters (Ipa1 and Ipa2), which are both required in soybean for the Ipa phenotype (Gillman et al., 2013; Gillman et al., 2009; Hitz et al., 2002). Unfortunately, many soybean Ipa mutants have trouble with germination and emergence (Anderson and Fehr, 2008; Maupin and Rainey, 2011; Maupin et al., 2011; Meis et al., 2003). However, initial characterization of a soybean mutant, ZC-2, with a novel Ipa mutation led to the discovery of no emergence or germination issues (Frank et al., 2009b; Yuan et al., 2007; Yuan et al., 2009).

Since PA and $\mathrm{Pi}$ are inversely related, when $\mathrm{ZC}-2$ was determined to have a reduction of about $20-50 \%$ of $\mathrm{PA}$, and additional studies discovered a proportional increase of $\mathrm{Pi}$ and lower inositols (Bilyeu et al., 2008; Frank et al., 2009a; Yuan et al., 2007). Characterization of the metabolite profile of ZC-2 indicated that there were no decreases in nutritional value (Frank et al., 2009b). Eventually, it was discovered that an orthologous inositol $(1,3,4,5,6)$ pentakisphosphate 2-kinase, or IPK1, gene was responsible for the Ipa phenotype in ZC-2 (Yuan et al., 2012). IPK1 is the enzyme that puts the last 
phosphorus on the inositol ring to create PA (reviewed in York et al., 1999). In soybean, there are three homologous IPK1 genes: Glyma04g03240, Glyma06g03310, and Glyma14g07880 (Yuan et al., 2012). ZC-2 contains a single nucleotide polymorphism in Glyma14g07880 causing a splice-site mutation and resulting in a nonfunctional IPK1, and this gene showed the highest IPK1 enzyme activity in immature soybean seeds, while the other two genes showed very low activity (Yuan et al., 2012).

Previously W82 seed was irradiated with fast neutrons (FN) resulting in a line that was shown to have a partially deleted IPK1 gene (Glyma06g03310) (see chapter 2). Our goal for this experiment was to breed the two lines, ZC-2 and FN38, with independent IPK1 mutations to create a population with double mutants in hopes of decreasing PA levels by more than $50 \%$ with a proportional increase in $\mathrm{Pi}$.

\section{Materials and Methods}

\section{Plant material and segregating population development}

A segregating population, designated 2-kinase, was developed by crossing FN38 and ZC-2, which are homozygous for mutant ipk1 homologs, Glyma06g03310 and Glyma14g07880, respectively. FN38 was developed by Dr. Bilyeu through fast neutron (FN) irradiation (Chapter 2: FN irradiation), and it contains a partially deleted IPK1 (Glyma06g03310) (Stacey and Stacey, personal communication, 2011). ZC-2 was developed through gamma irradiation, and it 
contains a SNP on a homologous IPK1 (Glyma14g07880) gene (Yuan et al., 2007; Yuan et al., 2012).

Seeds from the 2012 crosses were sent to our winter nursery in Upala, Costa Rica. FTA PlantSaver cards (Whatman Inc., Florham Park, NJ) were used to obtain leaf presses for genotypic analysis on $F_{1}$ crosses. DNA was isolated using the standard protocol (Whatman FTA Protocol BD05). $\mathrm{F}_{1}$ leaf press samples were used to identify true crosses by determining if the plants were heterozygous for IPK1 (Glyma14g07880) gene.

Since the cross-pollination was successful, our colleagues at the winter nursery in Costa Rico bulked planted the seeds, and each individual plant was tagged with a unique identifier for genotypic analysis of the two independent IPK1 genes. FTA PlantSaver cards were used to obtain leaf presses for genotypic analysis of $F_{2}$ plants. The $F_{2}$ leaf presses were used to identify four genotypic classes for the two IPK1 genes, and the selections were made based on homozygosity at either loci, Glyma14g07880 and Glyma06g03310: wildtype/wild-type (W/W), wild-type/mutant (W/M), mutant/wild-type (M/W), and mutant/mutant $(\mathrm{M} / \mathrm{M})$. For example, $\mathrm{W} / \mathrm{W}$ has wild-type sequence at both of the loci (Glyma14g07880/Glyma06g03310). All of the plants were analyzed for their genotype, but none of the heterozygotes for either gene were selected. Selected $F_{2}$ lines for each genotypic class were harvested and single plant threshed (SPT), so the $F_{2: 3}$ seed could be sent to Columbia, Missouri. For the parental lines, five plants each were grown out with the $F_{2}$ generation, and after harvest, 
parental lines were SPT and an individual packet for each plant was sent with the selected lines to Columbia, Missouri.

Seeds of the four non-segregating classes were grown at South Farm in Columbia, Missouri during the summer of 2013 using a complete randomized block design. There were three replicates of 13 different lines of the various genotypic classes; thus, there were the two parental lines and eleven $F_{3}$ population lines. The parental lines were FN38 (W/M) and ZC-2 (M/W), while the $F_{3}$ population lines were 2 each of the genotypic classes $W / W, W / M$, and $M / W$, and 5 of the $M / M$ class. Since $M / M$ was of the most interest, all lines from Costa Rica were planted. The population was harvested by plot, with every line and rep distinguished, and phenotypic analyses were performed by drying and grinding a 15-seed $F_{2: 4}$ sample of each plot. Two lines in all 3 reps, a W/W and $M / M$, and 3 $\mathrm{M} / \mathrm{M}$ lines in the $3^{\text {rd }}$ rep did not germinate or did not live to maturity due to disease; thus, the estimate for $\mathrm{W} / \mathrm{W}$ and $\mathrm{M} / \mathrm{M}$ was based on the other lines grown in the population. No value was entered for the $M / M$ lines missing one replication.

\section{IPK1 (Glyma14g07880) molecular assay development for use in genotyping}

\section{$F_{1}$ and $F_{2}$ plants grown in Costa Rica}

Primer sequences and SNP location obtained by Yuan et al. (2012) for IPK1 (Glyma14g07880) gene were utilized in developing a SimpleProbe for

analysis of our 2-kinase population. The SimpleProbe was designed using Roche Applied Science LightCycler Probe Design software 2.0 (version 1.0, 
February 2004) and the probe was ordered from Flourescentric, Inc. (Park City, UT). Primers were mixed in a 5:2 asymmetric ratio (final concentration $0.5 \mu \mathrm{M}$ IPK1f: 5'-CTCAGCTTCACCCCTTTC-3' and final concentration $0.2 \mu \mathrm{M}$ IPK1r: 5'CTAACTCAGATTTAATGCC-3'), with the SimpleProbe at a final concentration of

$0.2 \mu \mathrm{M}$ (IPK1: Fluorescein-SPC-GTAGGATGTACCTCTCCTTGAAGCAATTTCPhosphate).

Reactions were carried out in $20 \mu \mathrm{L}$ final volume containing 5-50 ng DNA template, primers, buffer (40 mM Tricine- $\mathrm{KOH}(\mathrm{pH} 8.0), 16 \mathrm{mM} \mathrm{KCl}, 3.5 \mathrm{mM}$ $\mathrm{MgCl}_{2}, 3.75 \mu \mathrm{gLL}^{-1} \mathrm{BSA}, 200 \mu \mathrm{M}$ dNTPs), SimpleProbe, and 0.2X Titanium Taq polymerase (BD Biosciences, Palo Alto, CA). The amplification and melt curve were carried out in a Roche 480 Light Cycler according to this reaction: $95^{\circ} \mathrm{C}$ for 3 minutes followed by 45 cycles of $95^{\circ} \mathrm{C}$ for 20 seconds, $51^{\circ} \mathrm{C}$ for 20 seconds, and $72^{\circ} \mathrm{C}$ for 30 seconds. A melt curve was performed by reading every $0.02^{\circ} \mathrm{C}$ for 1 second from $50^{\circ} \mathrm{C}$ to $75^{\circ} \mathrm{C}$ in order to visualize the properties of the products. Wild-type (FN38) lines have a peak present at $65^{\circ} \mathrm{C}$, while mutant (ZC-2) lines have a peak present at $59^{\circ} \mathrm{C}$; thus, heterozygous lines have two peaks at $59^{\circ} \mathrm{C}$ and $65^{\circ} \mathrm{C}$.

\section{Causative SNP mutation in the Glyma06g03310 IPK1}

A single seed from the 2-kinase parental lines, ZC-2 and FN38, from the 2012 harvest was powdered in liquid nitrogen for DNA isolation with DNeasy Plant Mini Kit (Qiagen Sciences Inc., Germantown, MD). Primers were designed using the reference sequence, W82, in SoyBase (www.soybase.org) and 
manufactured by IDT (Coralville, IA). They were created to flank the deletion in FN38 based on identified SNPs in various soybean genomes by Lam et al. (2010). Six primer sets were constructed, with three on the left side of the deletion and three on the right side, and FN38 was used as a control to verify the primer sets were not in the deletion, while ZC-2 would be sequenced for identification of a SNP.

Primers were at a final concentration of $0.5 \mu \mathrm{M}$ (Error! Reference source not found.), and reactions were carried out with a total volume of $20 \mu \mathrm{L}$ with the same components as before ("IPK1 (Glyma14g07880) molecular assay development for use in genotyping $F_{1}$ and $F_{2}$ plants grown in Costa Rica"). PCR was carried out on a thermocycler at these conditions: $95^{\circ} \mathrm{C}$ for 5 minutes trailed by 40 cycles of $95^{\circ} \mathrm{C}$ for 20 seconds, $60^{\circ} \mathrm{C}$ for 20 seconds, and $72^{\circ} \mathrm{C}$ for 2 minutes. An agarose gel, $1.2 \%$ concentration, was used to determine the presence of PCR product. Reactions with product were sent to the University of Missouri DNA Core Facility (web.rnet.missouri.edu/biotch/dnacore/index.html) for sequencing. Sequences were viewed and analyzed using the DNA Core's Chromatogram and aligned to the reference, W82, using the free internet program ClustalW (http://www.genome.jp/tools/clustalw/).

\section{IPK1 (Glyma06g03310)-linked molecular assay development for use in determining genotype for $F_{2}$ plants in Costa Rica}

The SimpleProbe was designed using Roche Applied Science LightCycler Probe Design software 2.0 (version 1.0, February 2004) and the probe was 
ordered from Flourescentric, Inc. (Park City, UT). Primers, designed closer to the ZC-2 SNP linked to IPK1 (Glyma06g03310), were mixed in a 2:5 asymmetric ratio (final concentration 0.2 $\mu$ M IP52Kf: 5'-GCATGAGAGGTAAGAG -3' and final concentration $0.5 \mu \mathrm{M}$ IP52Kr: 5'-GCCAAGGGAATTTCTCG -3'), with the SimpleProbe at a final concentration of $0.1 \mu \mathrm{M}$ (IP52K: Fluorescein-SPCGGCATTTCAATACCATGAGTGAAGACTGA-Phosphate). Reactions were carried out with almost identical specifications as before ("IPK1 (Glyma14g07880) molecular assay development for use in genotyping $F_{1}$ and $F_{2}$ plants grown in Costa Rica"). The only differences were that the annealing temperature was $56^{\circ} \mathrm{C}$, the extension time was 20 seconds, and the melt curve was performed from $52^{\circ} \mathrm{C}$ to $77^{\circ} \mathrm{C}$. The wild-type (FN38) peak was present at $65^{\circ} \mathrm{C}$, while the mutant $(\mathrm{ZC}-2)$ peak was at $60^{\circ} \mathrm{C}$; thus, the heterozygous peaks were at $60^{\circ} \mathrm{C}$ and $65^{\circ} \mathrm{C}$.

\section{Genotypic analysis of the FN38 deletion in mutants for IPK1 (Glyma06g03310)}

PCR analysis was performed to verify that the genotypes mutant for Glyma06g03310 contained the deletion segment. Primers were designed using the genetic sequence of W82, available from SoyBase (www.soybase.org), and were synthesized by IDT (Coralville, IA). Primers were designed to amplify $\sim 400$ base pairs (bps) in only the Glyma06g03310 IPK1 region, and primers were at a final concentration of $0.5 \mu \mathrm{M}$ (IP5delF: 5'-GGAGGAAGGTATAAGAGTG-3' and IP5deIR: 5'-CCAGCAGAAGCTGAACC-3'). Since the primers were in the 
deletion, homozygous wild-type and heterozygotes made product, while the homozygous mutants did not; thus, control primers were used to verify PCR success for the homozygous mutants. The control primers amplified $\sim 200 \mathrm{bps}$ in the wild-type FAD3A gene, which was not mutated in FN38, and they were at a final concentration of $0.5 \mu \mathrm{M}$ (3Aix: 5'-AGCTATTATCTAGCATTAACCTCA-3' and 3Ad1: 5'-TTGCATCACCATGGTCATCAT-3') (Bilyeu et al., 2005). Reactions were carried out in $20 \mu \mathrm{L}$ containing the same PCR set-up as before ("IPK1 (Glyma14g07880) molecular assay development for use in genotyping $F_{1}$ and $F_{2}$ plants grown in Costa Rica") with the addition of the control primers. The PCR conditions and visualization was the same as before ("Causative SNP mutation in the Glyma06g03310 IPK1") except that the denaturation and extension times were 3 minutes and 30 seconds, respectively.

\section{Germination study}

The germination experiment was performed using a version of the rag doll test (http://edis.ifas.ufl.edu/ag182). Three sheets of germination paper were wet with double de-ionized water. Excess water was allowed to drip off before laying two sheets flat and placing 25 seeds from each rep grown in Columbia, Missouri on the sheets. The other sheet of germination paper was placed on top of the seeds, and the sheets were then rolled into a tube and placed onto a tray. The tray was placed into an incubator at $28^{\circ} \mathrm{C}$, and each day, the tubes were wetted with double de-ionized water and placed back into the incubator after the excess 
water was off of the tubes. The seeds were counted after 3 days, and those seeds with a hypocotyl were identified as germinated seedlings.

\section{Pi quantification by colorimetric assay}

Through small variations of the assay described by Wilcox et al. (2000), Pi was quantified. Genotypic classes used for Pi analysis: ZC-2, FN38, W/W, $\mathrm{W} / \mathrm{M}, \mathrm{M} / \mathrm{W}$, and $\mathrm{M} / \mathrm{M}$. Of the 15-seed subset that were dried and ground for each line, $10-15 \mathrm{mg}$ were mixed with $0.5 \mathrm{~mL}$ of extraction buffer [12.5\% (V/W) TCA, 25 $\mathrm{mM} \mathrm{MgCl} 2$ ] and were shaken overnight at $4^{\circ} \mathrm{C}$. The suspensions were allowed to settle for roughly an hour; then, $10 \mu \mathrm{L}$ of supernatant, $90 \mu \mathrm{L}$ of deionized water, and $100 \mu \mathrm{L}$ of colorimetric reagent [1 volume $3 \mathrm{M} \mathrm{H}_{2} \mathrm{SO}_{4}, 1$ volume $0.02 \mathrm{M}$ ammonium molybdate, 1 volume 10\% (v/v) ascorbic acid, and 2 volumes deionized water] were placed into a 96-well spectrophotometer plate. The solutions were allowed to incubate for 1.5 hours before being read by a spectrophotometer at $825 \mathrm{~nm}$. A standard curve was made using $\mathrm{K}_{2} \mathrm{HPO}_{4}$, and it was applied to the sample results, which were then converted to $\mu \mathrm{g} \mathrm{P} \mathrm{mg} \mathrm{seed}^{-1}$.

\section{$P A, I P_{5}$, and $I P_{4}$ quantification by HPLC}

HPLC method was used to quantify PA from the field and growth chamber experiments (Chen and Li, 2003). Genotypic lines used for HPLC analysis: ZC2, FN38, W/W, W/M, M/W, and $M / M$. The same protocol was used for populations grown in Costa Rica and Missouri. Of the 15-seed subset that was dried and ground, $25 \mathrm{mg}$ were combined with $0.5 \mathrm{~mL}$ extraction buffer [500 mM $\mathrm{HCl}$, shaken for 1 hour at room temperature, spun at 20,000 $\mathrm{g}$ for 15 minutes, 
supernatant filtered through 0.22 -micron filter, and $75 \mu \mathrm{L}$ of filtrate analyzed by a linear gradient elution program on a Dionex CarboPac PA-100 guard column and a CarboPac PA-100 analytical column on an Agilent 1100 series HPLC system. The elution gradient was effected by two eluents: deionized water and $0.5 \mathrm{M} \mathrm{HCl}$; time 0 min, $8 \% 0.5 \mathrm{M} \mathrm{HCl}$; time 30, 100\% $0.5 \mathrm{M} \mathrm{HCl}$; time 35, $100 \% 0.5 \mathrm{M} \mathrm{HCl}$; time $35.1,100 \% 0.5 \mathrm{M} \mathrm{HCl}$; time 40, $8 \% 0.5 \mathrm{M} \mathrm{HCl}$. A post-column derivitization was achieved with a solution of $1 \mathrm{~g} \mathrm{~L}^{-1} \mathrm{Fe}\left(\mathrm{NO}_{3}\right)_{3}$ in $0.33 \mathrm{M} \mathrm{HClO}_{4}$ using a $750-\mathrm{mL}$ knitted coil and was followed by detection of $A_{295}$. Flow rates of eluent and postcolumn solution were 1.0 and $0.4 \mathrm{~mL}_{\text {minutes }}{ }^{-1}$, respectively. PA standard (PA dipotassium salt; Sigma), at $1 \mathrm{mM}$ concentration, eluted at 29.5 minutes, and a standard curve was calculated from serial dilutions of $4 \mathrm{mM}$ PA standard. Results were converted to $\mu \mathrm{g}$ PA-P mg seed $^{-1}$.

$\mathrm{I}(1,3,4,5,6) \mathrm{P}_{5}$ (inositol pentaphosphate ammonium salt; Cayman Chemical) and $\mathrm{I}(1,4,5,6) \mathrm{P}_{4}$ (inositol tetraphosphate sodium salt; Cayman Chemical) standards, at $1 \mathrm{mM}$ concentration, eluted at 22.5 and 15.0, respectively, minutes, and a standard curve was calculated from serial dilutions of $1 \mathrm{mM}$. Results were converted to $\mu \mathrm{g} \mathrm{IP}_{5}-\mathrm{P}$ mg seed ${ }^{-1}$ and $\mu \mathrm{g} \mathrm{IP}_{4^{-}}-\mathrm{P} \mathrm{mg} \mathrm{seed}^{-1}$.

\section{Statistical analysis}

All statistical analyses were carried out using the SAS 9.3 software (SAS Institute Inc., Cary, NC). All lines were grouped into 6 categories based on their genotype: each parental line (FN38 and ZC-2), W/W, W/M, M/W, and M/M. Each genotypic lines, excluding the parental lines, were either homozygous wild-type 
or mutant at either IPK1 allele. For Costa Rica, it was a completely randomized design, while Missouri was replicated three times in randomized complete block design. Basic statistic parameters for each data set were obtained using the MIXED procedure using either a single- or double-factor ANOVA. For Costa Rica, categories and lines were the classes used, with lines randomized and least square means determined for categories. For, Missouri, another class was used, designated block, due to the replication. For comparing the two locations, a double factor ANOVA was used including the location class. When comparing Missouri and Costa Rica, the classes were categories, location, and lines, but only lines were randomized. For $\mathrm{IP}_{5}$ and $\mathrm{IP}_{4}$, categories with a value of 0 (FN38, W/M, W/W) were deleted before analysis; however using the $\mathrm{F}$ value, the other categories were able to be identified as statistically different than 0. An ANOVA table with statistical values for all analyses was created (Table 3.2).

\section{Results}

\section{Molecular assay development for 2-kinase population}

Genotypic analysis of the $F_{1}$ generation allowed us to determine wild-type (FN38), mutant (ZC-2), and heterozygote (successful crosses of FN38 and ZC-2) lines for the 2-kinase population IPK1 (Glyma14g07880) gene. For this gene, we were able to use information by the Yuan et al. (2012) group for the SNP located in ZC-2 (Figure 3.1). The SimpleProbe assay showed that all plants in the $F_{1}$ generation were heterozygous for the IPK1 SNP (data not shown). We sought to 
identify a SNP linked to the IPK1 (Glyma06g03310) deletion, since the FN38 deletion PCR assay was sub-optimal and could not distinguish plants hemizygous for the deletion from those that were homozygous wild-type for the chromosome 6 region. With use of SNP locations for resequenced wild and cultivated soybean lines by Lam et al. (2010), we were able to identify a SNP just to the right of the IPK1 (Glyma06g03310) deletion (Figure 3.2) in the ZC-2 genome compared to W82. Primers were designed to amplify 200 bps around the SNP linked to the Glyma06g03310 deletion. This SNP is located at bp 2341942 on chromosome 6 in ZC-2 (Figure 3.2), and we used that primer set to develop a SimpleProbe assay. This assay allowed for easy identification of IPK1 (Glyma06g03310) wild-type and mutants in our population.

Genotypes containing W/W, W/M, M/W, and M/M for Glyma14g07880 and Glyma06g03310, respectively, were selected, such that M/M has homozygous mutant sequence at both of the loci (Glyma14g07880/Glyma06g03310). On these confirmed selections, we ran an FN38 deletion PCR assay. We were able to confirm that the lines mutant for Glyma06g03310 contained the FN38 deletion, while the lines wild-type for this IPK1 homolg did not contain the deletion (data not shown).

\section{Analyses of Costa Rica 2-kinase population}

After harvest in Costa Rica, selected lines, containing $F_{2: 3}$ seeds, were sent to Missouri for phenotypic analysis and as source seed for an additional field generation of growth. Five plants from the parental lines, as well as selected 
progeny lines from the four genotypic classes, were individually harvested, threshed, and put into packets. A 15-seed $\left(F_{2: 3}\right)$ sample set of each packet was lyophilized and ground for PA and Pi analysis. The spectrophotometer analysis of the colorimetric assay for available phosphorus showed that the double mutants $(M / M)$ and the parental line ZC-2 were not statistically different; however $\mathrm{M} / \mathrm{M}$ had a significant increase in $\mathrm{Pi}$ compared to the other genotypic classes, including parental line FN38 (Figure 3.3a). All other genotypic classes, including FN38, were statistically the same as one another and ZC-2 (Figure 3.3a).

HPLC was then used to measure the amount of PA and lower inositols, $I P_{5}$ and $I P_{4}$. HPLC results showed that the $M / M$ genotypes were significantly lower PA-P than the rest of the genotypes, including the parental lines (Figure 3.3b). All other genotypic classes, including the parental lines were not statistically different (Figure 3.3b). For the lower inositols, FN38, W/M (recreation of FN38), and W/W were homozygous wild-type for IPK1 (Glyma14g07880) and had peaks that were below detectable levels; thus, a value of 0 was used for statistical analysis. For $\mathrm{IP}_{5}$, the double mutants $(\mathrm{M} / \mathrm{M})$ were statistically the same as the parental line ZC-2; however, ZC-2 was also statistically the same as all other lines, including the undetectable levels of lines not containing the Glyma14g07880 SNP (Figure 3.4a). For $\mathrm{IP}_{4}, \mathrm{M} / \mathrm{M}$ was statistically higher than all other genotypic classes, including parental lines; however, unlike $\mathrm{IP}_{5}, \mathrm{ZC}-2$ and $\mathrm{M} / \mathrm{W}$ were statistically higher than those lines without the Glyma14g07880 SNP (Figure 3.4b). 
Previous studies have indicated that $\mathrm{I}(1,3,4,5) \mathrm{P}_{4}$ or $\mathrm{I}(1,3,4,6) \mathrm{P}_{4}$ was the immediate precursor to $\mathrm{IP}_{5}$ in plants; however, after HPLC analysis of these two inositols, we discovered that neither of these two had the correct retention time as the $\mathrm{IP}_{4}$ peak in $\mathrm{ZC}-2, \mathrm{M} / \mathrm{W}$, and $\mathrm{M} / \mathrm{M}$. Since we knew that $\mathrm{IP}_{5}$ did not have a $\mathrm{P}$ in the 2-position, we ran an $\mathrm{I}(1,4,5,6) \mathrm{P}_{4}$, which had the same retention time as the $\mathrm{IP}_{4}$ peak in $\mathrm{ZC}-2, \mathrm{M} / \mathrm{W}$, and $\mathrm{M} / \mathrm{M}$.

\section{Analyses of Missouri 2-kinase population}

During the summer of 2013 , each line, in all 3 reps, were analyzed for foliate leaflet number. All the lines, and their replicates, that contained the deleted IPK1 homolog (Glyma06g03310) had multifoliate leaflets (Table 3.3). Any line, and their replicate, that contained a wild-type IPK1 homolog (Glyma06g03310) had trifoliate leaflets seen in most soybean lines (Table 3.3). Three of the double mutant lines did not have any visible plants in the third replicate for observation.

After harvest in Missouri, a 15-seed ( $F_{3}$ bulk) sample set of each line was lyophilized and ground for PA and Pi analysis. Replicates for each line, plus parental lines, were used for statistical analysis and means estimates were determined using LSMEANS. Means $(\mu)$ and standard deviations $(\sigma)$ of the replicates for each line grown in Missouri were determined (Table 3.4). The spectrophotometer analysis of the colorimetric assay for available phosphorus

showed that the double mutants $(\mathrm{M} / \mathrm{M})$ had a significant increase in Pi compared to the other genotypic lines, including the parental lines (Figure 3.5a). The 
parental line, ZC-2, and $M / W$ were statistically the same, but both were statistically different than those lines with Glyma14g07880 SNP (FN38, W/M, and W/W) (Figure 3.5a).

HPLC was then used to measure the amount of PA and lower inositols, $\mathrm{IP}_{5}$ and $\mathrm{IP}_{4}$. HPLC results showed that the M/M contained significantly lower PA$P$ than the rest of the lines, including parental lines (Figure 3.5b). PA-P for the ZC-2, M/W, and FN38 were statistically the same, and FN38 was also statistically the same as W/W and W/M (Figure 3.5b).

For both lower inositols, FN38, W/M (re-creation of FN38), and W/W had peaks that were below detectable levels; thus, a value of 0 was used for statistical analysis. The double mutant $(\mathrm{M} / \mathrm{M})$ lines had significantly higher amounts of $\mathrm{IP}_{5} \mathrm{P}$ than the rest of the lines (Figure 3.6a). Parental line ZC-2 and M/W were statistically the same but higher than those lines with undetectable leveles (Figure 3.6a). For $\mathrm{IP}_{4} \mathrm{P}, \mathrm{ZC}-2, \mathrm{M} / \mathrm{M}$, and $\mathrm{M} / \mathrm{W}$ were statistically the same, but they were all statistically higher than the undetectable peaks (Figure 3.6b).

Germination scores for all of the genotypes were above $80 \%$. However, none of the genotypic classes were statistically different than one another (Figure $3.7)$.

\section{Comparison of the two locations: Costa Rica and Missouri}

When the two locations were ran for statistical analysis, each genotypic class from Costa Rica was the same as its Missouri counterpart. From highest to lowest Pi content, the genotypic classes: M/M, ZC-2, and M/W, were statistically 
different than one another; however, FN38, W/M, and W/W were statistically the same as one another but different than the other three genotypic classes (Figure 3.8a). PA-P data was much more complex, and $M / M$ was statistically the lowest compared to all other classes in all locations, except ZC-2 seed from Missouri was not statistically different than M/M seed from Costa Rica (Figure 3.8b). ZC-2 from Costa Rica and the two M/W classes were statistically the same as the ZC2 from Missouri, FN38, and W/W, and W/M was only statistically the same as FN38 and W/W from Missouri (Figure 3.8b).

For $\mathrm{IP}_{5}$ and $\mathrm{IP}_{4}$, the genotypes with undetectable values (FN38, W/M, and W/W) were statistically lower than all other genotypes (Figure 3.9). Both locations of $M / M$ had statistically higher levels of $\mathrm{IP}_{5}$ than other genotypes, but the Missouri location was statistically higher than Costa Rica (Figure 3.9a). ZC-2 and $\mathrm{M} / \mathrm{W}$ grown in Missouri were statistically the same but higher than their counterparts from Costa Rica, which were also statistically the same (Figure 3.9a). The double mutant $(M / M)$ from Costa Rica had the statistically highest level of $\mathrm{IP}_{4} \mathrm{P}$, while $\mathrm{M} / \mathrm{M}$ from Missouri and both locations for $\mathrm{ZC}-2$ and $\mathrm{M} / \mathrm{W}$ were statistically the same (Figure 3.9b).

\section{Discussion}

SimpleProbe assays were successful in distinguishing wild-type and mutant alleles for the two IPK1 homologs. The FN38 PCR assay for the deleted IPK1 (Glyma06g03310) was used as an extra measure to verify the SimpleProbe 
assay, and it worked sub-optimally. If the internal control primers were at too high of a concentration, the brightness of those bands made it difficult to identify presence or absence of the deleted IPK1 (Glyma06g03310). Visible observations of all lines in Missouri showed that those with a deleted IPK1 (Glyma06g03310) contained the multifoliate phenotype as the parental line, FN38.

When the two independent IPK1 homologs (Glyma14g07880 and Glyma06g03310) are mutated within soybean lines, the M/M genotype had statistically higher $\mathrm{Pi}$, except for ZC-2 from Costa Rica, and lower PA. The recreation line, M/W, was slightly different than the parental line, $\mathrm{ZC}-2$, in only $\mathrm{Pi}$ content, but since the rest of the M/W genome, besides the two IPK1 loci, is different than ZC-2, it is possible that other unknown reactions are occurring. Since not all molecular reactions are known within the PA pathway, it is possible that the other parent's genome is having an unknown minor effect on Pi and PA$\mathrm{P}$ content within the re-creations. The W/W genotype was very similar to FN38 and its re-creation, W/M. FN38, with a single IPK1 mutant (Glyma06g03310), did not increase Pi or decrease PA; thus, the double wild-type genotype (W/W) was expected to be similar to FN38.

When Costa Rica and Missouri results were compared to one another, results were much more complex. For $\mathrm{Pi}$ and $\mathrm{IP}_{4}$, there was no statistical difference between locations, except for $M / M I P_{4} P$. Costa Rica is a tropical climate and close to the equator, while Missouri is a humid continental climate 
that is much further north than the equator. Missouri grown $M / M$ lines gave decreased $\mathrm{IP}_{4} \mathrm{P}$ results compared to Costa Rica, but we can only speculate that the double mutants may have had more of an increase in inositols lower than $\mathrm{IP}_{4}$. Even though PA was decreased by more than $80 \%$ in the double mutants, germination rates were still over $80 \%$. 
Figures 


\section{ZC-2}

\section{Williams82}

\section{+1514GGAGAGgTACAT +1514GGAGAGaTACAT}

Figure 3.1. Single nucleotide polymorphism located in the low phytic acid mutant ZC-2. The bottom line, Williams 82 , is the reference sequence, while the top line is ZC-2. Nucleotides are numbered from +1 of the ATG start code. The $G$ to $A$ mutation, shown in lowercase with a box around the SNP, is located in the fifth intron between the between the fifth and sixth exon (underlined). (Modified from (Yuan et al., 2012). 




Figure 3.2. Single nucleotide polymorphism linked to the deletion of IPK1 in FN38. The rectangle shows the location of the deletion in FN38, caused by FN irradiation. The lines to the left and right of the box represents the sequence present in FN38. Six primer sets were designed to the left and right of the present deletion primers used for characterization of FN38 (See Figure 2.2). The right side of the deletion is circled because that is the location of the discovered SNP for ZC2 compared to W82, the reference sequence. The box below shows the location of the SNP, based on nucleotide position on chromosome 6 . Capitalized letters do not vary between the two lines, while the lowercase letters are the $C$ to $G$ mutation. The asterisks below the sequences represent identical nucleotide sequence. 

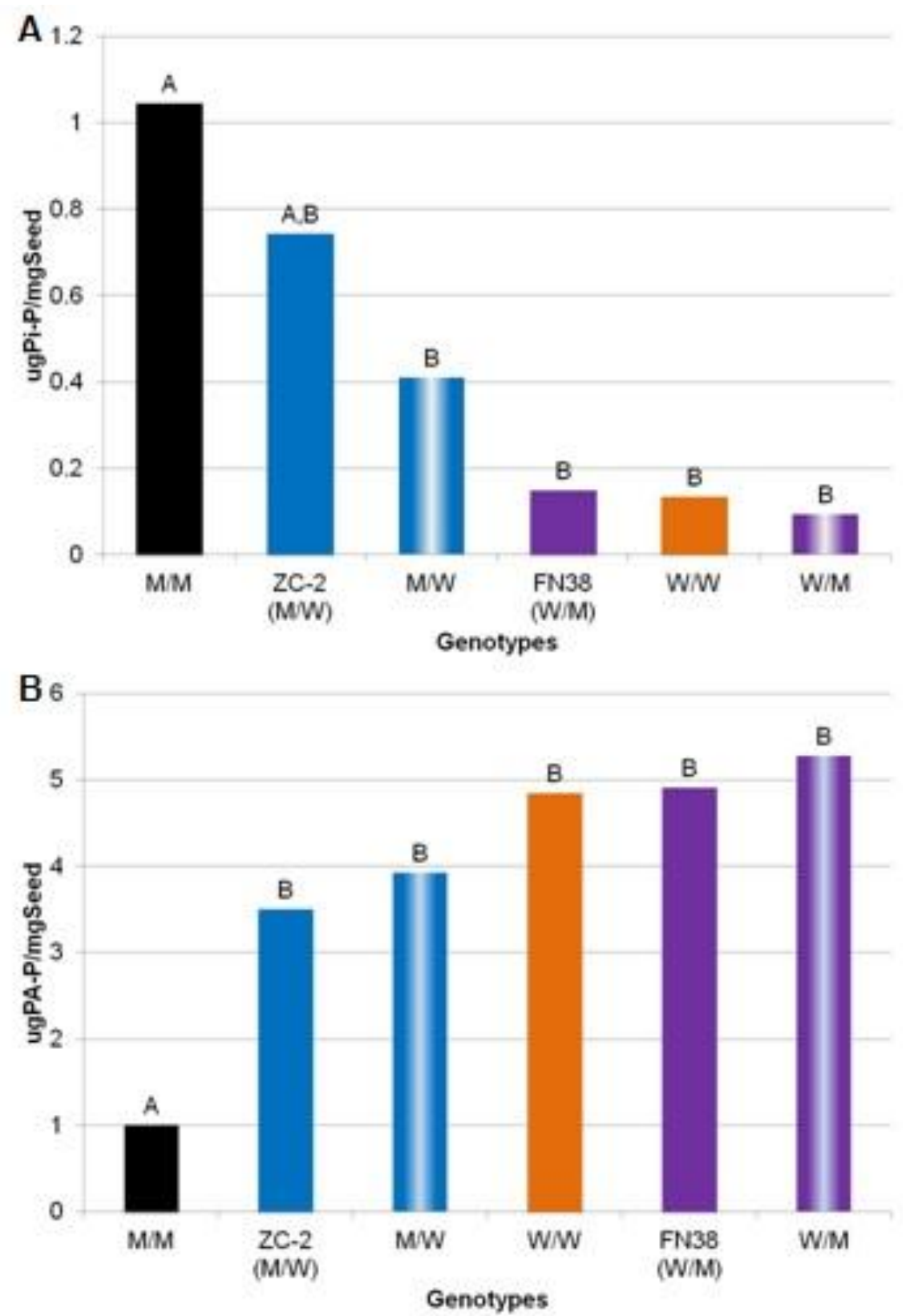

Figure 3.3. Phenotypic analyses for the 2-kinase population grown in Costa Rica. A. Inorganic phosphorus and $\mathbf{B}$. phytic acid phosphorus content for the $F_{2}$ population grown in the winter nursery. Letters above the bars shows the results of statistical analyses using the MIXED procedure with a Bonferoni adjustment on SAS 9.3. Bars with the same letter are not statistically different. 

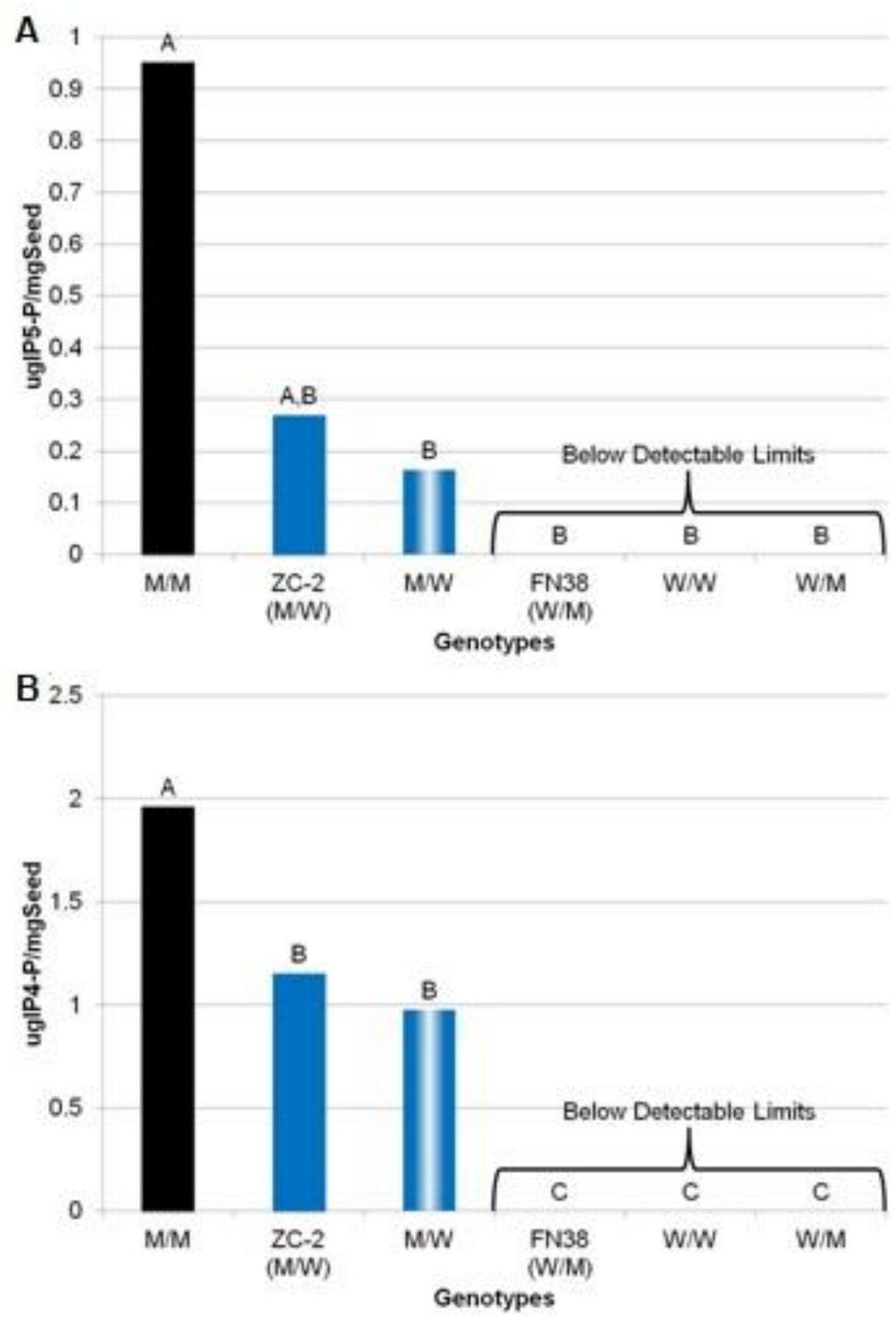

Figure 3.4. Lower inositol characterization of lines with the Glyma14g07880 mutation grown in Costa Rica. A. Inositol pentaphosphate phosphorus and B. inositol tetraphosphate phosphorus content for the $F_{2}$ population grown in the winter nursery. Bars with the same letter are not statistically different. Lines with the same genotype were used as the 'replicates' for statistical analysis. 

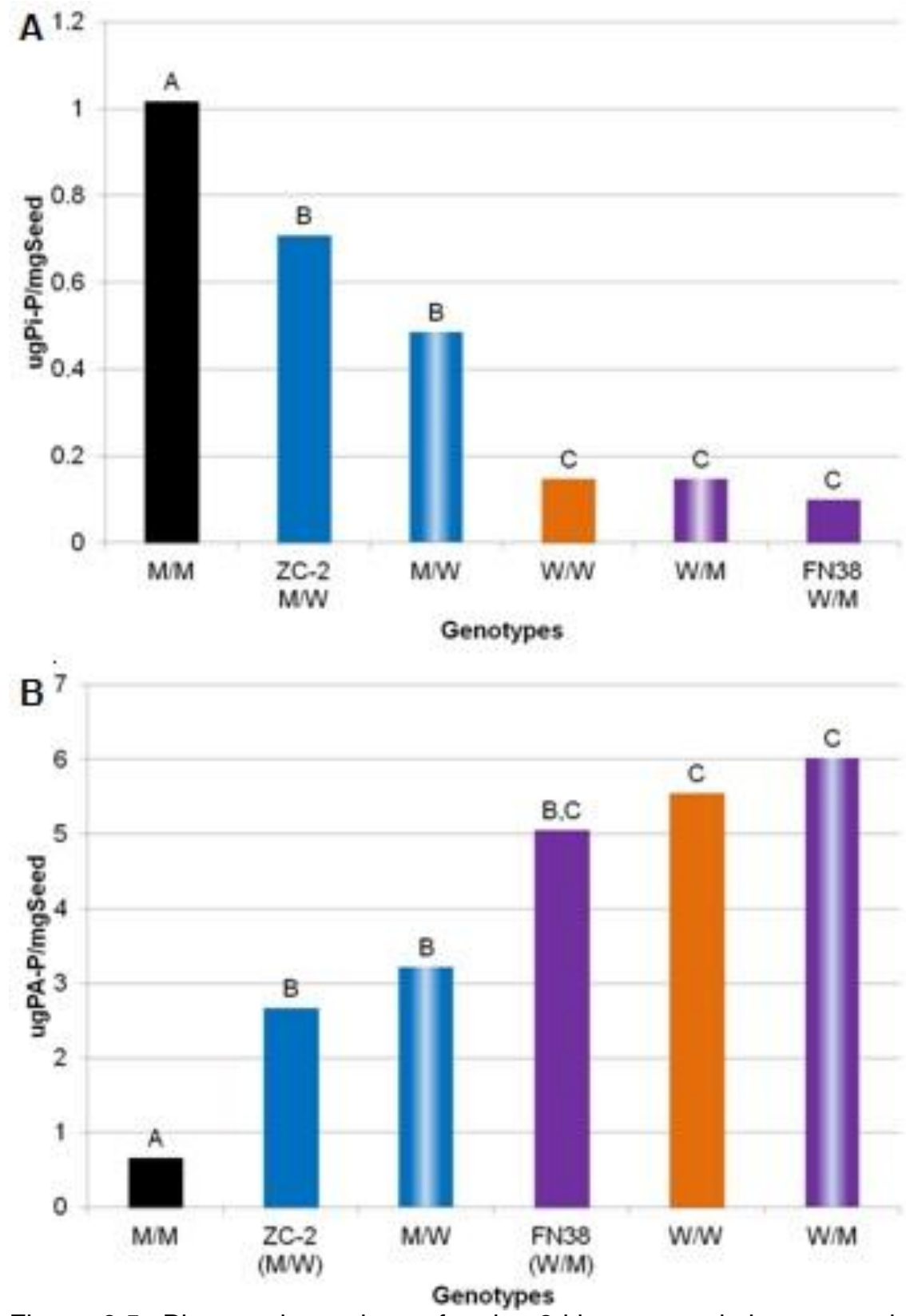

Figure 3.5. Phenotypic analyses for the 2-kinase population grown in Missouri. A. Inorganic phosphorus and $\mathbf{B}$. phytic acid phosphorus content for the $F_{3}$ population grown at South Farm. Letters above the bars shows the results of statistical analyses using the MIXED procedure with a Bonferoni adjustment on SAS 9.3. Bars with the same letter are not statistically different. 



Figure 3.6. Lower inositol characterization of lines with the Glyma14g07880 mutation grown in Missouri. A. Inositol pentaphosphate phosphorus and B. inositol tetraphosphate phosphorus content for the $F_{3}$ population grown at South Farm. Bars with the same letter are not statistically different. Lines with the same genotype were used as the 'replicates' for statistical analysis. 


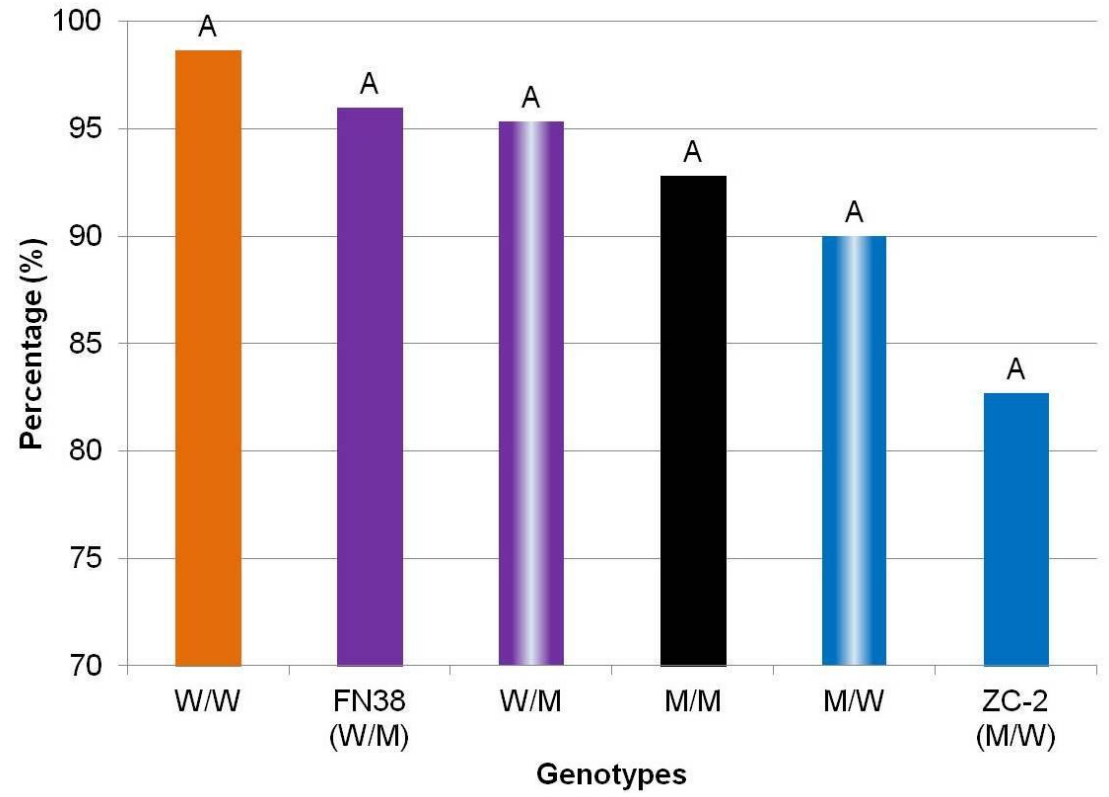

Figure 3.7. Germination percentages for $\mathrm{F}_{2: 4}$ seeds of the 2-kinase population grown in Missouri. Letters show the results of statistical analyses using the MIXED procedure with a Bonferroni adjustment on SAS 9.3. Bars with the same letter are not statistically diffe 

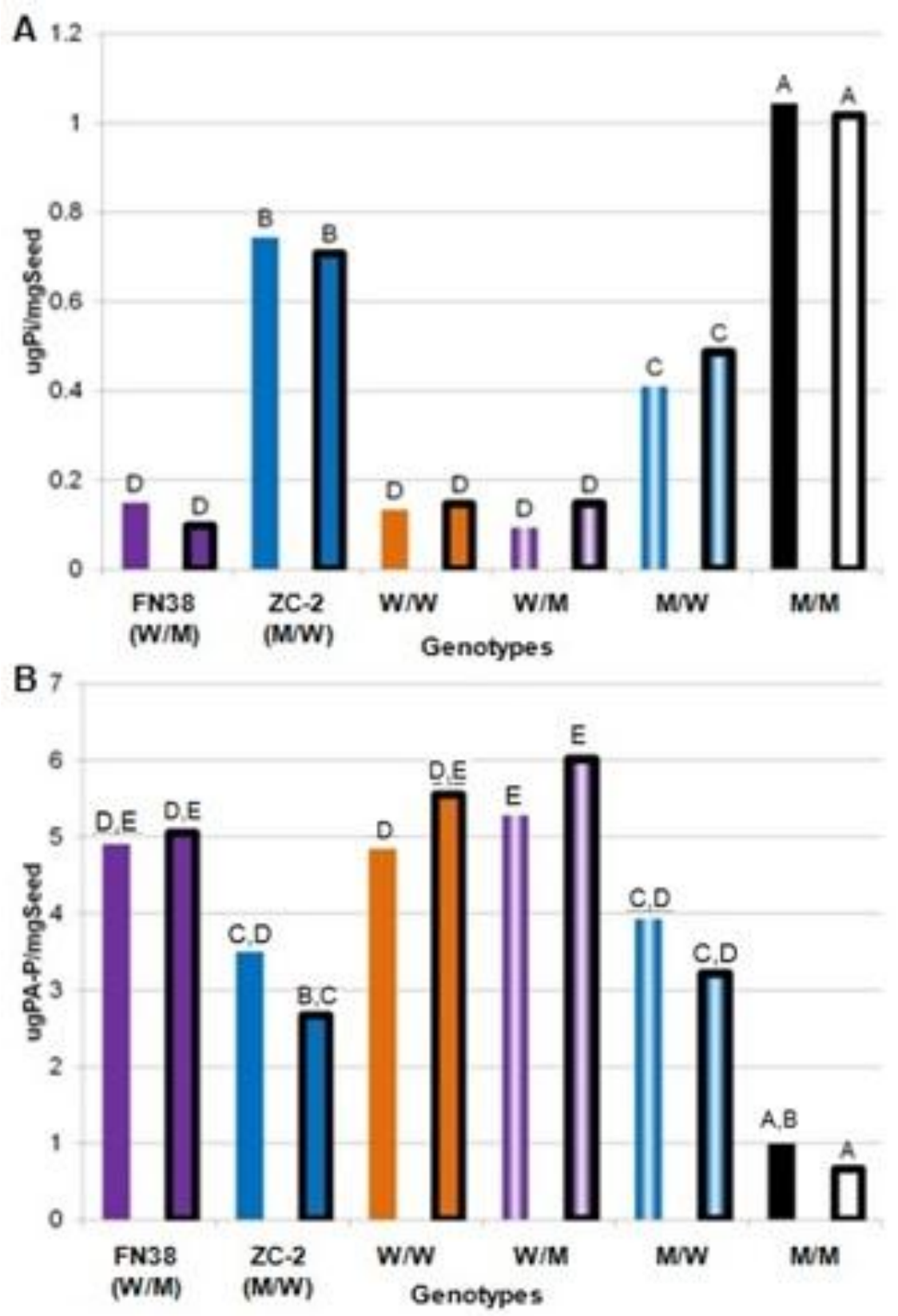

Figure 3.8. Phenotypic analyses for comparison of Costa Rica and Missouri. A. Inorganic phosphorus and $\mathbf{B}$. phytic acid phosphorus content for the $\mathrm{F}_{2: 3}$ seed from Costa Rica and the $\mathrm{F}_{2: 4}$ seed grown at South Farm. Bars without a black box around it (on the left) are LSMEANS of Costa Rica, while bars with a black box around it (on the right) are LSMEANS of Missouri. Bars with the same letter are not statistically different. Lines with the same genotype were used as the 'replicates' for statistical analysis. 



Figure 3.9. Glyma14g07880 mutation lower inositol comparison of the two locations: Costa Rica and Missouri. A. Inositol pentaphosphate phosphorus and B. inositol tetraphosphate phosphorus content for the $\mathrm{F}_{2: 3}$ seed from Costa Rica and the $\mathrm{F}_{2: 4}$ seed grown at South Farm. Bars without a black box around it (on the left) are LSMEANS of Costa Rica, while bars with a black box around it (on the right) are LSMEANS of Missouri. Bars with the same letter are not statistically different. Lines with the same genotype were used as the 'replicates' for statistical analysis. 
Tables 
Table 3.1. Primers used to determine a SNP in ZC-2 around the FN38 deletion.

\begin{tabular}{c|c|c|c|}
$\begin{array}{c}\text { Primer } \\
\text { Set }\end{array}$ & \multicolumn{2}{c}{ Forward (5'-3') } & \multicolumn{2}{c|}{$\begin{array}{c}\text { Reverse (5'-3') } \\
\text { Product } \\
\text { Size }\end{array}$} \\
\hline SNP-L1 & GTCCAAGTAAGATGAAG & GTCATTCTGGTCTCAGTG & 1883 \\
\hline SNP-L2 & GCTGTTCCCTATGCGATTC & GTTACTGCTGTAATCTC & 1741 \\
\hline SNP-L3 & GCCAAAACTACAGAAGC & GCAGGCCAAATTGTGTG & 1786 \\
\hline SNP-R1 & CAACTACATATGGTGCCGG & CTCCTGCTTTTGTCATCGCC & 1791 \\
\hline SNP-R2 & CTTCGCGGTGTAGAAAG & GCTGCTGTGCCGCACAGAGC & 1880 \\
\hline SNP-R3 & CCTACTTGGACATGTGGATC & GTAAAAAGTGCCCGATTC & 1691 \\
\hline
\end{tabular}

Primers are from $5^{\prime}$ to $3^{\prime}$. 
Table 3.2. Type 3 tests of fixed effects ANOVA table.

\begin{tabular}{|c|c|c|c|c|c|c|}
\hline Location & $\stackrel{\mathbf{P}}{\text { partitioning }}$ & Effect & Num DF & Den DF & F value & $\operatorname{Pr}>\mathbf{F}$ \\
\hline \multirow{4}{*}{ Costa Rica } & $\mathrm{Pi}$ & Cat & 5 & 8 & 27.95 & $<.0001$ \\
\hline & $\mathrm{PA}$ & Cat & 5 & 8 & 53.37 & $<.0001$ \\
\hline & $\mathrm{IP}_{5}$ & Cat & 2 & 4 & 10.05 & 0.0275 \\
\hline & $\mathrm{IP}_{4}$ & Cat & 2 & 4 & 21.15 & 0.0075 \\
\hline \multirow{5}{*}{ Missouri } & $\mathrm{Pi}$ & Cat & 5 & 17 & 69.63 & $<.0001$ \\
\hline & PA & Cat & 5 & 17 & 81.93 & $<.0001$ \\
\hline & $\mathrm{IP}_{5}$ & Cat & 2 & 9 & 40.63 & $<.0001$ \\
\hline & $\mathrm{IP}_{4}$ & Cat & 2 & 9 & 2.97 & 0.1023 \\
\hline & Germination & Cat & 5 & 16 & 1.49 & 0.2469 \\
\hline \multirow{12}{*}{$\begin{array}{c}\text { Costa Rica } \\
\text { vs } \\
\text { Missouri }\end{array}$} & \multirow{3}{*}{$\mathrm{Pi}$} & Cat & 5 & 32 & 75.98 & $<.0001$ \\
\hline & & LOC & 1 & 32 & 0.14 & 0.7104 \\
\hline & & Cat*Loc & 5 & 32 & 0.40 & 0.8464 \\
\hline & \multirow{3}{*}{ PA } & Cat & 5 & 32 & 49.71 & $<.0001$ \\
\hline & & Loc & 1 & 32 & 1.15 & 0.2912 \\
\hline & & Cat ${ }^{\star}$ LoC & 5 & 32 & 5.78 & 0.0007 \\
\hline & \multirow{3}{*}{$\mathrm{IP}_{5}$} & Cat & 2 & 19 & 40.51 & $<.0001$ \\
\hline & & LOC & 1 & 19 & 17.09 & 0.0006 \\
\hline & & Cat ${ }^{\star}$ LoC & 2 & 19 & 2.72 & 0.0913 \\
\hline & \multirow{3}{*}{$\mathrm{IP}_{4}$} & Cat & 2 & 19 & 10.70 & 0.0008 \\
\hline & & LOC & 1 & 19 & 0.32 & 0.5810 \\
\hline & & Cat*Loc & 2 & 19 & 15.43 & 0.0001 \\
\hline
\end{tabular}

This is the ANOVA table for $\mathrm{P}$ partitioning in Costa Rica, Missouri, and Costa Rica versus Missouri. For $\mathrm{IP}_{5}$ and $\mathrm{IP}_{4}$, categories containing a value of 0 (FN38, W/M, W/W) were deleted before analysis. Cat, Category; Loc, Location. 
Table 3.3. Leaflet number phenotype for the 2-Kinase population grown in Columbia, Missouri.

\begin{tabular}{|c|c|c|c|c|}
\hline \multicolumn{1}{c}{ Line } & $\begin{array}{c}\text { Genotype } \\
\text { (Glyma14g07880 / Glyma06g03310) }\end{array}$ & \multicolumn{2}{c}{ Rep 1 } & \multicolumn{2}{c|}{ Rep 2} & Rep 3 \\
\hline FN38 & $\mathrm{W} / \mathrm{M}$ & $4 / 5$ & $4 / 5$ & $4 / 5$ \\
\hline ZC-2 & $\mathrm{M} / \mathrm{W}$ & 3 & 3 & 3 \\
\hline 1650 & $\mathrm{~W} / \mathrm{W}$ & 3 & 3 & 3 \\
\hline 1626 & $\mathrm{~W} / \mathrm{M}$ & $4 / 5$ & $4 / 5$ & $4 / 5$ \\
\hline 1600 & $\mathrm{~W} / \mathrm{M}$ & $4 / 5$ & $4 / 5$ & $4 / 5$ \\
\hline 1646 & $\mathrm{M} / \mathrm{W}$ & 3 & 3 & 3 \\
\hline 1671 & $\mathrm{M} / \mathrm{W}$ & 3 & 3 & 3 \\
\hline 1592 & $\mathrm{M} / \mathrm{M}$ & $4 / 5$ & $4 / 5$ & No plants \\
\hline 1624 & $\mathrm{M} / \mathrm{M}$ & $4 / 5$ & $4 / 5$ & $4 / 5$ \\
\hline 1633 & $\mathrm{M} / \mathrm{M}$ & $4 / 5$ & $4 / 5$ & No plants \\
\hline 1652 & $\mathrm{M} / \mathrm{M}$ & $4 / 5$ & $4 / 5$ & No plants \\
\hline
\end{tabular}

Lines with ' $4 / 5$ ' in one or both reps had at least one node with a tetra- or pentafoliate leaflet number, while those with a ' 3 ' had at wild-type trifoliate leaflet number. Lines that contain ' 0 plants' did not have any plants to phenotype because of germination issues or death before maturity due to disease. 
Table 3.4. Mean and standard deviations for the reps of each line grown in Columbia, MO.

\begin{tabular}{|c|c|c|c|c|c|c|c|c|c|}
\hline & & & & & & & & & \\
\hline Line & $\begin{array}{c}\text { Genotype } \\
\text { (Glyma14g07880 / } \\
\text { Glyma06g03310) }\end{array}$ & $\boldsymbol{\mu}$ & $\boldsymbol{\sigma}$ & $\boldsymbol{\mu}$ & $\boldsymbol{\sigma}$ & $\boldsymbol{\mu}$ & $\boldsymbol{\sigma}$ & $\boldsymbol{\mu}$ & $\boldsymbol{\sigma}$ \\
\hline FN38 & $\mathrm{W} / \mathrm{M}$ & 5.05 & 0.27 & 0.10 & 0.05 & 0.00 & 0.00 & 0.00 & 0.00 \\
\hline ZC-2 & $\mathrm{M} / \mathrm{W}$ & 2.67 & 0.25 & 0.71 & 0.07 & 0.56 & 0.08 & 1.51 & 0.08 \\
\hline 1650 & $\mathrm{~W} / \mathrm{W}$ & 5.55 & 0.33 & 0.15 & 0.03 & 0.00 & 0.00 & 0.00 & 0.00 \\
\hline 1626 & $\mathrm{~W} / \mathrm{M}$ & 6.56 & 0.42 & 0.15 & 0.02 & 0.00 & 0.00 & 0.00 & 0.00 \\
\hline 1600 & $\mathrm{~W} / \mathrm{M}$ & 5.47 & 0.08 & 0.14 & 0.03 & 0.00 & 0.00 & 0.00 & 0.00 \\
\hline 1646 & $\mathrm{M} / \mathrm{W}$ & 2.99 & 0.16 & 0.45 & 0.04 & 0.41 & 0.19 & 1.12 & 0.04 \\
\hline 1671 & $\mathrm{M} / \mathrm{W}$ & 3.44 & 0.28 & 0.52 & 0.09 & 0.36 & 0.00 & 1.32 & 0.09 \\
\hline 1592 & $\mathrm{M} / \mathrm{M}$ & 0.62 & 0.06 & 0.98 & 0.15 & 1.55 & 0.03 & 1.55 & 0.15 \\
\hline 1633 & $\mathrm{M} / \mathrm{M}$ & 0.66 & 0.05 & 0.91 & 0.02 & 2.01 & 0.37 & 1.58 & 0.04 \\
\hline 1624 & $\mathrm{M} / \mathrm{M}$ & 0.76 & 0.02 & 1.11 & 0.11 & 1.52 & 0.14 & 1.57 & 0.17 \\
\hline 1652 & $\mathrm{M} / \mathrm{M}$ & 0.42 & 0.13 & 1.04 & 0.00 & 1.75 & 0.36 & 1.27 & 0.19 \\
\hline
\end{tabular}

All means $(\mu)$ and standard deviations $(\sigma)$ are in $\mu \mathrm{g} \mathrm{P} \mathrm{mg} \mathrm{seed}^{-1}$. 


\section{References}

Anderson B.P., Fehr W.R. (2008) Seed Source Affects Field Emergence of LowPhytate Soybean Lines. Crop Sci 48:929-932.

Bilyeu K., Palavalli L., Sleper D., Beuselinck P. (2005) Mutations in Soybean Microsomal Omega-3 Fatty Acid Desaturase Genes Reduce Linolenic Acid Concentration in Soybean Seeds. Crop Sci 45:1830.

Bilyeu K.D., Zeng P., Coello P., Zhang Z.J., Krishnan H.B., Bailey A., Beuselinck P.R., Polacco J.C. (2008) Quantitative Conversion of Phytate to Inorganic Phosphorus in Soybean Seeds Expressing a Bacterial Phytase. Plant Physiol 146:468-77.

Chen Q.-C., Li B.W. (2003) Separation of Phytic Acid and Other Related Inositol Phosphates by High-Performance Ion Chromatography and Its Applications. J Chromatogr 1018:41-52.

Clarke E.J., Wiseman J. (2000) Developments in Plant Breeding for Improved Nutritional Quality of Soya Beans ii. Anti-Nutritional Factors. J Ag Sci 134:125-136.

Daverede I.C., Kravchenko A.N., Hoeft R.G., Nafziger E.D., Bullock D.G., Warren J.J., Gonzini L.C. (2004) Phosphorus Runoff from Incorporated and Surface-Applied Liquid Swine Manure and Phosphorus Fertilizer. J Environ Qual 33:1535-1544.

Ferket P.R., van Heugten E., van Kempen T.A.T.G., Angel R. (2002) Nutritional Strategies to Reduce Environmental Emissions from Nonruminants. J Anim Sci 80:E168-E182.

Frank T., Habernegg R., Yuan F.-J., Shu Q.-Y., Engel K.-H. (2009a) Assessment of the Contents of Phytic Acid and Divalent Cations in Low Phytic Acid (Ipa) Mutants of Rice and Soybean. J Food Comp Anal 22:278-284.

Frank T., Norenberg S., Engel K.H. (2009b) Metabolite Profiling of Two Novel Low Phytic Acid (Ipa) Soybean Mutants. J Agric Food Chem 57:6408-16.

Gillman J.D., Baxter I., Bilyeu K. (2013) Phosphorus Partitioning of Soybean Lines Containing Different Mutant Alleles of Two Soybean Seed-Specific 
Adenosine Triphosphate-Binding Cassette Phytic Acid Transporter Paralogs. Plant Genome 6:1.

Gillman J.D., Pantalone V.R., Bilyeu K. (2009) The Low Phytic Acid Phenotype in Soybean Line CX1834 Is Due to Mutations in Two Homologs of the Maize Low Phytic Acid Gene. Plant Genome 2:179-190.

Hitz W.D., Carlson T.J., Kerr P.S., Sebastian S.A. (2002) Biochemical and Molecular Characterization of a Mutation That Confers a Decreased Raffinosaccharide and Phytic Acid Phenotype on Soybean Seeds. Plant Physiol 128:650-60.

Lam H.M., Xu X., Liu X., Chen W., Yang G., Wong F.L., Li M.W., He W., Qin N., Wang B., Li J., Jian M., Wang J., Shao G., Sun S.S., Zhang G. (2010) Resequencing of 31 Wild and Cultivated Soybean Genomes Identifies Patterns of Genetic Diversity and Selection. Nat Genet 42:1053-9.

Maupin L.M., Rainey K.M. (2011) Improving Emergence of Modified Phosphorus Composition Soybeans: Genotypes, Germplasm, Environments, and Selection. Crop Sci 51:1946-1955.

Maupin L.M., Rosso M.L., Rainey K.M. (2011) Environmental Effects on Soybean with Modified Phosphorus and Sugar Composition. Crop Sci 51:642-650.

Meis S.J., Fehr W.R., Schnebly S.R. (2003) Seed Source Effect on Field Emergence of Soybean Lines with Reduced Phytate and Raffinose Saccharides. Crop Sci 43:1336-1339.

Raboy V., Dickinson D.B., Below F.E. (1984) Variation in Seed Total Phosphorus, Phytic Acid, Zinc, Calcium, Magnesium, and Protein among Lines of Glycine max and G. soja. Crop Sci 24:431-434.

Raboy V., Young K.A., Dorsch J.A., Cook A. (2001) Genetics and Breeding of Seed Phosphorus and Phytic Acid. J Plant Physiol 158:489-497.

Sebastian S., Kerr P.S., Pearlstein R., Hitz W. (2000) Soybean Germplasm with Novel Genes for Improved Digestibility, in: J. Drackley (Ed.), Soy in Animal Nutrition, Federation of Animal Science Societies, Savoy, IL. pp. 56-74.

Sharpley A.N., Chapra S.C., Wedepohl R., Sims J.T., Daniel T.C., Reddy K.R. (1994) Managing Agricultural Phosphorus for Protection of Surface Waters: Issues and Options. J Environ Qual 23:437-451. 
Urbano G., López-Jurado M., Aranda P., Vidal-Valverde C., Tenorio E., Porres J. (2000) The Role of Phytic Acid in Legumes: Antinutrient or Beneficial Function? J Physiol Biochem 53:283-294.

Wilcox J.R., Premachandra G.S., Young K.A., Raboy V. (2000) Isolation of High Seed Inorganic P, Low-Phytate Soybean Mutants. Crop Sci 40:1601-1605.

York J.D., Odom A.R., Murphy R., Ives E.B., Wente S.R. (1999) A Phospholipase C-Dependent Inositol Polyphosphate Kinase Pathway Required for Efficient Messenger RNA Export. Science 285:96-100.

Yuan F.J., Zhao H.J., Ren X.L., Zhu S.L., Fu X.J., Shu Q.Y. (2007) Generation and Characterization of Two Novel Low Phytate Mutations in Soybean (Glycine max L. Merr.). Theor Appl Genet 115:945-57.

Yuan F.J., Zhu D.H., Deng B., Fu X.J., Dong D.K., Zhu S.L., Li B.Q., Shu Q.Y. (2009) Effects of Two Low Phytic Acid Mutations on Seed Quality and Nutritional Traits in Soybean (Glycine max L. Merr). J Agric Food Chem 57:3632-8.

Yuan F.J., Zhu D.H., Tan Y.Y., Dong D.K., Fu X.J., Zhu S.L., Li B.Q., Shu Q.Y. (2012) Identification and Characterization of the Soybean IPK1 Ortholog of a Low Phytic Acid Mutant Reveals an Exon-Excluding Splice-Site Mutation. Theor Appl Genet 125:1413-23. 


\section{CHAPTER 4}

General Conclusions and Perspectives 
Many livestock species, especially monogastric livestock (swine and poultry) consume soybeans as the major protein source in their diets (Krishnan, 2005; Soystats, 2012). Phytic acid (PA) is important for phosphorus (P) storage in soybean seeds (Urbano et al., 2000), and if the phytase enzyme is present, PA $\mathrm{P}$ is able to be broken down into inorganic phosphorus $(\mathrm{Pi})$, which is the available form of $\mathrm{P}$ for absorption (Hegeman and Grabau, 2001). Nevertheless, PA presents a problem when consumed by monogastric, or nonruminant, species, such as poultry and swine.

$\mathrm{PA}$ is a major anti-nutritional factor in crop grains causing deficiencies in $\mathrm{P}$ and important metal minerals. PA-P is indigestible by nonruminant livestock because they do not contain gut phytase enzymes to break down PA (Clarke and Wiseman, 2000; Raboy et al., 1984; Wilcox et al., 2000). PA is a chelating agent that binds to most metals, preventing mineral and protein absorption in nonruminant livestock; thus, soybean meal fed to monogastric animals are supplemented with $\mathrm{Pi}$ and minerals in order to supply adequate nutrients, as well as phytases to break down PA (Clarke and Wiseman, 2000; Wilcox et al., 2000). If the PA-P is not broken down, it is passed through the intestines of nonruminant livestock, ending up in the manure (Clarke and Wiseman, 2000; Daverede et al., 2004; Ferket et al., 2002).

Deleterious effects of $P$ runoff are expensive and timely to fix because when symptoms are visible, the damage is too great to be corrected simplistically (Sharpley et al., 1994). Manure, with high amounts of $P$, have a negative impact 
on the environment (Sharpley et al., 1994); however, with the discovery of low PA (Ipa) mutations in many grain crops, the reduction of $\mathrm{P}$ runoff, as well as more nutritious soybean meal, has increased (Wilcox et al., 2000).

Low phytic acid (Ipa) mutants were discovered to counter the negative nutritional and environmental impacts of phytic acid (PA) in soybean feed. Unfortunately, many lpa mutants have poor emergence and germination (Maupin and Rainey, 2011; Maupin et al., 2011). However, a gamma irradiated soybean line, named ZC-2, was discovered to decrease PA by up to $50 \%$ without emergence issues (Yuan et al., 2007). Further characterization of ZC-2 revealed that the Ipa mutation was caused by a single nucleotide polymorphism at a splice site resulting in a non-functional orthologous inositol pentakisphosphate 2-kinase (IPK1) (Yuan et al., 2012). IPK1 is the enzyme that phosphorylates the 2position on inositol $(1,3,4,5,6)$ pentakisphosphate to create PA. Our objective was to reduce PA levels with good emergence and germination by breeding a line created by fast neutron irradiation of Williams82 seed, named FN38, and the low PA mutant, ZC-2, to create a segregating population that contained lines with mutations at both IPK1 loci.

Two homeobox (HOX) genes deleted in FN38 were characterized to determine the cause of the multifoliate leaflet phenotype, and this was done by breeding FN38 and a registered variety with a trifoliate leaflet phenotype to develop a segregating population. There was variable expression of the multifoliate trait in early growth generations, but the phenotype did associate 
strongly with the deletion. The deletion was not able to be characterized, and possible reasons for this difficulty could be due to chromosomal rearrangement, insertion of unknown sequences, or interference from the other chromosome. However, initial characterization also indicated a homologous non-functional IPK1 (Glyma06g03310), so P partitioning was analyzed to determine if the IPK1 homolog could reduce PA like it's counterpart in ZC-2. Unfortunately, FN38 does not increase Pi or decrease PA-P compared to the registered cultivar line. These results are consistent with expression data reported by Yuan et al. (2012), in which Glyma14g07880 had higher expression in soybean seeds compared to the other two homologous genes (Glyma06g03310 and Glyma04g03240).

In hopes of decreasing PA-P levels by more than $50 \%$, our FN38 line was bred with ZC-2 to develop a segregating population. Statistical analyses showed that lines with a mutation at both IPK1 (Glyma14g07880 and Glyma06g03310) loci were able to decrease PA statistically more than all other genotypic classes, and the germination rates were higher than $80 \%$. Compared to the W/W genotypic class, the M/M genotype reduced PA P by roughly $80 \%$, while the parental line ZC-2, a confirmed low PA mutant, only reduces PA P by a maximum of $50 \%$.

Lines containing the Glyma14g07880 IPK1 SNP had an increase in lower inositols, while lines wild-type for this gene, such as FN38, had no detectable levels of lower inositols. Previous research has confirmed that the last step to synthesizing $\mathrm{PA}$ is phosphorylating the 2-position on inositol $(1,3,4,5,6)$ 
pentakisphosphate (reviewed in Brearley and Hanke, 1996a; Brearley and Hanke, 1996b). However, the location of phosphates for the inositol tetrakisphosphate varied depending on the route of the PA biosynthesis pathway. For phosphate locations of $3,4,5$, and 6 or $1,3,4$, and 5 , PA synthesis occurred through the lipid-independent pathway, but for phosphate locations on 1, 4, 5, and 6, PA synthesis went through the lipid-dependent pathway, with phosphatidyl inositol production. Since inositol tetrakisphosphate, along with inositol $(1,3,4,5,6)$, were the dominant lower inositols, $1 \mathrm{mM}$ standards of all three inositol tetrakisphosphates were ran on the high performance liquid chromatography. Based on the retention time of the peak in ZC-2 and the lines with a mutated Glyma14g07880 IPK1, it was determined that the accumulation of inositol tetrakisphosphate had phosphate positions in the $1,4,5$, and 6 positions.

Since these lines have over $80 \%$ germination success, it is quite promising for commercialization with further development and research. With results from previous research, developing low PA lines with excellent emergence and germination is encouraging; however, since it is not known if these lines will have higher nutritional value in nonruminant livestock, further testing must be completed. Yield studies or nutritional analysis, besides PA and $\mathrm{Pi}$, need to be performed on these lines, but in order to do this, further generations, through self-pollination or backcrossing to a cultivar or either parent, are needed. Currently, the double mutant lines were only progressed to the $F_{3}$ generation, and further advancement is needed to obtain analysis on agronomic 
traits, especially yield. Even though more work is needed, these double mutant lines are available for further characterization by interested researchers. 


\section{References}

Brearley C.A., Hanke D.E. (1996a) Inositol Phosphates in the Duckweed Spirodela polyrhiza L. Biochem J 314:215-225.

Brearley C.A., Hanke D.E. (1996b) Metabolic Evidence for the Order of Addition of Individual Phosphate Esters to the myo-Inositol Moiety of Inositol Hexakisphospate in the Duckweed Spirodela polyrhiza L. Biochem J 314:227-233.

Clarke E.J., Wiseman J. (2000) Developments in Plant Breeding for Improved Nutritional Quality of Soya Beans ii. Anti-Nutritional Factors. J Ag Sci 134:125-136.

Daverede I.C., Kravchenko A.N., Hoeft R.G., Nafziger E.D., Bullock D.G., Warren J.J., Gonzini L.C. (2004) Phosphorus Runoff from Incorporated and Surface-Applied Liquid Swine Manure and Phosphorus Fertilizer. J Environ Qual 33:1535-1544.

Ferket P.R., van Heugten E., van Kempen T.A.T.G., Angel R. (2002) Nutritional Strategies to Reduce Environmental Emissions from Nonruminants. J Anim Sci 80:E168-E182.

Hegeman C.E., Grabau E.A. (2001) A Novel Phytase with Sequence Similarity to Purple Acid Phosphatases Is Expressed in Cotyledons of Germinating Soybean Seedlings. Plant Physiol 126:1598-1608.

Krishnan H.B. (2005) Engineering Soybean for Enhanced Sulfur Amino Acid Content. Crop Sci 45:454-461.

Maupin L.M., Rainey K.M. (2011) Improving Emergence of Modified Phosphorus Composition Soybeans: Genotypes, Germplasm, Environments, and Selection. Crop Sci 51:1946-1955.

Maupin L.M., Rosso M.L., Rainey K.M. (2011) Environmental Effects on Soybean with Modified Phosphorus and Sugar Composition. Crop Sci 51:642-650.

Raboy V., Dickinson D.B., Below F.E. (1984) Variation in Seed Total Phosphorus, Phytic Acid, Zinc, Calcium, Magnesium, and Protein among Lines of Glycine max and G. soja. Crop Sci 24:431-434. 
Sharpley A.N., Chapra S.C., Wedepohl R., Sims J.T., Daniel T.C., Reddy K.R. (1994) Managing Agricultural Phosphorus for Protection of Surface Waters: Issues and Options. J Environ Qual 23:437-451.

Soystats. (2012) Available at http://www.soystats.com/.

Urbano G., López-Jurado M., Aranda P., Vidal-Valverde C., Tenorio E., Porres J. (2000) The Role of Phytic Acid in Legumes: Antinutrient or Beneficial Function? J Physiol Biochem 53:283-294.

Wilcox J.R., Premachandra G.S., Young K.A., Raboy V. (2000) Isolation of High Seed Inorganic P, Low-Phytate Soybean Mutants. Crop Sci 40:1601-1605.

Yuan F.J., Zhao H.J., Ren X.L., Zhu S.L., Fu X.J., Shu Q.Y. (2007) Generation and Characterization of Two Novel Low Phytate Mutations in Soybean (Glycine max L. Merr.). Theor Appl Genet 115:945-57.

Yuan F.J., Zhu D.H., Tan Y.Y., Dong D.K., Fu X.J., Zhu S.L., Li B.Q., Shu Q.Y. (2012) Identification and Characterization of the Soybean IPK1 Ortholog of a Low Phytic Acid Mutant Reveals an Exon-Excluding Splice-Site Mutation. Theor Appl Genet 125:1413-23. 


\section{REFERENCES}

Anderson B.P., Fehr W.R. (2008) Seed Source Affects Field Emergence of LowPhytate Soybean Lines. Crop Sci 48:929-932.

Bilyeu K., Palavalli L., Sleper D., Beuselinck P. (2005) Mutations in Soybean Microsomal Omega-3 Fatty Acid Desaturase Genes Reduce Linolenic Acid Concentration in Soybean Seeds. Crop Sci 45:1830.

Bilyeu K.D., Zeng P., Coello P., Zhang Z.J., Krishnan H.B., Bailey A., Beuselinck P.R., Polacco J.C. (2008) Quantitative Conversion of Phytate to Inorganic Phosphorus in Soybean Seeds Expressing a Bacterial Phytase. Plant Physiol 146:468-77.

Bolon Y.T., Haun W.J., Xu W.W., Grant D., Stacey M.G., Nelson R.T., Gerhardt D.J., Jeddeloh J.A., Stacey G., Muehlbauer G.J., Orf J.H., Naeve S.L., Stupar R.M., Vance C.P. (2011) Phenotypic and Genomic Analyses of a Fast Neutron Mutant Population Resource in Soybean. Plant Physiol 156:240-53.

Brearley C.A., Hanke D.E. (1996a) Inositol Phosphates in the Duckweed Spirodela polyrhiza L. Biochem J 314:215-225.

Brearley C.A., Hanke D.E. (1996b) Metabolic Evidence for the Order of Addition of Individual Phosphate Esters to the myo-Inositol Moiety of Inositol Hexakisphospate in the Duckweed Spirodela polyrhiza L. Biochem J 314:227-233.

Brehm M.A., Schenk T.M., Zhou X., Fanick W., Lin H., Windhorst S., Nalaskowski M.M., Kobras M., Shears S.B., Mayr G.W. (2007) Intracellular Localization of Human Ins $(1,3,4,5,6) \mathrm{P}_{5}$ 2-Kinase. Biochem $\mathrm{J}$ 408:335-45.

Champagne C.E., Goliber T.E., Wojciechowski M.F., Mei R.W., Townsley B.T., Wang K., Paz M.M., Geeta R., Sinha N.R. (2007) Compound Leaf Development and Evolution in the Legumes. Plant Cell 19:3369-78. 
Chappell A.S., Scaboo A.M., Wu X., Nguyen H., Pantalone V.R., Bilyeu K.D. (2006) Characterization of the MIPS Gene Family in Glycine max. Plant Breed 125:493-500.

Chen Q.-C., Li B.W. (2003) Separation of Phytic Acid and Other Related Inositol Phosphates by High-Performance Ion Chromatography and Its Applications. J Chromatogr 1018:41-52.

Clarke E.J., Wiseman J. (2000) Developments in Plant Breeding for Improved Nutritional Quality of Soya Beans ii. Anti-Nutritional Factors. J Ag Sci 134:125-136.

Daverede I.C., Kravchenko A.N., Hoeft R.G., Nafziger E.D., Bullock D.G., Warren J.J., Gonzini L.C. (2004) Phosphorus Runoff from Incorporated and Surface-Applied Liquid Swine Manure and Phosphorus Fertilizer. J Environ Qual 33:1535-1544.

Douglas M.W., Parsons C.M., Hymowitz T. (1999) Nutritional Evaluation of Lectin-Free Soybeans for Poultry. Poultry Sci 78:91-95.

East J.W., Nakayama T.O.M., Parkman S.B. (1972) Changes in Stachyose, Raffinose, Sucrose, and Monosaccharides During Germination of Soybeans. Crop Sci 12:7-9.

Ferket P.R., van Heugten E., van Kempen T.A.T.G., Angel R. (2002) Nutritional Strategies to Reduce Environmental Emissions from Nonruminants. J Anim Sci 80:E168-E182.

Frank T., Habernegg R., Yuan F.-J., Shu Q.-Y., Engel K.-H. (2009a) Assessment of the Contents of Phytic Acid and Divalent Cations in Low Phytic Acid (Ipa) Mutants of Rice and Soybean. J Food Comp Anal 22:278-284.

Frank T., Norenberg S., Engel K.H. (2009b) Metabolite Profiling of Two Novel Low Phytic Acid (Ipa) Soybean Mutants. J Agric Food Chem 57:6408-16.

Fujii M., York J.D. (2005) A Role for Rat Inositol Polyphosphate Kinases rIPK2 and rIPK1 in Inositol Pentakisphosphate and Inositol Hexakisphosphate Production in Rat-1 Cells. J Biol Chem 280:1156-64.

Gao Y., Biyashev R.M., Maroof M.A.S., Glover N.M., Tucker D.M., Buss G.R. (2008) Validation of Low-Phytate QTLs and Evaluation of Seedling Emergence of Low-Phytate Soybeans. Crop Sci 48:1355-1364. 
Gillman J.D., Baxter I., Bilyeu K. (2013) Phosphorus Partitioning of Soybean Lines Containing Different Mutant Alleles of Two Soybean Seed-Specific Adenosine Triphosphate-Binding Cassette Phytic Acid Transporter Paralogs. Plant Genome 6:1.

Gillman J.D., Pantalone V.R., Bilyeu K. (2009) The Low Phytic Acid Phenotype in Soybean Line CX1834 Is Due to Mutations in Two Homologs of the Maize Low Phytic Acid Gene. Plant Genome 2:179-190.

Hegeman C.E., Grabau E.A. (2001) A Novel Phytase with Sequence Similarity to Purple Acid Phosphatases Is Expressed in Cotyledons of Germinating Soybean Seedlings. Plant Physiol 126:1598-1608.

Hitz W.D., Carlson T.J., Kerr P.S., Sebastian S.A. (2002) Biochemical and Molecular Characterization of a Mutation That Confers a Decreased Raffinosaccharide and Phytic Acid Phenotype on Soybean Seeds. Plant Physiol 128:650-60.

Hymowitz T. (1970) On the Domestication of the Soybean. Ec Bot 24:408-421.

Hymowitz T. (1990) Soybeans: The Success Story, in: J. Janick and J. E. Simon (Eds.), Advances in New Crops, Timber Press, Portland, Oregan. pp. 159163.

Hymowitz T. (2008) The History of the Soybean, in: L. A. Johnson, et al. (Eds.), Soybeans: Chemistry, Production, Processing, and Utilization, AOCS Press, Urbana, IL. pp. 1-31.

Hymowitz T., Harlan J.R. (1983) Introduction of Soybean to North America by Samuel Bowen in 1765. Ec Bot 37:371-379.

Hymowitz T., Kaizuma N. (1979) Dissemination of Soybeans (Glycine max): Seed Protein Electrophoresis Profiles among Japanese Cultivars. Ec Bot 33:311-319.

Hymowitz T., Newell C.A. (1980) Taxonomy, Speciation, Domestication, Dissemination, Germplasm Resources and Variation in the Genus Glycine, in: R. Summerfield and A. Bunting (Eds.), Advances in Legume Science, Royal Botanical Garden, Kew, England. pp. 251-264.

Hymowitz T., Newell C.A. (1981) Taxonomy of the Genus Glycine, Domestication and Uses of Soybeans. Ec Bot 35:272-288. 
Irvine R., Schell M. (2001) Back in the Water: The Return of the Inositol Phosphates. Nat Rev Mol Cell Biol 2:327-338.

Ives E.B., Nichols J., Wente S.R., York J.D. (2000) Biochemical and Functional Characterization of Inositol 1,3,4,5, 6-Pentakisphosphate 2-Kinases. J Biol Chem 275:36575-83.

Janick J., Blase M.G., Johnson D.L., Jolliff G.D., Myers R.L. (1996) Diversifying U.S. Crop Production, in: J. Janick (Ed.), Progress in New Crops, ASHS Press, Alexandria, VA. pp. 98-109.

Janssen B., Lund L., Sinha N. (1998) Overexpression of Homeobox Gene, LeT6, Reveals Indeterminate Features in the Tomato Compound Leaf. Plant Physiol 117:771-786.

Kakade M.L., Arnold R.L., Leiner I.E., Waibel P.E. (1969) Unavailability of Cystine from Trypsin Inhibitors as a Factor Contributing to the Poor Nutritive Value of Navy Beans. J Nutr 99:34-42.

Kakade M.L., Hoffa D.E., Leiner I.E. (1973) Contribution of Trypsin Inhibitors to the Deleterious Effects of Unheated Soybeans Fed to Rats. J Nutr 103:1772-1778.

Krishnan H.B. (2005) Engineering Soybean for Enhanced Sulfur Amino Acid Content. Crop Sci 45:454-461.

Lam H.M., Xu X., Liu X., Chen W., Yang G., Wong F.L., Li M.W., He W., Qin N., Wang B., Li J., Jian M., Wang J., Shao G., Sun S.S., Zhang G. (2010) Resequencing of 31 Wild and Cultivated Soybean Genomes Identifies Patterns of Genetic Diversity and Selection. Nat Genet 42:1053-9.

Liu K. (1999) Chemistry and Nutritional Value of Soybean Components, Soybeans: Chemistry, Technology, and Utilization, Aspen Publishers, Gaithersburg, MD. pp. 25-113.

Maroof M.A.S., Glover N.M., Biyashev R.M., Buss G.R., Grabau E.A. (2009) Genetic Basis of the Low-Phytate Trait in the Soybean Line CX1834. Crop Sci 49:69-76.

Maupin L.M., Rainey K.M. (2011) Improving Emergence of Modified Phosphorus Composition Soybeans: Genotypes, Germplasm, Environments, and Selection. Crop Sci 51:1946-1955. 
Maupin L.M., Rosso M.L., Rainey K.M. (2011) Environmental Effects on Soybean with Modified Phosphorus and Sugar Composition. Crop Sci 51:642-650.

Meis S.J., Fehr W.R., Schnebly S.R. (2003) Seed Source Effect on Field Emergence of Soybean Lines with Reduced Phytate and Raffinose Saccharides. Crop Sci 43:1336-1339.

Miller A.L., Suntharalingam M., Johnson S.L., Audhya A., Emr S.D., Wente S.R. (2004) Cytoplasmic Inositol Hexakisphosphate Production Is Sufficient for Mediating the Gle1-mRNA Export Pathway. J Biol Chem 279:51022-32.

Montgomery K.S. (2003) Soy Protein. J Perinat Educ 12:42-45.

Oltmans S.E., Fehr W.R., Welke G.A., Cianzio S.R. (2004) Inheritance of LowPhytate Phosphorus in Soybean. Crop Sci 44:433-435.

Ongusaha P., Hughes P., Davey J., Michell R. (1998) Inositol Hexakisphosphate in Schizosaccharomyces pombe: Synthesis from Ins $(1,4,5) \mathrm{P}_{3}$ and Osmotic Regulation. Biochem J 335:671-679.

Peng J., Yu J., Wang H., Guo Y., Li G., Bai G., Chen R. (2011) Regulation of Compound Leaf Development in Medicago truncatula by Fused Compound Leaf1, a Class M KNOX Gene. Plant Cell 23:3929-43.

Pham A.-T., Lee J.-D., Shannon J.G., Bilyeu K. (2010) Mutant Alleles of FAD2$1 \mathrm{~A}$ and FAD2-1B Combine to Produce Soybeans with the High Oleic Acid Seed Oil Trait. BMC Plant Biol 10:195.

Phillippy B.Q., Ullah A.H., Ehrlich K.C. (1994) Purification and Some Properties of Inositol 1,3,4,5,6-Pentakisphosphate 2-Kinase from Immature Soybean Seeds. J Biol Chem 269:28393-9.

Raboy V., Dickinson D.B. (1984) Effect of Phosphorus and Zinc Nutrition on Soybean Seed Phytic Acid and Zinc. Plant Physiol 75:1094-1098.

Raboy V., Dickinson D.B. (1987) The Timing and Rate of Phytic Acid Accumulation in Developing Soybean Seeds. Plant Physiol 85:841-844.

Raboy V., Dickinson D.B., Below F.E. (1984) Variation in Seed Total Phosphorus, Phytic Acid, Zinc, Calcium, Magnesium, and Protein among Lines of Glycine max and G. soja. Crop Sci 24:431-434.

Raboy V., Gerbasi P. (1996) Genetics of myo-Inositol Phosphate Synthesis and Accumulation, in: B. B. Biswas and S. Biswas (Eds.), myo-Inositol 
Phosphates, Phosphoinositides, and Signal Transduction, Plenum Press, New York. pp. 257-285.

Raboy V., Gerbasi P.F., Young K.A., Stoneberg S.D., Pickett S.G., Bauman A.T., Murthy P.P.N., Sheridan W.F., Ertl D.S. (2000) Origin and Seed Phenotype of Maize Low Phytic Acid 1-1 and Low Phytic Acid 2-1. Plant Physiol 124:355-368.

Raboy V., Young K.A., Dorsch J.A., Cook A. (2001) Genetics and Breeding of Seed Phosphorus and Phytic Acid. J Plant Physiol 158:489-497.

Sarmah B., Wente S.R. (2009) Dual Functions for the Schizosaccharomyces pombe Inositol Kinase IPK1 in Nuclear mRNA Export and Polarized Cell Growth. Eukaryot Cell 8:134-46.

Scaboo A.M., Pantalone V.R., Walker D.R., Boerma H.R., West D.R., Walker F.R., Sams C.E. (2009) Confirmation of Molecular Markers and Agronomic Traits Associated with Seed Phytate Content in Two Soybean RIL Populations. Crop Sci 49:426-432.

Sebastian S., Kerr P.S., Pearlstein R., Hitz W. (2000) Soybean Germplasm with Novel Genes for Improved Digestibility, in: J. Drackley (Ed.), Soy in Animal Nutrition, Federation of Animal Science Societies, Savoy, IL. pp. 56-74.

Seeds A.M., Sandquist J.C., Spana E.P., York J.D. (2004) A Molecular Basis for Inositol Polyphosphate Synthesis in Drosophila melanogaster. J Biol Chem 279:47222-32.

Shannon J.G., Wrather J.A., Sleper D.A., Robbins R.T., Nguyen H.T., Anand S.C. (2007) Registration of 'Jake' Soybean. Journal of Plant Registrations $1: 29$.

Sharpley A.N., Chapra S.C., Wedepohl R., Sims J.T., Daniel T.C., Reddy K.R. (1994) Managing Agricultural Phosphorus for Protection of Surface Waters: Issues and Options. J Environ Qual 23:437-451.

Shears S.B. (1998) Review: The Versatility of Inositol Phosphates as Cellular Signals. Biochim Biophys Acta 1436:49-67.

Shi J., Wang H., Schellin K., Li B., Faller M., Stoop J.M., Meeley R.B., Ertl D.S., Ranch J.P., Glassman K. (2007) Embryo-Specific Silencing of a Transporter Reduces Phytic Acid Content of Maize and Soybean Seeds. Nat Biotechnol 25:930-7. 
Soystats. (2012) Available at http://www.soystats.com/.

Stephens L., Hawkins P., Stanley A., Moore T., Poyner D., Morris P., Hanley M., Kay R., Irvine R. (1991) myo-Inositol Pentakisphospates: Structure, Biological Occurrence, and Phosphorylation to myo-Inositol Hexakisphosphate. Biochem J 275:485-499.

Stephens L., Irvine R. (1990) Stepwise Phosphorylation of myo-Inositol Leading to myo-Inositol Hexakisphosphate in Dictyostelium. Nature 346:580-583.

Stevenson-Paulik J., Bastidas R.J., Chiou S.T., Frye R.A., York J.D. (2005) Generation of Phytate-Free Seeds in Arabidopsis through Disruption of Inositol Polyphosphate Kinases. Proc Natl Acad Sci U S A 102:12612-7.

Suarez F.L., Springfield J., Furne J.K., Lohrmann T.T., Kerr P.S., Levitt M.D. (1999) Gas Production in Human Ingesting a Soybean Flour Derived from Beans Naturally Low in Oligosaccharides. Am J Clin Nutr 69:135-139.

Sun Y., Thompson M., Lin G., Butler H., Gao Z., Thornburgh S., Yau K., Smith D.A., Shukla V.K. (2007) Inositol 1,3,4,5,6-Pentakisphosphate 2-Kinase from Maize: Molecular and Biochemical Characterization. Plant Physiol 144:1278-91.

Suzuki M., Tanaka K., Kuwano M., Yoshida K.T. (2007) Expression Pattern of Inositol Phosphate-Related Enzymes in Rice (Oryza sativa L.): Implications for the Phytic Acid Biosynthetic Pathway. Gene 405:55-64.

Sweetman D., Johnson S., Caddick S.E., Hanke D.E., Brearley C.A. (2006) Characterization of an Arabidopsis Inositol 1,3,4,5,6-Pentakisphosphate 2Kinase (AtIPK1). Biochem J 394:95-103.

Urbano G., López-Jurado M., Aranda P., Vidal-Valverde C., Tenorio E., Porres J. (2000) The Role of Phytic Acid in Legumes: Antinutrient or Beneficial Function? J Physiol Biochem 53:283-294.

USDA-ERS. (2012) Soybeans \& Oil Crops: Overview. Available at http://www.ers.usda.gov/topics/crops/soybeans-oilcrops.aspx\#.UZKnkrWG2So.

Verbsky J., Lavine K., Majerus P.W. (2005) Disruption of the Mouse Inositol 1,3,4,5,6-Pentakisphosphate 2-Kinase Gene, Associated Lethality, and Tissue Distribution of 2-Kinase Expression. Proc Natl Acad Sci U S A 102:8448-53. 
Verbsky J.W., Wilson M.P., Kisseleva M.V., Majerus P.W., Wente S.R. (2002) The Synthesis of Inositol Hexakisphosphate. Characterization of Human Inositol 1,3,4,5,6-Pentakisphosphate 2-Kinase. J Biol Chem 277:3185762.

Walker D.R., Scaboo A.M., Pantalone V.R., Wilcox J.R., Boerma H.R. (2006) Genetic Mapping of Loci Associated with Seed Phytic Acid Content in CX1834-1-2 Soybean. Crop Sci 46:390-397.

Wang J., Wu Y., Yu Z. (2007) A New Soybean [Glycine max (L.) Merr.] Mutant with Multifoliolate Compound Leaf Acquired by Ion Beam Irradiation. Nuclear Instruments and Methods in Physics Research Section B: Beam Interactions with Materials and Atoms 255:326-330.

Wilcox J.R., Premachandra G.S., Young K.A., Raboy V. (2000) Isolation of High Seed Inorganic P, Low-Phytate Soybean Mutants. Crop Sci 40:1601-1605.

York J.D., Odom A.R., Murphy R., Ives E.B., Wente S.R. (1999) A Phospholipase C-Dependent Inositol Polyphosphate Kinase Pathway Required for Efficient Messenger RNA Export. Science 285:96-100.

Yuan F.J., Zhao H.J., Ren X.L., Zhu S.L., Fu X.J., Shu Q.Y. (2007) Generation and Characterization of Two Novel Low Phytate Mutations in Soybean (Glycine max L. Merr.). Theor Appl Genet 115:945-57.

Yuan F.J., Zhu D.H., Deng B., Fu X.J., Dong D.K., Zhu S.L., Li B.Q., Shu Q.Y. (2009) Effects of Two Low Phytic Acid Mutations on Seed Quality and Nutritional Traits in Soybean (Glycine max L. Merr). J Agric Food Chem 57:3632-8.

Yuan F.J., Zhu D.H., Tan Y.Y., Dong D.K., Fu X.J., Zhu S.L., Li B.Q., Shu Q.Y. (2012) Identification and Characterization of the Soybean IPK1 Ortholog of a Low Phytic Acid Mutant Reveals an Exon-Excluding Splice-Site Mutation. Theor Appl Genet 125:1413-23. 